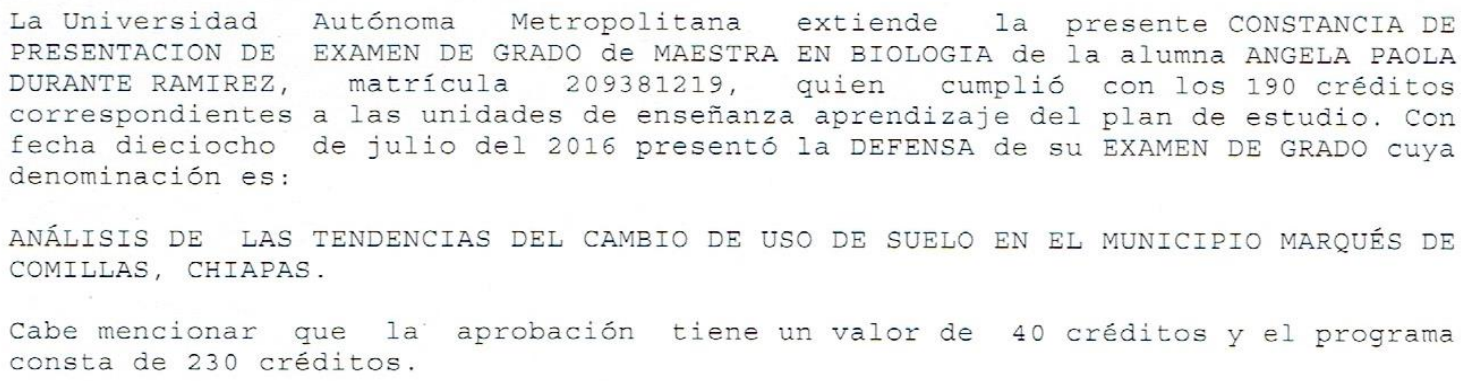

El jurado del examen ha tenido a bien otorgarle la calificación de:

\title{
APROBADA
}

JURADO

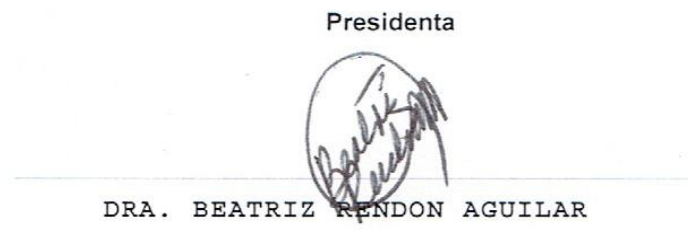

Vocal

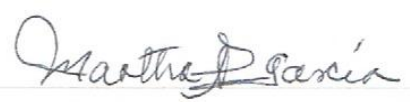

M. EN C. MARTHA PEREZ GARCIA

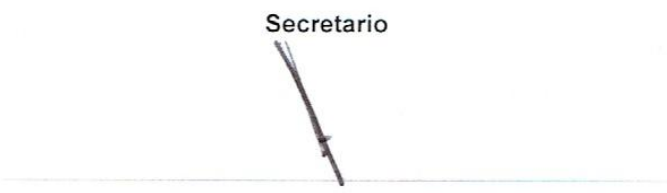

M. EN C. FERNANDO VITE GONZALEZ

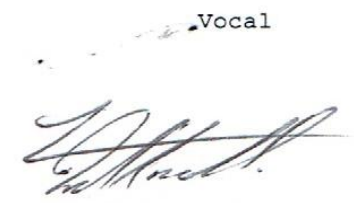

DR. MIGUEL ANGEL ARMELLA VILLALPANDO 


\title{
UNIVERSIDAD AUTÓNOMA METROPOLITANA Unidad Iztapalapa
}

\section{ANÁLISIS DE LAS TENDENCIAS DEL CAMBIO DE USO DE SUELO EN EL MUNICIPIO DE MARQUÉS DE COMILLAS, CHIAPAS.}

\author{
T $\quad E \quad S \quad I \quad S$ \\ QUE PARA OBTENER EL GRADO DE: \\ MAESTRA EN BIOLOGÍA
}

PRESENTA:

ANGELA PAOLA DURANTE RAMÍREI

DIRECTOR

DR. JOSÉ ALEJANDRO ZAVALA HURTADO

CIUDAD DE MÉXICO

JULI0, 2016 
La Maestría en Biología de la Universidad Autónoma Metropolitana pertenece al Padrón de Nacional de

Postgrados de Calidad del Consejo Nacional de Ciencia y Tecnologia (CONACyT) como programa consolidado 
El jurado designado por la Comisión la Maestría en Biología de la Universidad Autónoma Metropolitana, Unidad Iztapalapa, aprobó la Tesis que presentó

\section{Ángela Paola Durante Ramírez}
El día mes 2016.

Sinodales:

Dra. Beatriz Rendón Aguilar. (Presidente)

Dra. Fernando Vite González (Secretario)

Dr. Miguel Ángel Armella Villalpando (Vocal)

M. en C. Martha Pérez García (Vocal) 
Dedicada a:

A mi Madre 


\section{Agradecimientos}

Al Dr. José Alejandro Zavala Hurtado por la dirección de la presente tesis. Por considerarme parte de su equipo de trabajo. Por su confianza, apoyo y paciencia; por estar siempre cuando lo necesité. Gracias por todo profe'.

A la Dra. Beatríz Rendón Aguilar por sus valiosas aportaciones y oportunos comentarios que enriquecieron este trabajo.

Al Mtro. Fernando Vite por sus correcciones y sugerencias que ayudaron a mejorar esta tesis.

A la Mtra. Martha Pérez por haber aceptado participar en este quehacer; por esas pláticas inolvidables y por ser un ejemplo de vida.

Al Dr. Miguel Ángel Armella Villalpando por su todo su apoyo y entusiasmo para finalizar está tesis.

Al Biól. Gilberto Hernández Cárdenas por compartir sus conocimientos. Por su desinteresado apoyo en cada una de las etapas de este trabajo. Gracias a su compromiso e ideas está tesis fue posible. Por aventurarse a abrirme las puertas de su laboratorio y por su gran amistad.

A mis compañeras y amigas de ambos laboratorios, por transformar esos momentos difíciles en recuerdos gratos e inolvidables.

A Monse por ofrecerme su amistad y apoyo incondicional.

A mi Ángel por estar en todo momento junto a mí.

A la Universidad Autónoma Metropolitana por formar a la persona que soy. Por haberme dado a mis más grandes amores: mis profesores que llegaron a ser entrañables amigos, a mis hermanas UAMeras, al amor de mi vida y a mis fieles compañeras. 


\section{CONTENIDO}

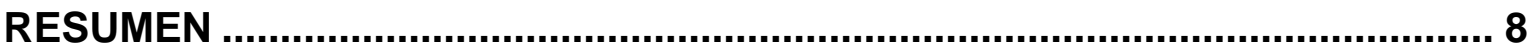

ABSTRACT

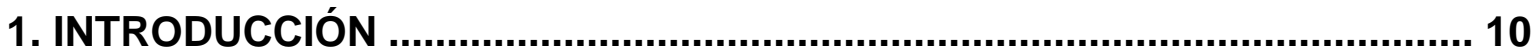

1.1. Cambio de uso de suelo............................................................... 13

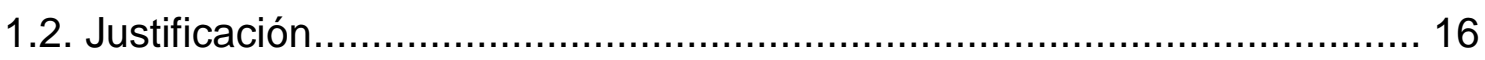

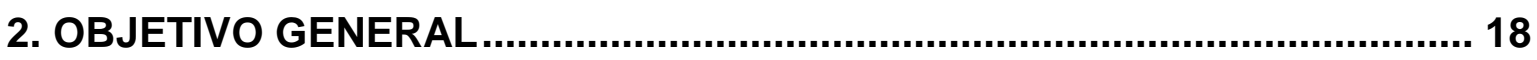

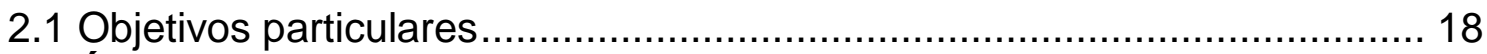

3. HIPÓTESIS GENERAL....................................................................... 19

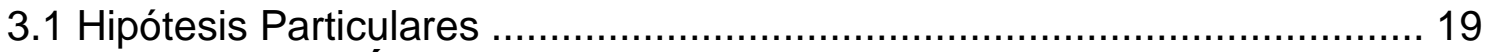

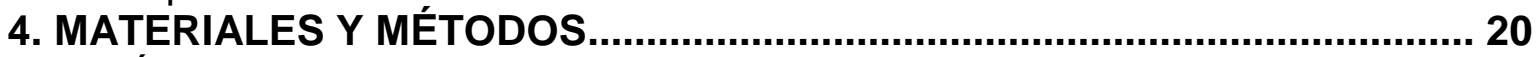

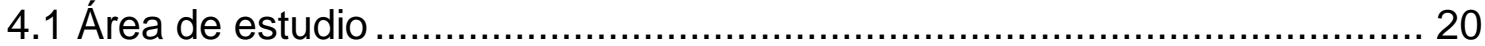

4.1.1. Ubicación y principales rasgos..................................................................20

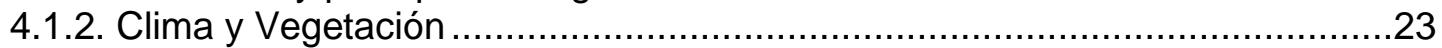

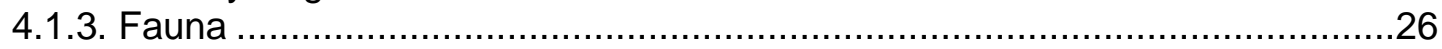

4.2. Obtención de imágenes de satélite ..................................................... 29

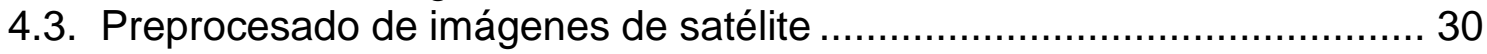

4.3.1. Corrección Geométrica ............................................................................31

4.3.2. Corrección Atmosférica........................................................................31

4.4. Índice de Vegetación de Diferencias Normalizadas ............................... 32

4.4.1. Selección y Apilado de bandas ..................................................................33

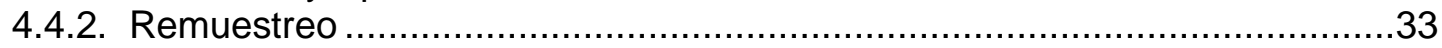

4.5. Clasificación digital....................................................................... 34

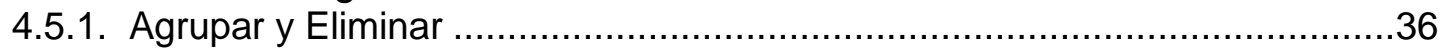

4.5.2. Extracción por máscara …………………………………………….......36

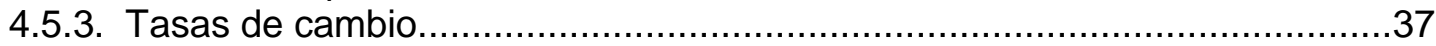

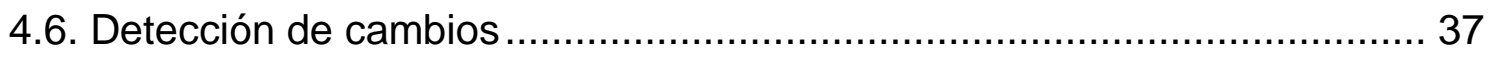

4.7. Escenarios prospectivos de cambio .................................................. 39

4.7.1. Matriz de transición ............................................................................ 42

4.7.2. Escenarios Prospectivos de Cambio.........................................................43

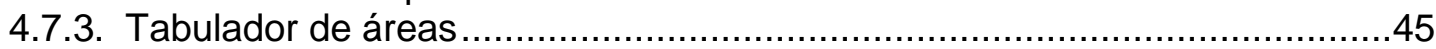

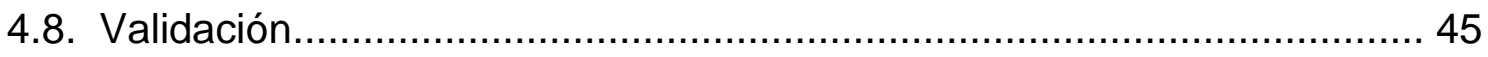

4.8.1. Verificación de la clasificación con datos de campo ....................................46

4.8.2. Evaluación de la clasificación a partir de una malla ……………………....48

4.8.3. Validación del modelo de Markov. ............................................................48

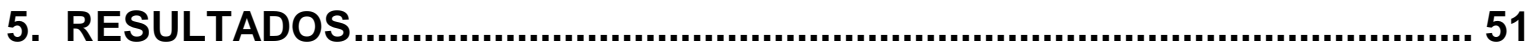

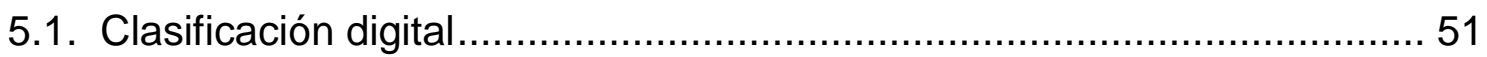

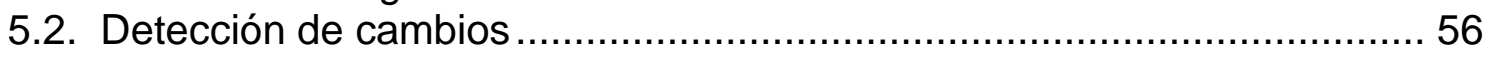

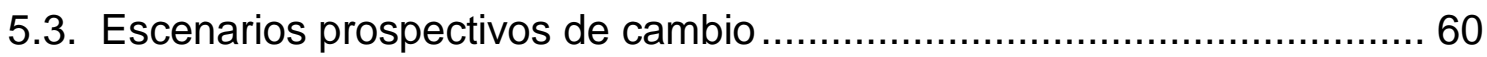

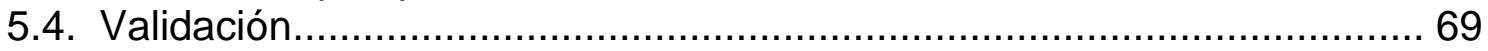

5.4.1. Verificación de la clasificación con datos de campo ......................................69

5.4.2. Evaluación de la clasificación a partir de una malla ......................................71

5.4.3. Validación del modelo de Markov. ……………………...........................72

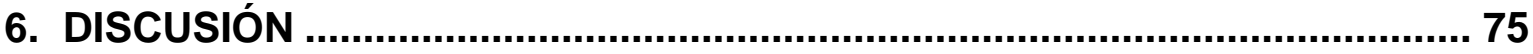

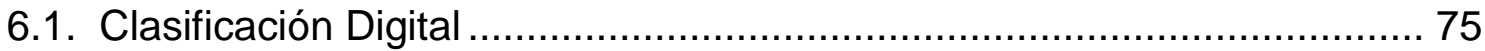

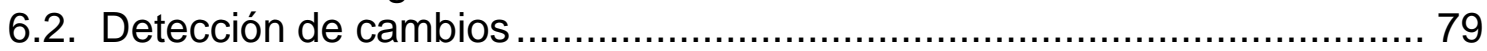

6.3. Escenarios prospectivos ………................................................. 90

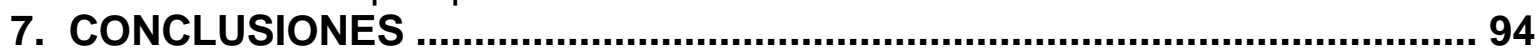

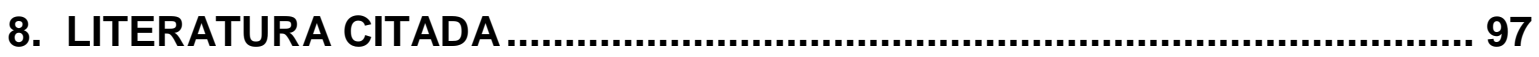




\section{RESUMEN}

La Selva Lacandona es considerada el área de mayor diversidad biológica de Norteamérica y parte de su extensión es protegida por la Reserva de la Biosfera Montes Azules. Dentro de la Selva Lacandona se encuentra el municipio Marqués de Comillas en Chiapas, que colinda con la Reserva de la Biosfera Montes Azules, por lo que es considerado una zona de amortiguamiento y forma parte del Corredor Biológico Mesoaméricano que promueve la conservación de hábitats para un gran número de especies de flora y fauna de Mesoamérica. Desafortunadamente, el municipio de Marqués de Comillas ha sufrido una intensa deforestación y degradación de la vegetación natural debido a las actividades antropogénicas.

En este trabajo se realizó un modelo de detección de cambios en el municipio Marqués de Comillas en Chiapas, con el cual se pudo conocer la dinámica de los cambios de uso del suelo que tuvo la Selva Alta Perennifolia de 1986 al 2007. A partir de este análisis en un periodo de 21 años, se generaron escenarios a futuro que consideraron algunas variantes antropogénicas. Estos escenarios prospectivos muestran las posibles tendencias de cambio de uso del suelo, que podrían resultar de gran ayuda en la toma de decisiones para la conservación y restauración de la selva.

En la primer fecha de análisis la selva ocupaba $80,469.7$ ha que corresponden al $87 \%$ del territorio municipal, en 1997 su extensión ocupó 66,064.9 ha (71\%) y para el 2007 disminuyó hasta 48,246.9 ha (52\%), además, en ese mismo año, la vegetación recuperó $3,285.9$ ha; dicho escenario coincidió con varios programas gubernamentales de apoyo al campo. A partir de los datos anteriores se predice que la selva disminuirá, para el año 2022, constantemente hasta llegar al $43 \%$ del territorio municipal y esta pérdida se ubicará principalmente a los costados de las carreteras y los poblados.

Dado que en el área de estudio se están llevando a cabo procesos de recuperación de la vegetación sería conveniente realizar estudios de monitoreo a mediano y largo plazo en las áreas recuperadas para conocer qué dirección toman y qué características van adquiriendo con el tiempo.

Por último, gracias a las características que presenta la zona de estudio y de acuerdo con los resultados obtenidos en este análisis, no sería aventurado decir que el municipio Marqués de Comillas es un escenario ideal para implementar una estrategia en el uso del suelo, que establezca las posibles actividades antropogénicas que se adapten mejor a las necesidades de los pobladores y que cubran los requerimientos de una zona de amortiguamiento. 


\section{ABSTRACT}

The Selva Lacandona is considered the most biologically diverse area in North America and part of its extension is protected by the Biosphere Reserve Montes Azules. Within the Lacandon Jungle is the municipality Marqués de Comillas in Chiapas, adjoins the Biosphere Reserve Montes Azules so is considered a buffer zone and is part of the Mesoamerican Biological Corridor that promotes conservation of habitat for a large number of flora and fauna of Mesoamerica. Unfortunately the municipality of Marques de Comillas has suffered intense deforestation and degradation of natural vegetation due to anthropogenic activities.

This paper presents a model change detection in the municipality Marqués de Comillas in Chiapas, with which it was known the dynamics of changes in land use that had the Selva Alta Perennifolia 1986 to 2007. From held this analysis in the period of 21 years, future scenarios that anthropogenic considered some variants were generated. These prospective scenarios show possible trends of land use change, which could be helpful in making decisions for the conservation and restoration of the forest.

In the first analysis date the jungle occupied 80469.7 has corresponding to $87 \%$ of the municipal territory, in 1997 its extension took 66,064.9 ha (71\%) and for 2007 decreased to $48,246.9$ ha $(52 \%)$ also in the same year, vegetation has recovered 3285.9; this scenario coincided with various government support programs field. From the above data it is predicted that the forest decline, 2022, constantly to $43 \%$ of the municipal territory and this loss is mainly located on the sides of the roads and towns.

Since in the study area are ongoing recovery processes would be desirable vegetation monitoring studies medium and long term in the areas recovered to know which direction to take and what characteristics they acquire over time.

Finally, thanks to the features found in the study area and according to the results of this analysis, it would be safe to say that the municipality Marqués de Comillas is an ideal place to implement a strategy on land use scenario established possible anthropogenic activities to the needs of the people adapt and cover the requirements of a buffer zone. 


\section{INTRODUCCIÓN}

En las últimas décadas se ha observado cierto incremento en la población humana y otro tanto en la frecuencia de sus movimientos migratorios, ambos aspectos han causando cambios importantes en los ecosistemas naturales ya que hacen uso de estos para satisfacer sus necesidades básicas. A nivel global se estima que esos cambios han abarcado entre el 30 y $50 \%$ de la superficie terrestre (Noble y Dirzo, 1997; Vitousek et al., 1986; Cincotta et al., 2000).

Entre los factores más evidentes que desencadenan la transformación de los ecosistemas, se encuentran la pérdida de cobertura vegetal, la sobreexplotación de recursos y la presencia de especies invasoras (Challenger et al., 2009); a su vez, algunos de estos factores pueden ser consecuencia de otros, por ejemplo, la sobreexplotación de algún recurso podría permitir la permanencia de especies invasoras o conducir a la pérdida de la cobertura vegetal.

La pérdida de la cobertura vegetal puede ocasionar alteraciones a diferentes niveles. A nivel global, se puede alterar el ciclo del carbono por la disminución de las áreas de cobertura vegetal que capturan dicho gas, contribuyendo de esta forma a la emisión de gases de efecto invernadero. Por otra parte, al aumentar la superficie de coberturas que reflejan la radiación solar (efecto albedo) se contribuye al cambio del clima global (Lambin et al., 2003) y también se pueden ver afectados los ciclos hidrológicos por la disminución de la evapotranspiración (Velázquez et al., 2002). 
A nivel local, los hábitats y la biodiversidad se reducen drásticamente provocando una baja en la calidad de los bienes y servicios; además, generalmente el suelo se erosiona después del desmonte cuando las áreas de cobertura vegetal son preparadas para usarse intensamente en la agricultura y la ganadería, dando como resultado la disminución de las tierras útiles para los cultivos o para la reforestación.

El avance de las actividades agrícolas hacia áreas de vegetación natural ha traído como consecuencia la aparición de una superficie de labor frágil, con alta susceptibilidad a los procesos erosivos y con baja productividad (Orozco et al., 2004); esto es especialmente grave sí se considera que en los años ochenta se estimó que una fracción significativa de la superficie terrestre (entre el 10 y 15\%) se encontraba ocupada por la agricultura o zonas urbanas e industriales, y cerca del $8 \%$ se había transformado a pastizales (Olson et al., 1983). Hacia finales del siglo XX se calculó que en Latinoamérica se reduciría la cobertura vegetal natural de selvas y bosques hasta un $53 \%$, de los cuales el $32 \%$ sería aportado por Brasil, México y Costa Rica (FAO, 1995).

Recientemente se registró a nivel mundial una pérdida de 13 millones de hectáreas de vegetación natural por año, las cuales fueron cambiadas a otros usos o se perdieron por causas naturales (FAO, 2010).

En México, los ecosistemas naturales han sufrido un serio impacto en los últimos 50 años. En un lapso de nueve años (1993 al 2002), el país perdió casi 
tres millones de hectáreas de vegetación natural, a un ritmo de 306 mil hectáreas por año, las cuales fueron cambiadas a otros usos (DGEIA, 2005); en téminos de cobertura vegetal, para el 2002 se registró que casi un 73\% del territorio estaba cubierto por vegetación natural y el resto (27\%) lo ocupaban zonas agropecuarias y urbanas (INEGI, 2005).

En general, las modificaciones de la cubierta vegetal causadas por las actividades humanas promueven el establecimiento de la vegetación secundaria la cual se compone de comunidades de plantas que se establecen como consecuencia de la destrucción total o parcial de la vegetación clímax. Por ejemplo, en la mayor parte de las áreas correspondientes a la Selva Alta Perennifolia y al Bosque Mesófilo de Montaña la vegetación consiste en un mosaico de diferentes comunidades secundarias (Rendwiski, 2006).

Datos correspondientes al 2005 proporcionados por la Organización para la Alimentación y la Agricultura (FAO, por sus siglas en ingles) colocaron a México como el octavo país con más superficie boscosa y al mismo tiempo ocupó el cuarto lugar entre los países con mayor superficie deforestada (FAO, 2006). Algunas predicciones consideran que para el 2025, México contará con 0.3 ha. per capita de superficie forestal (Masera 1996; Velázquez et al., 2001). Particularmente, un estudio realizado en siete ejidos rivereños del río Lacantún en la porción sur de la Reserva de la Biosfera Montes Azules (RBMA), pronosticó un escenario donde desaparecería por completo la superficie arbolada para el año 2030 (Carabias et al., 2006). 
Ante estos escenarios resulta apremiante realizar estudios sobre el uso del suelo y su cambio, ya que estos pueden proporcionar las bases para mostrar las tendencias de los procesos de deforestación, desertificación, degradación y merma de la biodiversidad de una región (Lambin et al., 2001); de la misma manera, estos estudios permiten comprender mejor los aspectos fundamentales que intervienen en los procesos dinámicos de las comunidades naturales.

\subsection{Cambio de uso de suelo}

Para emprender un análisis del proceso de cambio de uso del suelo se necesita comprender de forma previa a que se refiere dicho término. El Instituto Nacional de Estadística y Geografía (INEGI) define el Cambio de Uso de Suelo (CUS) como la remoción total o parcial de la vegetación en los terrenos forestales para destinarlos a actividades no forestales (INEGI, 2009), por ejemplo: áreas habitacionales, agrícolas o pecuarias y parques industriales, tomando en cuenta que el cambio de uso del suelo es un proceso que modifica el ambiente y que está asociado al hombre (Chen y Yang, 2008; Lambin, 1997), no es de extrañar que sea un término que se pueda encontrar en alguna legislación, específicamente en la que concierne a la protección del ambiente e impactos ambientales donde se define el CUS como la modificación de la vocación natural o predominante de los terrenos, llevada a cabo por el hombre a través de la remoción total o parcial de la vegetación (DOF, 2000). 
Para algunos investigadores (Anderson et al., 1976) el CUS es el resultado de las actividades socioeconómicas que se desarrollan (o desarrollaron) sobre una cobertura vegetal natural. Esta definición sugiere que la vegetación natural es transformada para obtener bienes y servicios tal como ocurre en las zonas tropicales que son modificadas por las actividades agrícolas, ganaderas y de urbanización; la transformación de las selvas en pastizales implica su desaparición total y permanente, ya que, en este proceso se sustituye la biodiversidad de las selvas por sólo algunas especies de gramíneas.

Díaz y colaboradores (2008) encontraron que en el Corredor Biológico Mesoamericano, específicamente en la parte que corresponde a México (CBMM), el reemplazo de la vegetación natural por agricultura de temporal constituye el cambio de uso de suelo más antiguo, realizado por las culturas mesoamericanas, en el que se procesan ciertas áreas de selva para cultivar por un lapso corto (de dos a cuatro años) con policultivos y posteriormente, estas áreas dejan de cultivarse por alrededor de 10 años. En estos casos de impacto moderado, durante el lapso de descanso, se podrían generar condiciones para el restablecimiento de la vegetación natural y la fertilidad del suelo, pero este proceso puede tomar diferentes caminos ya que depende de diferentes factores como el tipo de perturbación (Ferguson et al., 2003), la calidad del suelo (Guariguata y Ostertag, 2001), la disponibilidad de semillas (Wijdeven y Kuzee, 2000) y la vegetación residual. 
En las definiciones antes mencionadas se asume que las actividades antropogénicas son las principales promotoras del CUS, pero simultáneamente, la transformación de la cobertura y el incremento del uso son procesos que comúnmente se encuentran comprendidos en lo que se conoce como degradación forestal y se asocian a disturbios ecológicos en casi todos los niveles (Bocco et al., 2001).

Con el propósito de incorporar el enfoque anterior, se propone en este trabajo una definición en la que se expresan los efectos que tiene el CUS a nivel de las comunidades; el CUS puede considerarse como cualquier modificación en los patrones y procesos de la dinámica de comunidades naturales resultantes de la intervención humana que implican diferentes niveles de alteración del hábitat como en la estructura, las interacciones y el funcionamiento de las comunidades; estas alteraciones a su vez, se reflejan en cambios de los patrones de distribución y abundancia de las especies, en el reparto de recursos y en las variables sintéticas como lo son la diversidad y la conectancia (Zavala, J. com. pers.).

Considerando las definiciones anteriores se puede decir que el primer aspecto general que se tomó en cuenta en este trabajo es la correlación que existe entre el ser humano y el medio ambiente debido a la complejidad de sus interacciones. $\mathrm{Y}$ el segundo, directamente relacionado con el primero, es la acción de cambiar una cubierta natural por una distinta. 
De las definiciones mencionadas, la que más se apega al enfoque de este trabajo es la propuesta por la Ley General del Equilibrio Ecológico y la Protección al Ambiente la cual hace referencia a la modificación de la vocación natural o predominante de los terrenos, a estas modificaciones iniciales se podrían incorporar los cambios sucesivos al inicial de manera que el CUS no implique solo un cambio. Por ello, realizar estudios sobre el uso de suelo y su cambio pueden proporcionar las bases para exponer las tendencias de los procesos de deforestación, desertificación, degradación y merma de la biodiversidad de una región (Lambin et al., 2001). De la misma manera, estos estudios pueden mostrar aspectos fundamentales que intervienen en los procesos dinámicos de las comunidades naturales en un mundo cambiante.

\subsection{Justificación}

La Selva lacandona es considerada el área de mayor diversidad biológica de México y de América del norte (de la Maza, 1997). En ella se encuentra concentrado el $20 \%$ de todas las especies del país en un área que representa el $0.16 \%$ del territorio nacional (de la Maza, 2010). Cabe señalar que los servicios ambientales que proporciona La Lacandona, como lo es la mitigación del $\mathrm{CO}_{2}$ y la generación y aporte de agua, son contribuciones que no solo benefician a la propia región, sino que favorecen al país y, por consecuencia, al planeta entero. 
Por otra parte y debido a la colindancia del municipio Marqués de Comillas con la Reserva de la Biosfera Montes Azules (REBIMA) y a la cercanía con las selvas del Petén y Quiché, es considerada una zona de amortiguamiento y forma parte del Corredor Biológico Mesoaméricano, México (CBMM) que opera desde el 2001. La existencia de este corredor promueve la conservación de hábitat para un gran número de especies de la flora y fauna de Mesoamérica (Cortez, 1998).

El paisaje actual del municipio Marqués de Comillas, es consecuencia de los cambios de uso del suelo que colocan en una situación crítica a los remanentes de vegetación natural (de Jong et al., 2000; Castillo-Santiago et al., 2007) ya que éstos cubren una parte significativa del territorio municipal. A pesar de la cercanía que tiene el municipio con la REBIMA, los estudios dirigidos hacia esta zona son pocos, por ello es necesario analizar la dimensión, la dinámica y la distribución de los cambios de uso del suelo a través del tiempo para que la pérdida de la cobertura vegetal sea monitoreada y se tomen medidas para controlar dichos cambios y a su vez conservar los remanentes de selva que presenta el municipio. 


\section{OBJETIVO GENERAL}

Estudiar la dinámica de cambio de uso del suelo relacionada con la Selva Alta Perennifolia en una ventana temporal de veintiún años (1986-2007) y generar escenarios prospectivos que muestren las tendencias del cambio a cinco, diez y quince años en el municipio Marqués de Comillas, Chiapas.

\subsection{Objetivos particulares}

1. Identificar las distintas coberturas y usos del suelo presentes en el municipio.

2. Localizar y cuantificar las dinámicas de cambio de uso del suelo durante el periodo 1986-2007.

3. A partir del escenario del 2007, generar modelos de cambio de la Selva Alta Perennifolia a cinco, quince y veinte años, donde intervengan algunas variables antropogénicas. 


\section{HIPÓTESIS GENERAL}

La tendencia en el cambio de uso de suelo, en el municipio Marqués de Comillas, entre los años 1986 y 2022 corresponde a una reducción de las áreas con cubierta forestal natural y a un aumento de las áreas con algún aprovechamiento antropogénico.

\subsection{Hipótesis Particulares}

1. El municipio Marqués de Comillas presentará alta heterogeneidad de coberturas debido al aprovechamiento antropogénico.

2. La Selva Alta Perennifolia mostrará importantes disminuciones en su extensión debido al incremento constante del cambio de uso de suelo durante el periodo 1997-2007.

3. La dinámica de cambio de uso de suelo observada durante el periodo 1986-2007 será consistente en los escenarios prospectivos, mostrando una disminución significativa en la superficie de la Selva Alta Perennifolia. 


\section{MATERIALES Y MÉTODOS}

\section{1 Área de estudio}

\subsubsection{Ubicación y principales rasgos}

Este estudio se enfoca en el municipio Marqués de Comillas, Chiapas $\left(16^{\circ}\right.$ $\left.20^{\prime} \mathrm{N} ; 92^{\circ} 46^{\prime} \mathrm{O}\right)$ el cual cuenta con una superficie de 93,261 hectáreas. EI municipio limita al norte y al este con el municipio Benemérito de las Américas, al sur con Guatemala, y al oeste con la Reserva de la Biosfera Montes Azules (RBMA) a través del río Lacantún (Figura1).

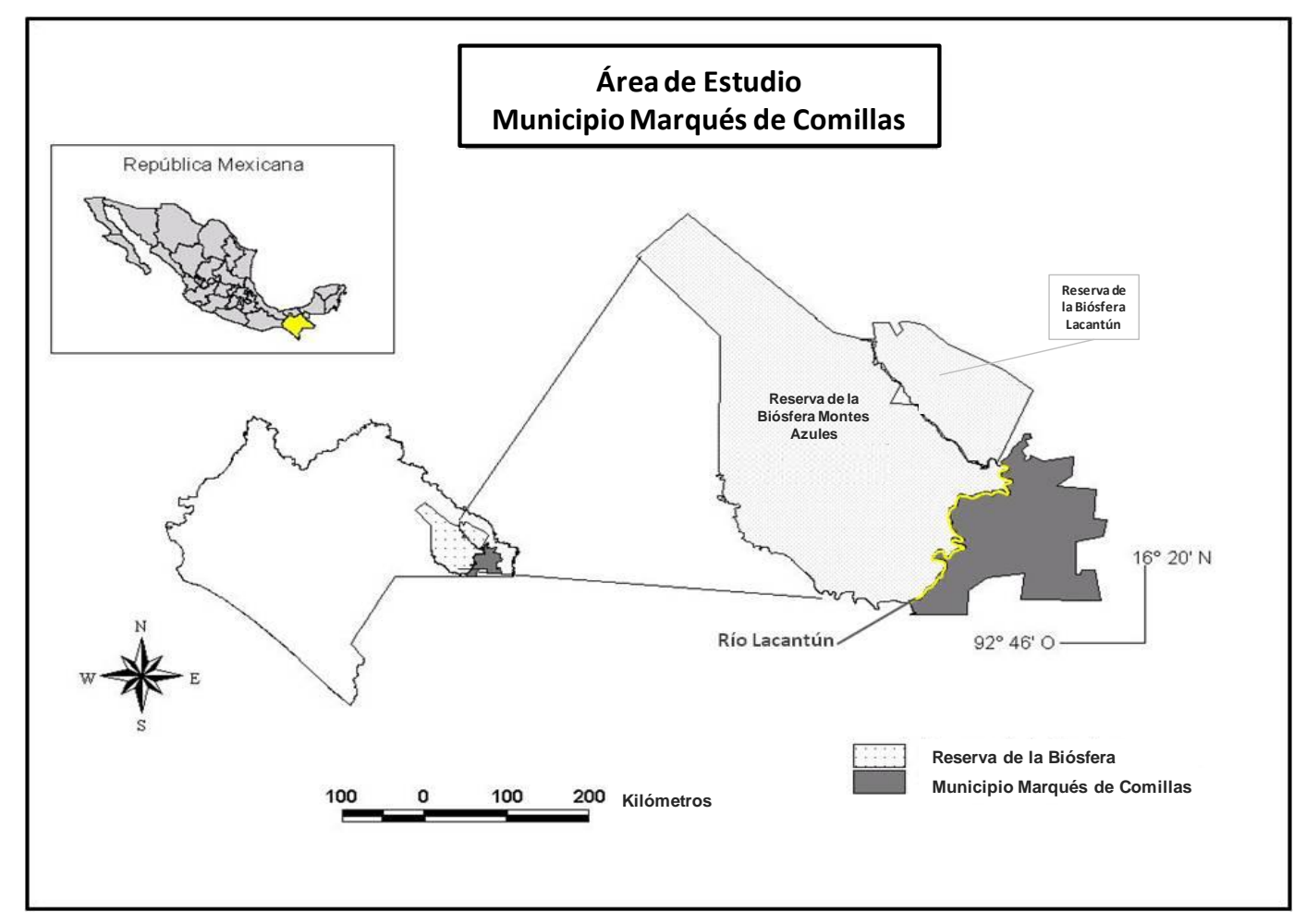

Fig. 1.- Ubicación del municipio Marqués de Comillas. 
La mayor parte del territorio municipal (98.68\%) es plano, con algunas elevaciones que van principalmente del centro hacia el sur, alcanzando como máximo 260 m s.n.m y el $1.32 \%$ restante lo ocupan cuerpos de agua.

Marqués de Comillas se localiza dentro de la subcuenca Lacantún y en menor proporción en las subcuencas Chajul (ambas de la cuenca Río Lacantún) y Chixoy (de la cuenca Río Chixoy); los principales ríos perennes son el Lacantún, Delicias, Salado y el Arroyo Bravo.

Dentro del municipio se pueden encontrar cuatro tipos de suelo, el Acrisol que abarca el 84.89\%, Gleysol con 13.07\% (aluvial), Rendzina con $1.78 \%$ (Caliza) y el Regosol con el 0.12\% (SEPLADE, 2013).

Los suelos Acrisol son normalmente usados para la agricultura con rendimientos muy bajos y para la ganadería con pastos inducidos o cultivados. Sin embargo, el uso más adecuado para la conservación de estos suelos es el forestal ya que son moderadamente susceptibles a la erosión (INEGI, 2004).

La actividad agrícola en los Acrisol suele depender en gran medida de las temporadas de descanso, de lo contrario requerirán de grandes cantidades de fertilizantes para obtener rendimientos satisfactorios de los cultivos debido a su deficiencia en nutrientes.

El tipo Gleysol presenta generalmente pastos y en algunas zonas costeras se pueden encontrar cañaverales o manglares. En el sureste del país son usados 
para la ganadería de bovinos con resultados de moderados a altos y en otros casos se utilizan para la agricultura con cultivos que requieren o toleran las inundaciones, tales como el arroz y la caña (INEGI, 2004).

En el suelo tipo Rendzina se puede encontrar vegetación de Selva Alta Perennifolia y no es recomendado desmontar para usarse en la ganadería porque se pueden tener bajos rendimientos y un alto riesgo de erosión, ya que son moderadamente susceptibles a ésta (INEGI, 2004).

Las condiciones que presenta el municipio Marqués de Comillas (elevadas temperaturas e intensa humedad) durante todo el año pueden favorecer los procesos de degradación de los minerales y la descomposición de la materia orgánica acumulada en el suelo (PDM, 2012); sin embargo, la capacidad de erosión del suelo se ve acrecentada por los desmontes y la deforestación, ya que la falta de cobertura vegetal los torna vulnerables, principalmente en áreas con lomeríos que se emplean primero para cultivo de productos básicos como maíz, fríjol y chile, para después destinarse a la ganadería extensiva con sobrepastoreo y uso indiscriminado de agroquímicos. De esta manera, se reducen drásticamente sus rendimientos al tercer o cuarto año de uso, por lo que se incrementa la aplicación y la potencia de los agroquímicos hasta que se vuelven totalmente improductivos y son finalmente abandonados (PDM, 2012). 


\subsubsection{Clima y Vegetación}

El clima predominante en Marqués de Comillas es cálido húmedo, con lluvias en verano y una estación seca de diciembre a abril, siendo los meses más secos marzo y abril, durante los cuales la precipitación no pasa de $40 \mathrm{~mm}$ mensuales.

Dentro del municipio existen una serie de sutiles diferencias climáticas; por ejemplo, en el norte la temperatura promedio anual más alta es de $26.4^{\circ} \mathrm{C}$ y la temperatura más baja en el sur es de $24.3^{\circ} \mathrm{C}$; de forma contraria, las precipitaciones más bajas por año se dan al norte $(1930 \mathrm{~mm})$ y hacia el sur van aumentando hasta llegar a 2950 mm/año (García-Amaro, 2004).

El principal tipo de vegetación es la Selva Alta Perennifolia (SAP), que se caracteriza por ser una comunidad vegetal densa, dominada por una gran diversidad de árboles que siempre conservan su follaje verde y pueden llegar hasta los $30 \mathrm{~m}$ de altura; asociados a éstos se pueden encontrar bejucos y plantas epifitas (Miranda y Hernández, 1963). Este tipo de vegetación se puede encontrar desde los 100 a los 900 m s.n.m. Las especies distintivas de este tipo de vegetación son la caoba (Swietenia macrophylla), el guanacaxtle o palo picho (Schizolobium parahybum), ramón (Brosimum alicastrum), el chicozapote (Manilkara zapota), el guapaque (Dialium guianense) y el canshán (Terminalia amazonia), palo mulato (Bursera simruba) (Rzedowsky, 1998 y Miranda et al., 1963). 
De acuerdo con Miranda y Hernández (1963), también se encuentra dentro del área de estudio la selva mediana subperennifolia, específicamente se localiza en áreas de mayor pendiente con suelos someros de roca caliza y su característica principal es la pérdida del follaje de una cuarta parte de los árboles durante la época de secas. Algunas especies arbóreas de este tipo de selva son el Zapote (Achras zapota); el pucté (Bucida buceras); el ramón (Brosimum alicastrum) y la caoba (Swietenia macrophylla) (Pennington y Sarukhán, 2005).

La vegetación que se localiza en las orillas de ríos que no presentan cambios bruscos en el nivel de agua o en áreas planas con suelos anegables se conoce como vegetación riparia; es una comunidad densa que puede presentar hasta dos estratos arbóreos con alturas que oscilan entre 20 y 40 m (estrato superior). Algunas de las especies que se localizan dentro de este tipo de vegetación son: el frijolillo (Pithecellobium arboreum); el chacté (Loanchocarpus guatemalensis); el chalahuite (Inga spuria) y el pío (Licania platypus) (López M. 1980).

Existen otras comunidades vegetales muy densas que también se localizan en la ribera de río Lacantún llamadas jimbal, en las cueles domina la gramínea leñosa Bambusa longifolia que puede llegar a medir hasta 15m (Castillo-Campos y Narave, 1992).

En cuanto a la extensión de las principales coberturas vegetales y usos de suelo, existen discrepancias a entre las fuentes de información debido a los 
distintos autores y a los años de publicación, por ello se presenta a continuación una tabla donde se resume esta información (Tabla 1).

Tabla 1. Extensiones, en porcentaje, de las diferentes coberturas y usos del suelo en el municipio Marqués de Comillas.

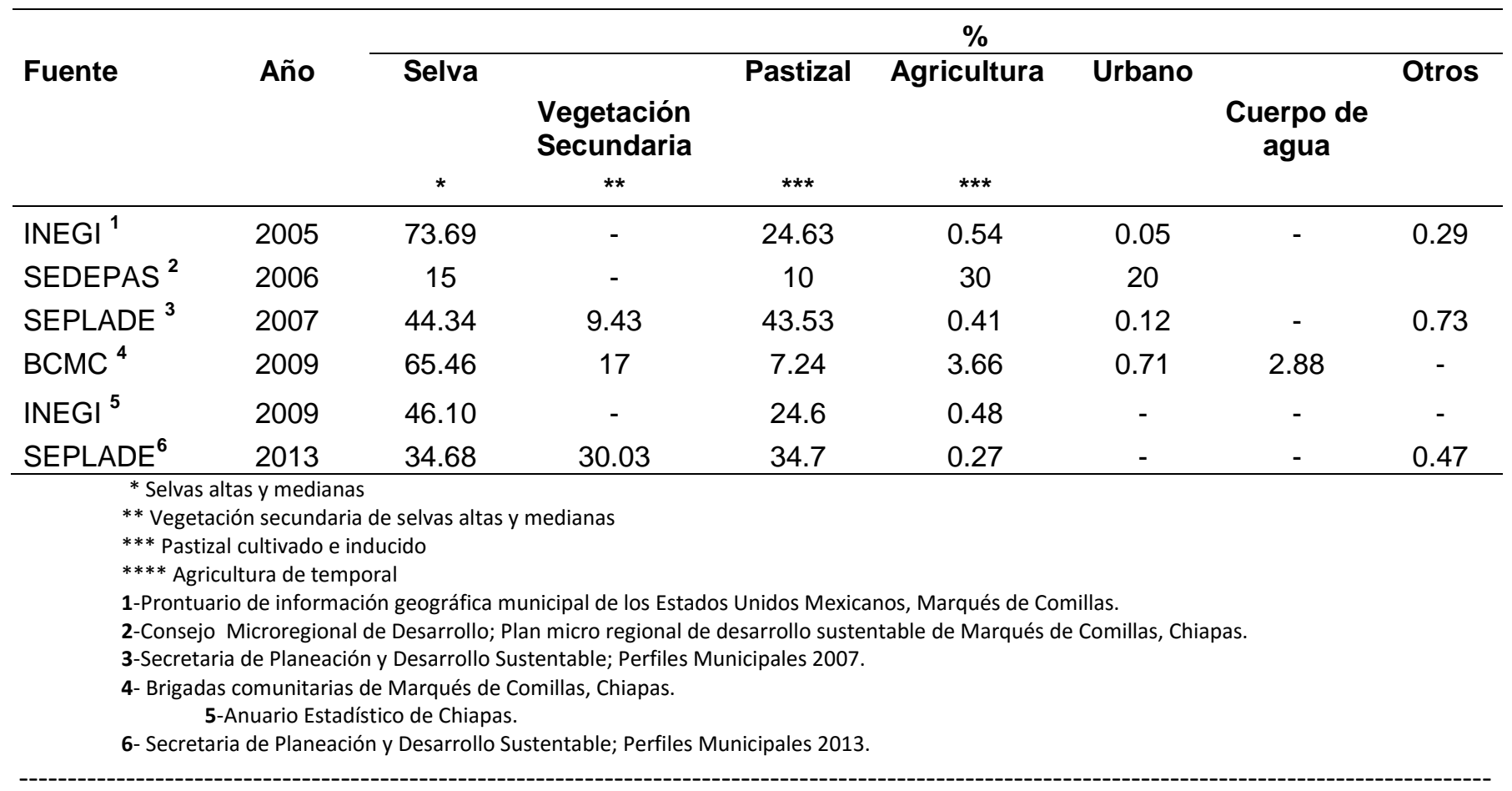




\subsubsection{Fauna}

Gracias a su ubicación, las condiciones del relieve, el clima y los tipos de vegetación presentes en el municipio, existe una gran riqueza de fauna. Por ejemplo, se tienen registradas para la Selva Lacandona, aproximadamente, 1135 especies de invertebrados que corresponderían al 3\% de la diversidad estimada para la región (Morón 1992); de este número de especies, casi el 50\% pertenecen a los grupos más estudiados (mariposas y escarabajos). Para la región de Boca de Chajul se reportan 543 tipos de mariposas diurnas y 110 especies de coleópteros (De la Maza y De la Maza,1985), de las cuales seis se registran por primera vez en México. Muchas de estas especies de invertebrados tienen su límite septentrional en Montes Azules, brindándole una gran importancia a La Selva Lacandona como corredor de especies neotropicales (Morón et al., 1985).

En la cuenca del río Usumacinta, que incluye a Marqués de Comillas, se encuentran reportadas 112 especies de peces; entre ellas existen tres especies consideradas endémicas de la región, Ictiobus meridionalis, Potamarius nelsoni y Cichlasoma bifasciatum (Miller, 1998); También se tienen registradas cuatro especies con distribución restringida a los ríos Lacanjá y Lacantún, el peje rey (Atractosteus tropicus), el bagre lacandón (Potamarius nelsoni), mojarra canchay (Cichlasoma irregulare) y la panza colorada (Cichlasoma bifasciatum) (Rodiles, 1999).

En cuanto a la herpetofauna, posee 77 especies de las cuales 23 son anfibios y 54 reptiles; con 28 especies de serpientes, 21 especies de ranas y 
sapos; seis de tortugas; dos de cocodrilos, los cuales se encuentran en peligro de extinción: el cocodrilo de río (Crocodylus acutus), el cocodrilo de pantano ( $C$. moreletti) y dos de salamandras. El 100\% de las especies de anfibios y el $92 \%$ de las especies de reptiles se comparten entre la Selva Lacandona y el Petén de Guatemala y Belice (Lazcano-Barrero et al., 1992).

Para las aves se tienen 341 especies registradas, dentro de las cuales se encuentran en peligro de extinción la guacamaya roja (Ara macao); el águila arpía (Harpía harpyja); el águila solitaria (Harpyhaliaetus solitarius); el zopilote rey (Sarcoramphus papa); el pato real (Cairina moschata) y el Hocofaisán (Crax rubra) (González, 1992).

Todos los órdenes de mamíferos se encuentran representados en la Selva Lacandona, se tienen reportadas 112 especies de mamíferos y 17 de ellas son endémicas de Mesoamérica, entre los que podemos encontrar a murciélagos como Tonatia evotis, Mimon cozumelae y Myotis elegans, así como los roedores con las especies Sciurus deppei, S. aureogaster, Tylomys nudicaudatus, Ototylomys phyllotis y Sphiggurus mexicanus. Las especies en peligro de extinción son el jaguar (Panthera onca), el ocelote (Leopardus pardalis), el tigrillo (Leopardus wiedii), el tapir (Tapirus bairdii), la nutria (Lontra longicaudis), el agouti (Dasyprocta punctata), la tayra (Eira bárbara), los primates mono aullador (Alouatta pigra) y el mono araña (Ateles geoffroyi), el armadillo centroamericano (Cabassous centralis) y el vampiro falso (Vampyrum spectrum) (Medellín, 1992 y 1994). 
Dadas las condiciones de cambio de uso del suelo y a la presión que ejercen los pobladores con la deforestación, la cacería y la extracción de especies, un gran número de éstas se han adaptado aparentemente a las áreas con algún tipo de disturbio de tal manera que se tienen registradas, por pobladores locales, algunas especies que han sido observadas en estas áreas. Se tiene registro de nueve mamíferos, el Ocelote, Mono araña, Mono aullador, Nutria, Guaqueque, Armadillo, Pecarí, Venado y Tepezcuintle; nueve aves, Tucán real, Guacamaya roja, Ocofaisan, Pava, Tecolote, Paloma blanca, Codorniz, Chachalaca, Loro; cuatro reptiles, Cocodrilo de rió, Cocodrilo de pantano, Tortuga plana y Turipache; y un marsupial, el Tlacuache (Entrevistas Semi-estructuradas, 2002).

A pesar de que las selvas presentan alta biodiversidad, la destrucción y la alteración del ecosistema está repercutiendo de manera importante en la disminución acelerada de la flora y fauna silvestre en todo el municipio. Las áreas que han sufrido un bajo impacto por el hombre presentan todavía una gran cantidad de árboles distribuidos uno muy cerca de otro; en las áreas donde el impacto es fuerte prácticamente no hay árboles, y esto se puede observar principalmente en los potreros que se utilizan para el pastoreo extensivo del ganado vacuno (PRODESIS, 2012).

Por razones como las antes mencionadas, se han asignado voluntariamente áreas de conservación dentro del municipio con una superficie de 
1563.90 ha más 45.91 ha que forman parte de la Reserva de la Biósfera Montes Azules, unidas representan el $1.77 \%$ de la superficie municipal y el $0.02 \%$ de la superficie estatal (SEPLADE, 2013).

\subsection{Obtención de imágenes de satélite}

Para analizar el cambio de uso del suelo se utilizaron imágenes de satélite Landsat 7 ETM+ con resolución espacial de $30 \mathrm{~m}$, las cuales se obtuvieron del archivo histórico del sitio Glovis de la NASA (Tabla 2). Para el año 2007 se utilizó una escena con resolución espacial de $10 \mathrm{~m}$ perteneciente al sensor Spot 5, la cual se obtuvo en la Estación de Recepción de México (ERMEX). El procesamiento de las imágenes de satélite se realizó por medio de paquetes informáticos especializados.

Tabla 2. Imágenes de satélite usadas para el análisis de cambio de uso del suelo.

\begin{tabular}{c|c|c|c}
\hline Satélite & Fecha & Sensor & Resolución Espacial \\
\hline Landsat 5 & 13 de Marzo de 1986 & TM & $30 \mathrm{~m}$ \\
Landsat 5 & 24 de Diciembre de 1997 & TM & $30 \mathrm{~m}$ \\
Spot 5 & 7 de Marzo de 2007 & HRG2 & $10 \mathrm{~m}$ \\
\hline
\end{tabular}

El software que se utilizó para el análisis estuvo integrado por programas especializados para los Sistemas de Información Geográfica (SIG); para el preprocesamiento de las imágenes de satélite se usó el ERDAS Imagine, Arcgis, Idrisi The Kilimanjaro, Arcview y, para la modelación de los escenarios, se usó la extensión de Idrisi para Arcgis llamada Land Change Modeler. 
La metodología para analizar el cambio de uso del suelo se dividió en cinco fases que se encuentran ligadas de manera consecutiva (Figura 2); la primera fase consiste en estandarizar las imágenes de satélite para asegurar una buena calidad en la clasificación digital (segunda fase); la tercera fase se enfocó en la detección de los cambios en la cobertura; la cuarta en la elaboración de modelos de cambio; y por último, en la quinta fase (de validación) el objetivo fue corroborar y validar la clasificación digital y los modelos de cambio elaborados.

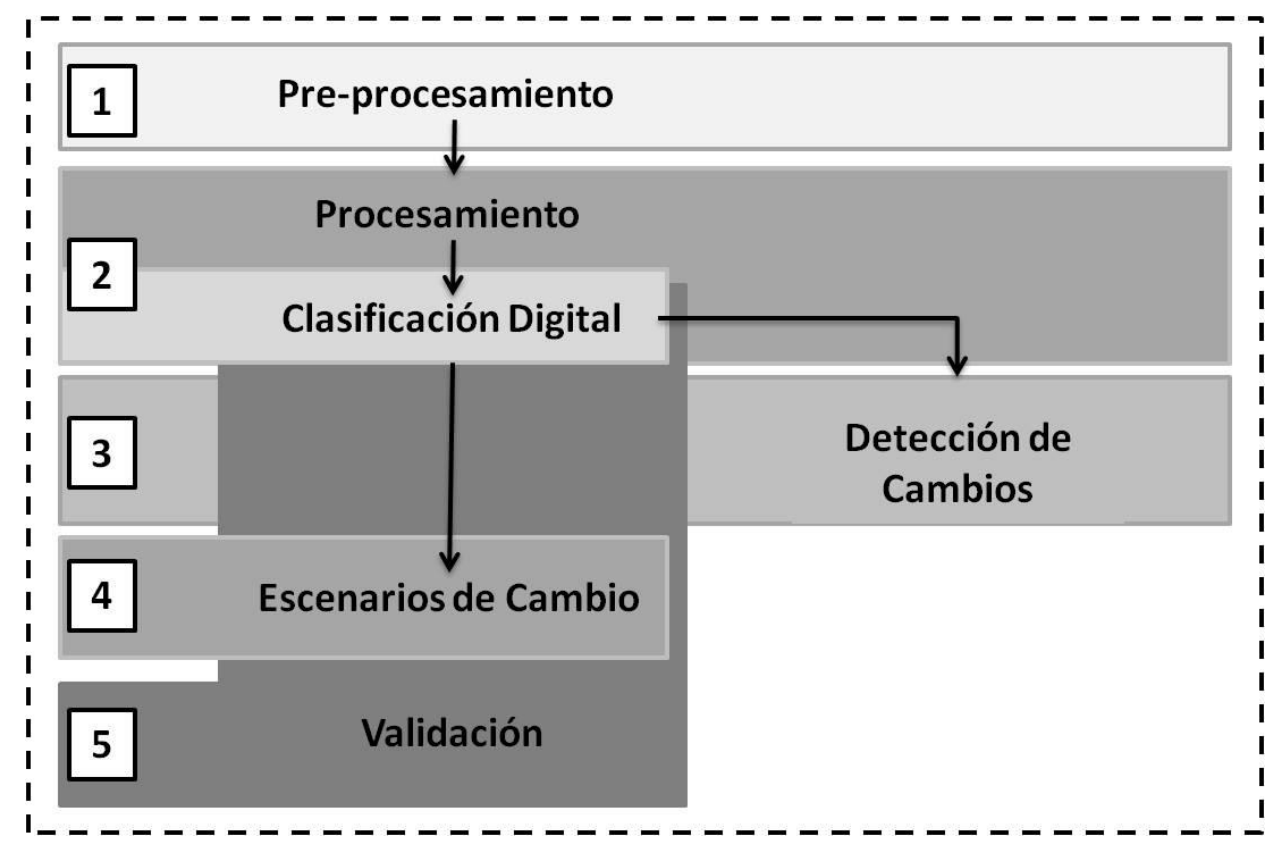

Figura 2. Esquema de la metodología para obtener escenarios prospectivos del cambio de uso del suelo.

\subsection{Preprocesado de imágenes de satélite}

El objetivo de esta etapa fue aplicar una serie de procesos que permitieran mejorar y hacer evidentes ciertos detalles que serán de utilidad para la interpretación espacial y espectral de las imágenes de satélite, así como para la 
posterior extracción de la información. La disminución de los errores ("ruido") permite la comparación de escenas de diferentes fechas con diferentes condiciones de toma de la imagen y del terreno (Chuvieco, 2002). Los preprocesamientos aplicados fueron la ortorectificación y corrección atmosférica que se explican a continuación.

\subsubsection{Corrección Geométrica}

Para la imagen Spot se realizó la ortorectificación a través del modelo geométrico Spot en el programa Leica ERDAS (9.1), tomando en cuenta que el error es aceptable cuando se obtiene un valor menor que la resolución del píxel. En el caso de las imágenes Landsat, no se requirió la corrección geométrica debido al nivel de procesamiento (L1T) que tienen las imágenes al momento de la adquisición.

\subsubsection{Corrección Atmosférica}

Esta es la corrección que elimina las distorsiones provocadas por elementos atmosféricos que interactúan con la energía captada por el sensor y que varían en el tiempo y espacio (Chuvieco, 2002).

Cuando se trata de estudios multitemporales es necesario homogeneizar las imágenes de satélite, minimizando los efectos de los elementos atmosféricos a través de la Corrección Atmosférica. El método aplicado es el propuesto por Chander (2003) donde se utilizan los datos de la fecha de la toma, el ángulo de 
elevación del sol y los valores de radiancia. El resultado es la imagen en reflectividad (Figura 3).

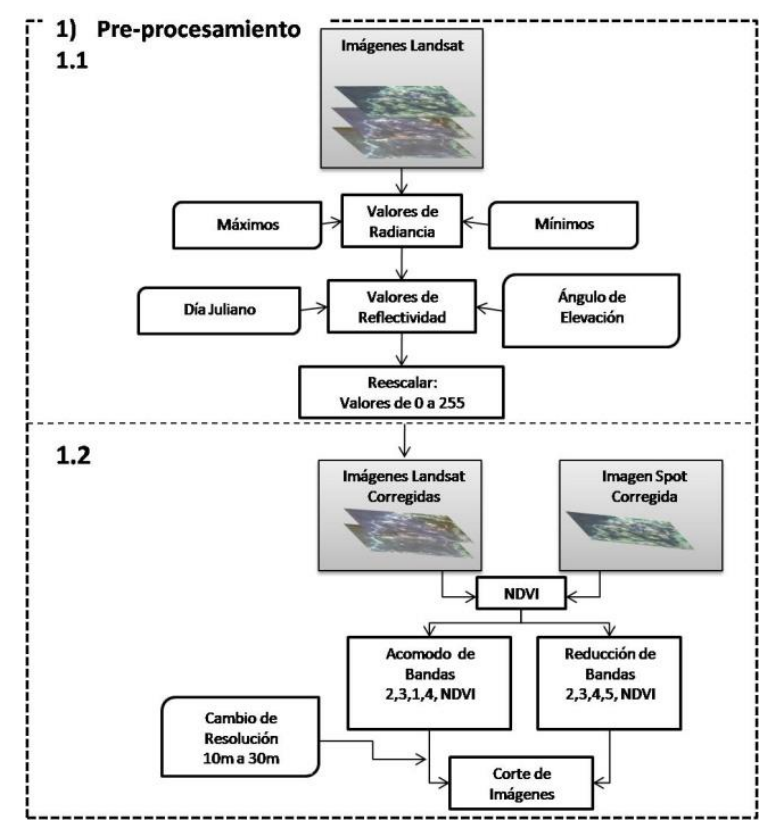

Figura 3. Procesos previos a la clasificación digital para corregir las imágenes de satélite.

\section{4. Índice de Vegetación de Diferencias Normalizadas}

El Índice de Vegetación de Diferencias Normalizadas (NDVI, por sus siglas en inglés) se basa en la diferencia registrada entre la banda del rojo en el espectro visible y el infrarrojo cercano (Ecuación 1). Como resultado se obtiene una imagen con valores que van desde menos uno (ausencia de vegetación) a uno (vegetación densa) (Erdas, 1999; Chuvieco, 2002). 
$N D V I=\frac{(N I R-R E D)}{(N I R+R E D)}$

Ecuación 1

Donde NIR es la reflectividad en la región espectral del infrarrojo cercano y $R E D$ es la reflectividad en la región espectral del rojo.

El NDVI se obtuvo para las tres imágenes con el objetivo de diferenciar la cantidad relativa de biomasa vegetal del área de estudio y usar posteriormente esta información como un auxiliar en la clasificación digital.

\subsubsection{Selección y Apilado de bandas}

Debido a la diferencia espectral entre sensores, se seleccionaron las bandas cuyo intervalo de longitud de onda fuera equivalente entre sensores. Para la imagen Landsat se seleccionaron las bandas 2, 3, 4, 5 y se adicionó el NDVI y para la imagen Spot fueron las bandas 1, 2, 3, 4 y se adicionó el NDVI.

\subsubsection{Remuestreo}

La resolución espacial está determinada por el tamaño del píxel, esto significa que a menor tamaño de área representada por un píxel será mayor el detalle captado por la imagen (Erdas, 1999). Las imágenes que se usaron para este trabajo cuentan con resoluciones espaciales diferentes (Tabla 2), por ello se remuestrearon las bandas de la imagen Spot a 30 metros, para asegurar la comparación correcta entre sensores. 


\subsection{Clasificación digital}

La clasificación digital significa categorizar una imagen multibanda para obtener una imagen con el mismo tamaño pero con pixeles asignados a diferentes categorías; actualmente existen dos tipos de clasificación digital, la clasificación supervisada y la no supervisada. De las dos modalidades de clasificación se utilizó la supervisada con el algoritmo de máxima verosimilitud (Figura 4).

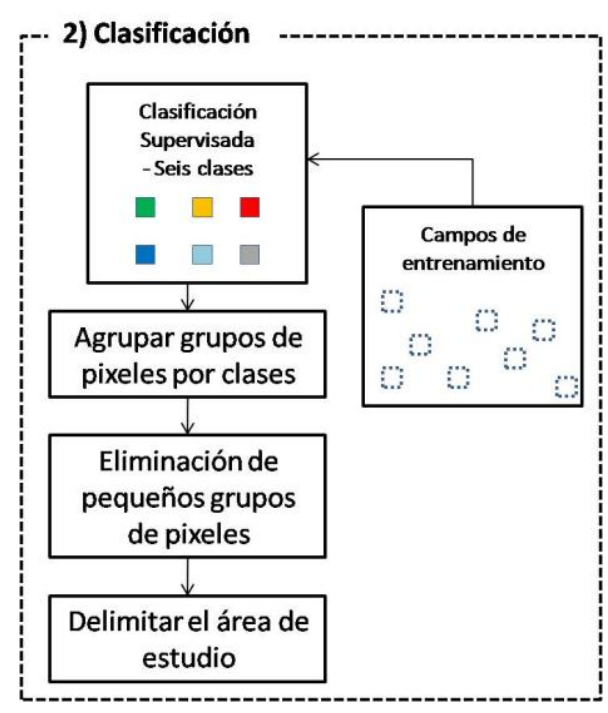

Figura 4. Esquema del método usado para clasificar las imágenes de satélite.

La clasificación supervisada parte de un conocimiento previo del área de estudio. Este conocimiento proporciona elementos (color, forma, textura, tamaño, ubicación) para identificar visualmente los diferentes usos y coberturas del suelo, a partir de este conocimiento se seleccionan pequeñas áreas representativas 
(campos de entrenamiento) de cada una de las categorías para formar grupos de valores espectrales homogéneos llamados clases (Chuvieco, 2002).

Fueron 144 campos de entrenamiento (muestra de píxeles) los que se elaboraron en escena de la imagen de satélite. Con ellos se calcularon las firmas espectrales y sus promedios fueron considerados para asignar las distintas coberturas y usos del suelo.

Se distinguieron ocho categorías, seis de estas son coberturas y usos del suelo y las dos restantes son otras cubiertas. Para fines de este trabajo se interpretaron de la siguiente manera:

1. Selva Alta Perennifolia (SAP): Tipo de vegetación caracterizado por presentar una gran riqueza de especies vegetales, en clima muy lluvioso y cálido. La copa puede llegar a los 50 metros de altura y siempre conserva una parte importante de su follaje. Bajo los árboles más altos hay varios estratos de vegetación de diferentes estaturas. Es una de las comunidades biológicas más diversas del mundo.

2. Cobertura Antropogénica (CA): Áreas donde la vegetación es parcial o totalmente distinta de la original al ser modificada por el hombre; dentro de esta categoría se incluyen los siguientes tipos de cubierta: agropecuaria (agrícola y ganadera) y vegetación secundaria. La vegetación secundaria comprende áreas donde una porción de la comunidad biológica ha sido explotada parcialmente o se encuentra en recuperación después de su remoción.

3. Abierto (Ab): Áreas que recientemente y de manera temporal sufrieron una remoción total de la vegetación arbórea por diversas posibles causas, siendo tal vez la más común la tala.

4. Sin cobertura vegetal (SCV): Áreas sin cobertura vegetal aparente, está constituidas por tres tipos de coberturas del suelo: asentamientos humanos, carreteras y bancos de arena. Se detectaron 23 asentamientos humanos para el año 2007 que ocupan un $0.0009 \%$ del territorio, todos se encuentran comunicados por carreteras, la mayoría de pavimento. El asentamiento Zamora Pico de Oro ocupa la extensión más grande y funge como la cabecera municipal. Los bancos de arena se 
refieren a las playas formadas a la orilla del río Lacantún. Esta cobertura también incluye bancos de material presentes en el área, aunque, estos no pudieron ser representados cartográficamente debido a que su superficie era menor a la unidad mínima de mapeo.

5. Inundable (In): Áreas temporal y permanentemente inundadas que pueden disminuir su extensión durante los meses de secas y presentan vegetación afín a estas condiciones como el jimbal.

6. Cuerpos de Agua (CuA): Corrientes de agua que fluyen todo el año.

7. Nubes (Nub): Nubes dentro del área de estudio.

8. Sombras (Somb): Sombras, principalmente, de las nubes dentro del área de estudio.

\subsubsection{Agrupar y Eliminar}

Una vez concluida la clasificación digital se presentaron algunos píxeles aislados asignados a una clase distinta a la de los pixeles contiguos y para incorporarlos a la clase correcta se reclasificaron con el uso del filtro de mayoría usando cuatro píxeles vecinos.

\subsubsection{Extracción por máscara}

Este proceso se refiere a la extracción de los píxeles que correspondieron con las áreas definidas por una máscara, en este caso el límite del municipio.

Se extrajo el área del municipio de las imágenes resultantes de la clasificación digital para limitar el análisis al área de estudio; la extracción se realizó en el programa ArcGIS. 


\subsubsection{Tasas de cambio}

En función de las superficies clasificadas $(1986,2007$ y 2027) se calcularon, en una hoja de cálculo, las tasas de cambio de los seis usos del suelo encontrados en el área de estudio, dichas tasas se calcularon para dos periodos de tiempo, el primero de once años (1986-1997) y el segundo de diez años (19972027).

La fórmula utilizada para calcular las tasas de cambio fue la propuesta por la FAO en 1996 (Ecuación 2), la cual se usó en dicho documento para calcular la deforestación:

$$
r=\left[1-\left(1-\frac{A_{1-} A_{2}}{A_{1}}\right)^{(1 / t)}\right] X 100
$$

Ecuación 2

Donde $r$ es la tasa de cambio en porcentaje, $A_{1}$ es la superficie en el tiempo inicial, $A_{2}$ es la superficie en el tiempo siguiente y $t$ es el intervalo de tiempo entre las dos fechas.

\subsection{Detección de cambios}

Los objetivos de la detección de cambios es identificar, calcular y resaltar los cambios sufridos en un área a partir de tres mapas temáticos de diferentes fechas. Estos objetivos se logran a partir del análisis de cada píxel para determinar que áreas han cambiado a través del tiempo. Para cada cambio se 
asigna un color y una categoría, de este modo se puede identificar los diferentes tipos de cambio, como la transformación de bosques a zonas de cultivo.

A partir de los mapas temáticos, producto de la clasificación digital, se obtuvieron tres capas binarias de la categoría CA (uno de cada año), donde las áreas con presencia de CA tuvieron valor de uno y las de ausencia, valor de cero. De cada capa se hizo una copia y se reclasificó para formar tres capas inversas que mostraran la ausencia de la categoría CA, ahora con valor de uno y la presencia con valor de cero. Por último se combinaron (intersección) las seis capas siguiendo el orden secuencial de la fechas para obtener una imagen con ocho categorías que muestran los cambios que ha tenido la categoría CA a partir del año 1986.

Las categorías se asignaron con base en las propuestas por Hayes y Sader (2001). Para ello se comparó la presencia de la categoría CA en las tres fechas y se les asignó un color dependiendo del estado de cambio que expresaran (Tabla 3).

De forma general los procesos de cambio se agruparon en tres tipos: 1) Permanencia (coberturas sin cambio), se refiere a las coberturas que no han sufrido cambios importantes; 2) Procesos negativos (Aclareo), son aquellos procesos que propician la ganancia en la áreas de la cubierta CA y pérdida de la cobertura vegetal natural; y 3) Procesos positivos (Regeneración), son aquellos 
procesos que propician la ganancia en la áreas de SAP y disminución en la cubierta CA (SEMARNAT-INE, 2008).

Tabla 3. Procesos de cambio de la CA. Modificación de los colores y números asignados al falso color en RGB.

\begin{tabular}{clc}
\hline Clase & \multicolumn{1}{c}{ Procesos de Cambio de SAP } & Color \\
\hline $\mathbf{1}$ & Sin cambio, CA & \\
\hline $\mathbf{2}$ & Aclareo de SAP desde 86 hasta 97, regeneración en 07 \\
\hline $\mathbf{3}$ & Aclareo de SAP en 86, en regeneración a partir del 97 hasta 07 & \\
\hline $\mathbf{4}$ & Aclareo de SAP en 86, regeneración en 97, aclareo en 07 \\
\hline $\mathbf{5}$ & Con SAP en 86, aclareo de 97 hasta 07 & \\
\hline $\mathbf{6}$ & Con SAP en 86, aclareo 97, regeneración en 07 & \\
\hline $\mathbf{7}$ & Con SAP en 86 hasta 97, aclareo en 07 \\
\hline $\mathbf{8}$ & Sin cambio, SAP & \\
\hline
\end{tabular}

\subsection{Escenarios prospectivos de cambio}

Un modelo puede considerarse como una abstracción de la realidad que se logra por medio de la simplificación de las relaciones existentes en el mundo real de manera que se puedan comprender y analizar (Valderrama, 2009), por ello son muy utilizados para hacer simulaciones de realidades complejas (Rubio, 2000). Los modelos estocásticos, son modelos probabilísticos que integran la incertidumbre al análisis, de esta manera se utilizan para simular las probabilidades de distribución de eventos que podrían ocurrir por efecto del azar; uno de los modelos estocásticos más empleados es el Modelo de Markov.

Un modelo de Markov es un modelo matemático (matricial) que describe los procesos de forma precisa y genera predicciones que pueden probarse en el mundo real. Este modelo matricial empleado en la ecología puede describir en 
términos generales los cambios o sucesiones que las comunidades sufren al pasar de un estado a otro a través del tiempo. Este método puede considerarse simple pero es poderoso para describir los cambios ocurridos en las comunidades y poblaciones (Gotelli, 2008).

Como se mencionó anteriormente, el modelo de Markov es un modelo que requiere de operaciones matriciales, específicamente de matrices de transición, estas matrices se multiplican secuencialmente por un vector para producir un cambio en las etapas de una comunidad (Gotelli, 2008).

En el caso del cambio de uso del suelo un modelo de Markov sería un modelo estocástico de los usos del suelo en el que se asume que un área se debe encontrar siempre bajo un solo estado (clase de uso del suelo) de un número finito de estados (estados de Markov), los cuales deben ser posibles y mutuamente excluyentes, es decir, un área no puede estar bajo dos usos al mismo tiempo para representar de esta forma la evolución temporal de los cambios de uso del suelo de un área (Figura 5).

Los pasos que deben seguirse para la elaboración de un modelo de Markov son los siguientes: 1) establecer la dimensión de los ciclos (tiempo transcurrido t), 2) definir el número de elementos que existen de un estado en particular en el tiempo inicial (vector), 3) establecer las probabilidades de transición $\left(p_{i j}\right)$ entre los estados $j$ e $i$ (matriz de transición) y 4) una multiplicación 
secuencial de la matriz de transición por el vector para producir un cambio en las estados.

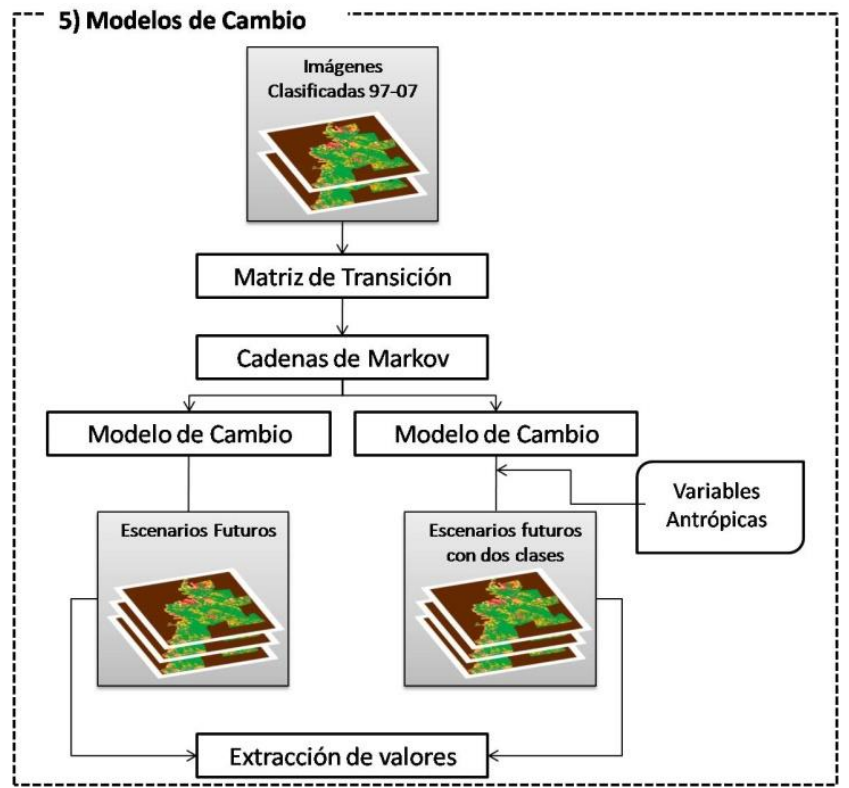

Figura 5. Pasos a seguir para obtener los modelos de cambio de uso de suelo.

Previo a la formación de las matrices de Markov se debe tomar en cuenta que:

- $\quad$ En un momento dado un área puede estar bajo una clase y solo una de las clases especificadas y estas deben ser mutuamente excluyentes; las clases deben incluir todas las posibilidades del área.

- $\quad$ Se debe especificar el intervalo de tiempo del modelo.

- $\quad$ La imagen se compone de un gran número de pixeles, el vector indica el número de pixeles que se encuentran en cada una de las clases.

- $\quad$ La matriz de transición será cuadrada ya que hay "n" clases en el modelo; todas las entradas deberán ser números positivos y encontrarse dentro de un rango de 0.0 a 1.0 ya que las probabilidades de cambio no pueden ser 
mayores a 1 o menor que 0 debido a que los estados (clases) son mutuamente excluyentes.

\subsubsection{Matriz de transición}

Para estimar y cuantificar el cambio de uso de suelo se necesita tener conocimiento previo de alguno de sus momentos, en este caso, se usaron dos mapas temáticos correspondientes a las fechas 1997 y 2007. Con ambos mapas se formó una matriz de transición; ésta se construye calculando los porcentajes de cambio entre las categorías de vegetación y usos del suelo con las que se hayan clasificado en las imágenes, estableciendo la probabilidad de cambio de cada clase entre los dos mapas (Eastman, 2004).

Los nombres de las filas y las columnas de la matriz corresponden a las clases, y las entradas de la matriz indican la probabilidad de cambio $\left(P_{i j}\right)$ de que el estado (clase) pase de la etapa $j$ en el tiempo $t$ al estado (clase) $i$ en el tiempo $t+1$. Las diagonales de la matriz indican la probabilidad de que un píxel se mantenga en su clase actual y no cambie a cualquiera de las otras clases durante un intervalo de tiempo y la suma total de los valores de cada columna debe ser uno, por la restricción de que las clases deben ser excluyentes mutuamente (Figura 6). 


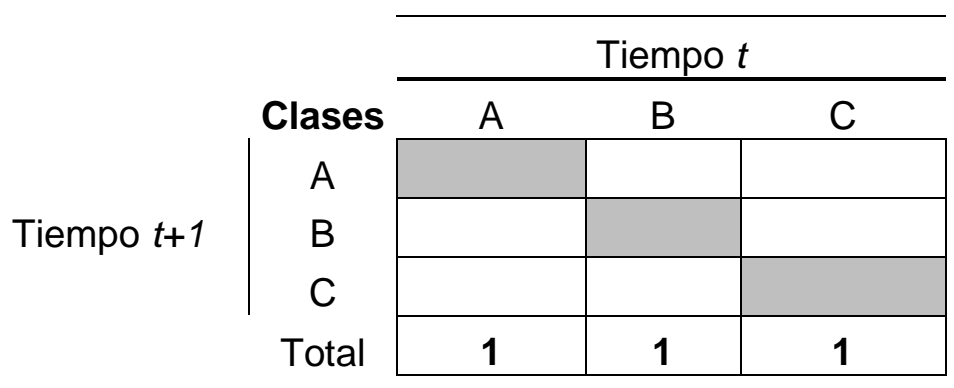

Figura 6. Ejemplo de una matriz de transición compuesta por tres clases

Finalmente la multiplicación de una matriz de transición con un vector que resulta válida para una sucesión de periodos de tiempo se le denomina Cadena de Markov (Espinoza, 2007).

\subsubsection{Escenarios Prospectivos de Cambio}

El Modelo de Markov es un procedimiento de predicción que añade un elemento de contigüidad espacial llamado autómata celular; en éste, la evolución de cada píxel se ve afectada por su propio estado y el estado de sus vecinos más próximos, así como la probabilidad de distribución espacial de las transiciones del análisis de la cadena de Markov (Eastman, 2004); en otras palabras, formar escenarios a partir de operaciones entre matrices brinda un pronóstico de los cambios de uso de suelo dependiendo de las probabilidades de cambio que tiene cada uno de los usos y coberturas existentes en los mapas temáticos.

Para obtener los modelos de cambio se multiplican las entradas de la matriz de transición $(\boldsymbol{A})$ por el vector de estado $(\boldsymbol{s})$ del $\boldsymbol{t}$ para producir el siguiente vector de estado $(s)$ para el $t+1$ (Ecuación 3). 


$$
s=(t+1)=A s(t)
$$

Ecuación 3

Se procesaron escenarios de cambio a partir de cadenas de Markov, pero en este caso sólo se usaron dos clases (SAP y CA) y debido a la naturaleza estocástica de las matrices de transición los modelos (escenarios) no tienen un poder explicativo ya que enmascaran las variables causales (ambientales y socioeconómicas) (Lambin, 1997). Para complementar los modelos se añadieron dos variables antropogénicas, vías de comunicación y poblados, para conocer si existirá alguna influencia de estos sobre la probabilidad de distribución espacial de la clase SAP; este proceso fue realizado con la extensión de Idrisi para Arcmap llamado LandChange Modeler (Eastman, 2007).

Para incorporar las variables antropogénicas al análisis, primero se digitalizaron las principales vías de comunicación y poblados de las tres fechas de análisis (1986, 1997, 2007), después se crearon cinco capas de las áreas de influencia (Buffer); las áreas de influencia son desplazamientos, a distancias específicas, que van formando un polígono (área) alrededor de una entidad (vías de comunicación y poblados) y se determinaron cinco distancias $(500,1000$, 1500, 2000 y 2500 metros) partiendo de las variables antropogénicas.

Estas capas se integraron al LandChange Modeler, específicamente en la sección de Transition Sub-Model Structure, donde se incorporaron como variables 
explicativas y se tomaron en cuenta para generar los escenarios prospectivos (Eastman, 2007).

\subsubsection{Tabulador de áreas}

Esta fase del análisis se aplicó para calcular la superficie de las clases que presentaron las imágenes resultantes de la clasificación, la detección de cambios y los escenarios prospectivos. A través del programa Arcmap, se usaron las capas del límite municipal y las áreas de influencia (Buffer) para delimitar la extracción de la información, dicho en otras palabras se usaron para identificar y conocer la superficie de los usos del suelo que se localizan dentro de los polígonos.

\subsection{Validación}

El proceso de clasificación de imágenes de satélite implica la evaluación de la exactitud con respecto a la discriminación de clases y para dicha evaluación se requieren datos de campo, los cuales se comparan con las clases interpretadas en las imágenes de satélite, formando una matriz bidimensional denominada matriz de confusión (Bocco et al, 2001), la cual muestra una visión general de si las asignaciones fueron correctas o incorrectas (Pinilla, 1995) 


\subsubsection{Verificación de la clasificación con datos de campo}

A partir de puntos de control, se obtuvo la concordancia entre lo representado en la cartografía temática y lo observado en los puntos de control; se usaron puntos de control provenientes de recorridos de campo y de las unidades de verificación (conglomerados) utilizados por la Comisión Nacional Forestal (CONAFOR) para el Inventario Forestal Nacional.

Se realizaron dos recorridos en el área de estudio, el primero fue en el 2009 y el segundo en el 2010, por cuestiones de logística se acordó tomar puntos de control en sitios representativos de los usos del suelo presentes en el municipio (un recorrido fue hacia el norte y otro hacia el centro); el desplazamiento se realizó con un vehículo y a pie usando un GPS para registrar los puntos de control y un formato impreso para tomar nota de la estructura vertical de la vegetación y los usos de suelo; se obtuvieron 66 registros. Por otra parte se seleccionaron 28 puntos de la capa de conglomerados de la CONAFOR que correspondían al área de estudio, la capa de conglomerados tenía adjuntas tablas de información referente a la diversidad de especies, estratos de la vegetación, así como información cualitativa de las condiciones del sitio correspondiente a cada punto.

Con el listado de puntos se formó una matriz de confusión y con ella se obtuvo el estadístico Kappa. El estadístico Kappa (k) definió si la clasificación logró discriminar las categorías con exactitud significativamente mayor a la que se 
hubiera obtenido con una asignación aleatoria, en otras palabras el estadístico indica la diferencia entre el mapa temático y la realidad observada.

Para obtener el índice kappa se necesita en primer lugar un listado de puntos de verificación de los cuales se posee la cobertura real y la deducida por la clasificación. Con la lista se genera una matriz de confusión cuadrada $(n \times n)$ donde las columnas representan las clases de referencia y las filas indican las categorías deducidas de la clasificación.

La diagonal de la matriz expresa el número de puntos de verificación en donde se produce un acuerdo entre las dos fuentes (cartografía temática y puntos de control); las entradas marginales expresan errores de asignación. La fiabilidad total del mapa es la relación entre el número de puntos correctamente asignados y el total. Los residuales en las columnas indican los tipos de cubierta real que no se incluyeron en el mapa (error de omisión) y los residuales de la filas implican cubiertas que no corresponden con lo observado en los puntos de control (error de comisión).

La estimación de $k$ se obtiene a partir de la siguiente fórmula:

$$
k=\frac{n \sum_{i=1, n} X_{i i}-\sum_{i=i, n} X_{i+} X_{+i}}{n^{2}-\sum_{i=i, n} X_{i+} X_{+i}}
$$

Ecuación 4

En donde $n$ es el tamaño de la muestra, $X_{i i}$ el acuerdo observado, y el producto de los marginales $\left(X_{i+}, X_{+i}\right)$ el acuerdo esperado en cada categoría $i$. El 
acuerdo observado aparece en la diagonal de la matriz, y el esperado sirve para calcular el ajuste entre el mapa y la realidad.

Un valor de $k$ igual a uno indica un acuerdo pleno entre lo observado en los puntos de control y la cartografía temática generada, mientras que un valor cercano a cero insinúa que el acuerdo observado es debido al azar (Chuvieco, 2002). Un índice $k$ con valor por arriba de 0.75 expresa buenos resultados de la clasificación (Monserud y Leamoans, 1992).

\subsubsection{Evaluación de la clasificación a partir de una malla}

A partir de puntos de control de una malla regular, se obtuvo la concordancia entre lo representado en la cartografía temática y lo observado en la imagen de satélite.

Se generó una malla regular de 405 puntos con los cuales se obtuvo, de las tres fechas, un listado de presencia y ausencia de SAP; con el listado se generó una matriz de confusión, para cada fecha, y a partir de ésta se obtuvieron los estadísticos kappa.

\subsubsection{Validación del modelo de Markov.}

Como se ha mencionado, las matrices de confusión son una herramienta objetiva para obtener la fiabilidad de las clasificaciones digitales y también a partir 
de ellas se pueden obtener parámetros estadísticos o índices que permiten validar cuantitativamente los resultados de la clasificación. En este caso se usó la matriz de confusión para evaluar las proyecciones producto de las cadenas de Markov (Figura 7).

En primer lugar se generó una proyección del año 2007 a partir de los mapas temáticos de 1986 y 1997; después el mapa temático del 2007 y la proyección 2007 se sometieron a un proceso de sobreposición llamado cruce de tablas o Crosstab del programa Idrisi, el cual genera una tabla de contingencia (matriz de transición) donde se comparan las superficies de ambos mapas con sus respectivas transiciones (Bocco et al, 2001) y dos índices de asociación entre las imágenes. En la tabla de contingencia las columnas representan las categorías del mapa temático y las filas representan las clases de la proyección (Eastman, 2004).

El primer índice que proporciona es la $V$ de Cramer (Ecuación 5), este es un coeficiente de correlación que puede indicar que no existe correlación entre ambos mapas, cuando el valor es cero o hasta que existe una correlación perfecta cuando su valor es uno, y los valores intermedios indicarían, dependiendo de la cercanía que tengan con los valores extremos $(0$ - 1), una baja correlación o una correlación fuerte. El segundo índice que proporciona es el estadístico Kappa el cual sólo tiene sentido si las categorías en los dos mapas muestran el mismo tipo de datos con las mismas clases de datos (Eastman, 2004). 


$$
v=\sqrt{x^{2}} / n-[\min (r, c)-1]
$$

Ecuación 5

Donde: $\mathrm{n}$ es el número total de observaciones en la tabla; min $[r, c]$ es el valor menor entre los valores de la filas y los valores de las columnas. Si el valor de la $V$ es igual o mayor a 0.6 indica que hay una correlación relativamente fuerte entre ambos mapas (Zavaleta, 2012).

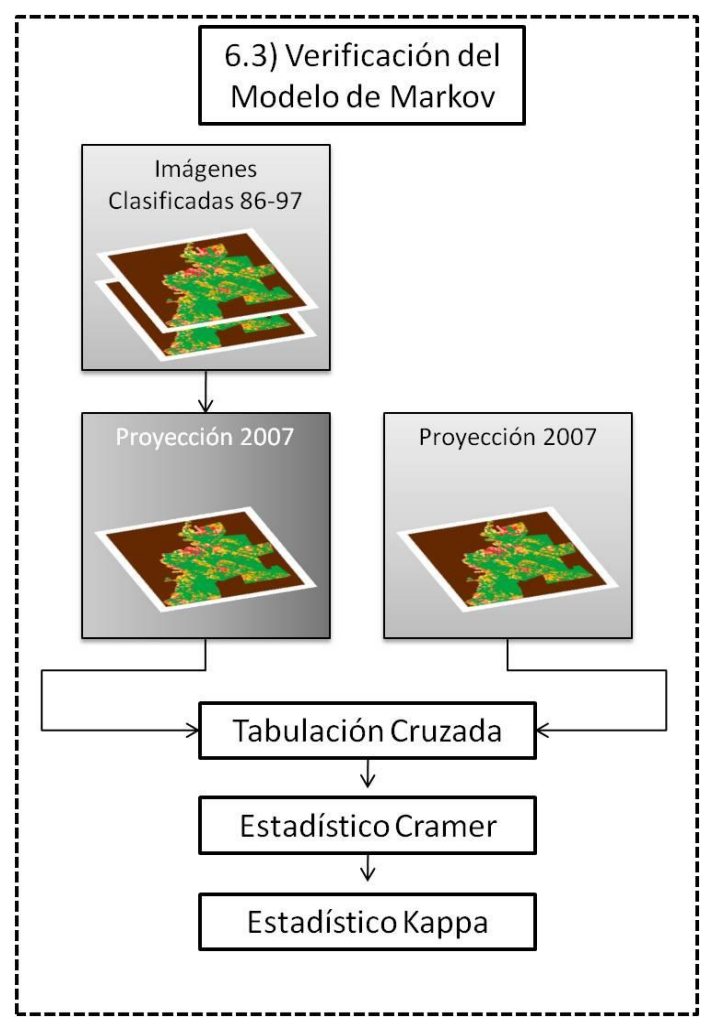

Figura 7. Pasos a seguir para verificar los modelos de Markov. 


\section{RESULTADOS}

\subsection{Clasificación digital}

En el análisis de interpretación de las imágenes de satélite que comprende el periodo 1986-2007, el área total del municipio de Marqués de Comillas fue aproximadamente de 92,932 hectáreas, de las cuales se encontró que más de la mitad de la superficie presentó algún tipo de cobertura vegetal durante las tres fechas de análisis y el porcentaje restante no presentó aparentemente ninguno. De la clasificación digital supervisada se distinguieron ocho categorías, de las cuales sólo seis se consideraron para los análisis posteriores, ya que dos de estas no eran usos ni coberturas del suelo:

1. Selva Alta Perennifolia (SAP)

2. Cobertura Antopogénica(CA)

3. Abierto $(\mathrm{Ab})$
4. Sin cobertura vegetal (SCV)

5. Inundable (In)

6. Cuerpos de Agua (CuA)

La cobertura SAP al inicio del periodo contó con una extensión que representó la mayor parte de la superficie del municipio (87\%), para el año 2007 disminuyó un 35\%, presentando tasas de cambio de -2\% para el periodo 86-97 y una tasa de $-3 \%$ para el periodo $97-07$. Por el contrario, la cobertura antropogénica ocupó para 1986 un 7\% de la superficie, para 1997 esta superficie aumentó al doble con una tasa de cambio de $7 \%$ y finalmente para el 2007 alcanzó un 29\% de la superficie con una tasa de cambio de 5\%. Esta diferencia en las tasas indicó que el cambio de uso del suelo de CA más importante y donde se produjo una ganancia significativa en la superficie ocurrió durante el periodo 86-97 (Tablas 4 y 5). Las figuras 8, 9 y 10 muestran 
los mapas de distribución de las diferentes coberturas y usos del suelo en el municipio Marqués de Comillas de 1986 al 2007.

Tabla 4. Superficie por tipo de cobertura de suelo en Marqués de Comillas, de acuerdo con la clasificación digital supervisada. SAP-Selva Alta Perennifolia; CA-Cobertura Antropogénica; Ab-Abierto, SCV-Sin cobertura vegetal; In-Inundable; CuA-Cuerpos de Agua; Nub-Nubes; Somb-Sombras.

\begin{tabular}{|c|c|c|c|c|c|c|}
\hline & \multicolumn{4}{|c|}{$\begin{array}{c}\text { Superficie en } \\
\text { Hectáreas }\end{array}$} & \multirow[b]{2}{*}{2007} & \multirow[b]{2}{*}{$\%$} \\
\hline & 1986 & $\%$ & 1997 & $\%$ & & \\
\hline SAP & $80,469.72$ & 87 & $66,064.86$ & 71 & $48,246.93$ & 52 \\
\hline CA & $8,026.38$ & 7 & $16,798.95$ & 13 & $27,084.51$ & 29 \\
\hline $\mathbf{A b}$ & $1,223.64$ & 0 & $6,077.79$ & 1 & 3295.8 & 4 \\
\hline SCV & $3,077.73$ & 0 & $3,758.13$ & 0 & $13,750.47$ & 15 \\
\hline In & 13.95 & 0 & 24.39 & 0 & 96.75 & 0 \\
\hline CuA & 120.69 & 0 & 207.99 & 0 & 252 & 0 \\
\hline Total & $92,932.11$ & & $92,932.11$ & & $92,726.5$ & \\
\hline
\end{tabular}

Tabla 5. Tasas de cambio de las coberturas y usos de suelo para los periodos 1986-1997 y 1997-2007.

\begin{tabular}{lcc}
\hline \multicolumn{3}{c}{ Tasas de Cambio } \\
\hline & $\mathbf{1 9 8 6 - 1 9 9 7}$ & $\mathbf{1 9 9 7 - 2 0 0 7}$ \\
\cline { 2 - 3 } & & \\
SAP & $-2 \%$ & $-3 \%$ \\
CA & $7 \%$ & $5 \%$ \\
Ab & $16 \%$ & $-6 \%$ \\
SCV & $2 \%$ & $14 \%$ \\
In & $5 \%$ & $15 \%$ \\
CuA & $5 \%$ & $2 \%$ \\
\hline
\end{tabular}




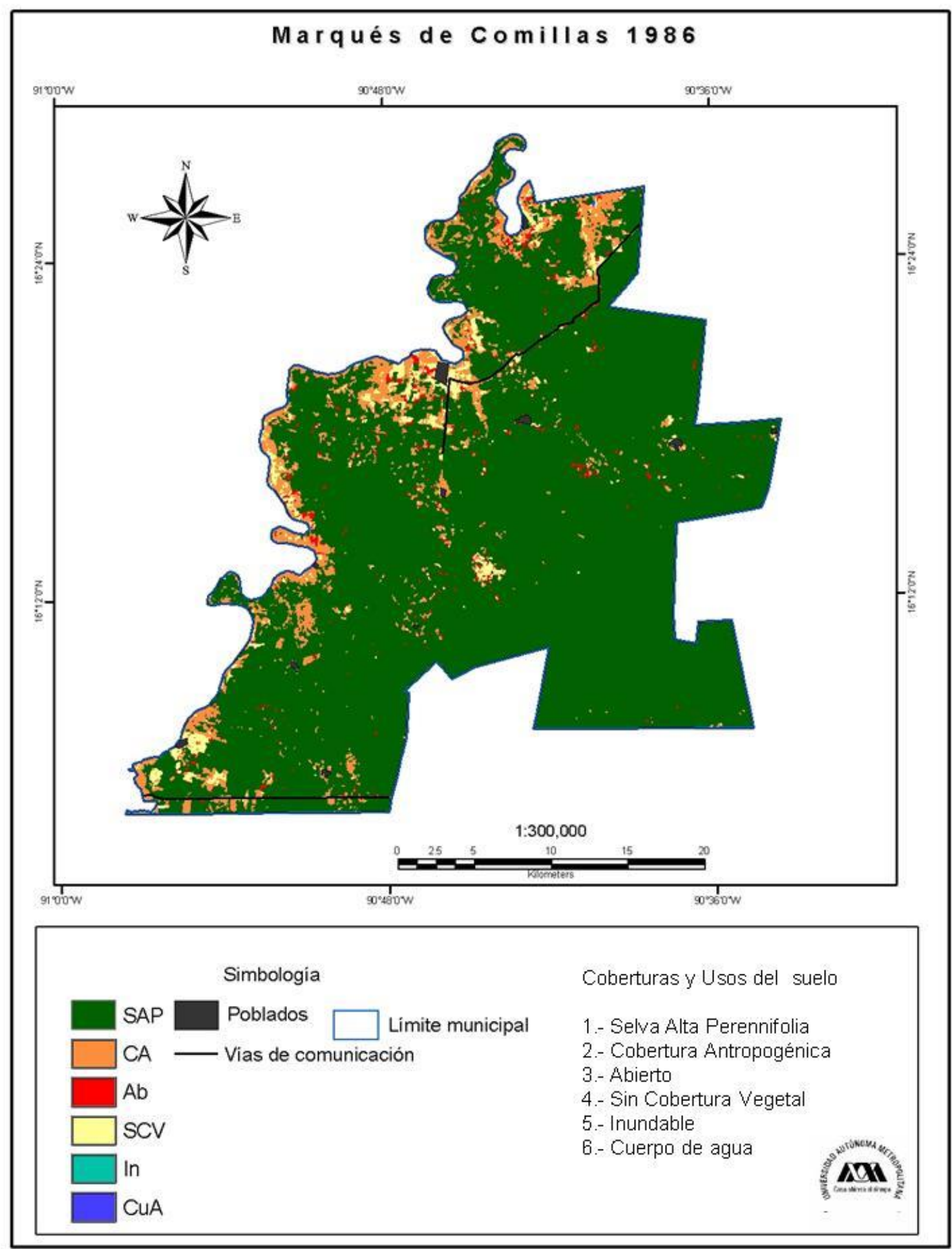

Figura 8. Mapa de Marqués de Comillas de 1986 resultado de la clasificación supervisada. 


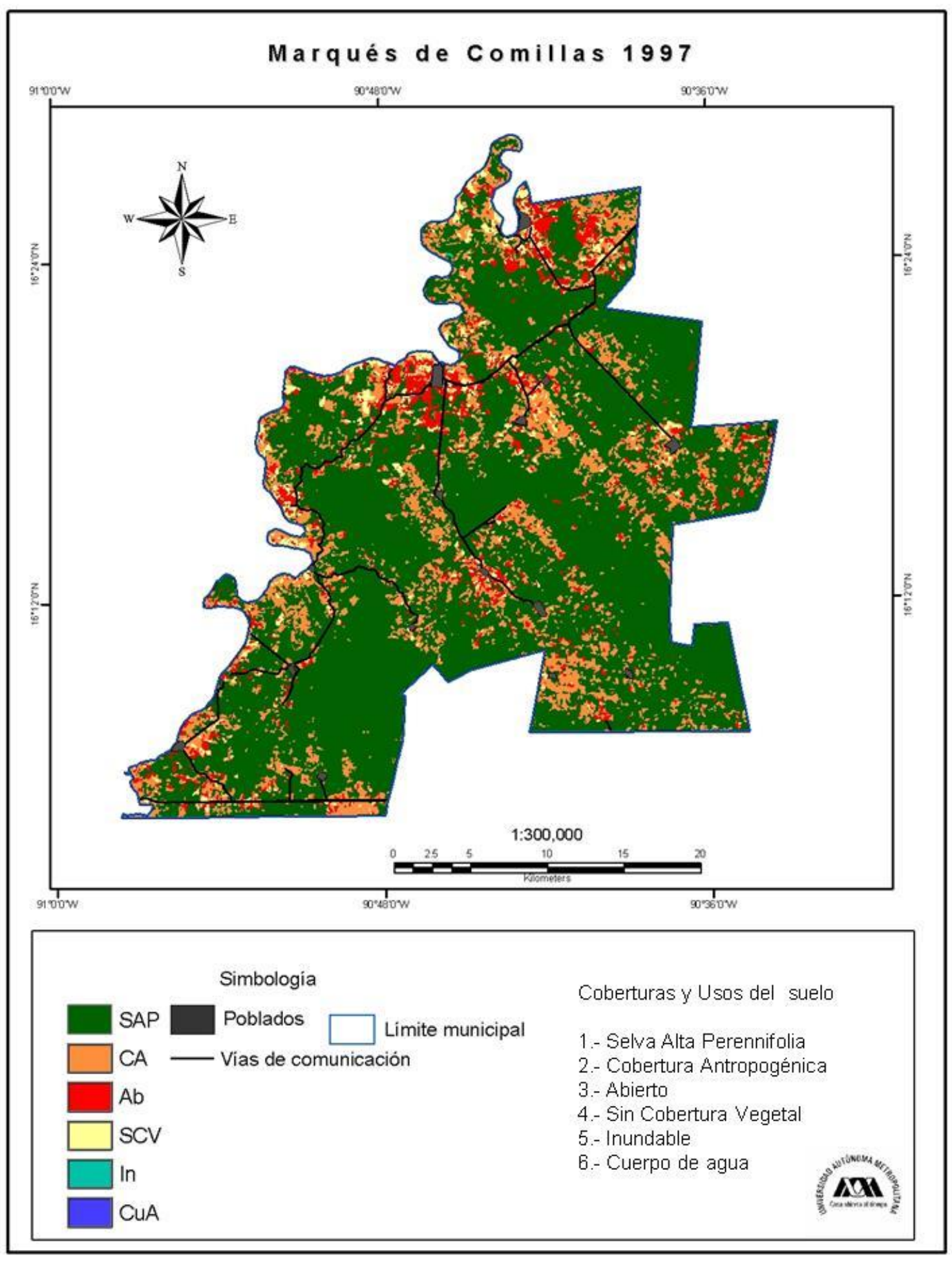

Figura 9. Mapa de Marqués de Comillas de 1997 resultado de la clasificación supervisada. 


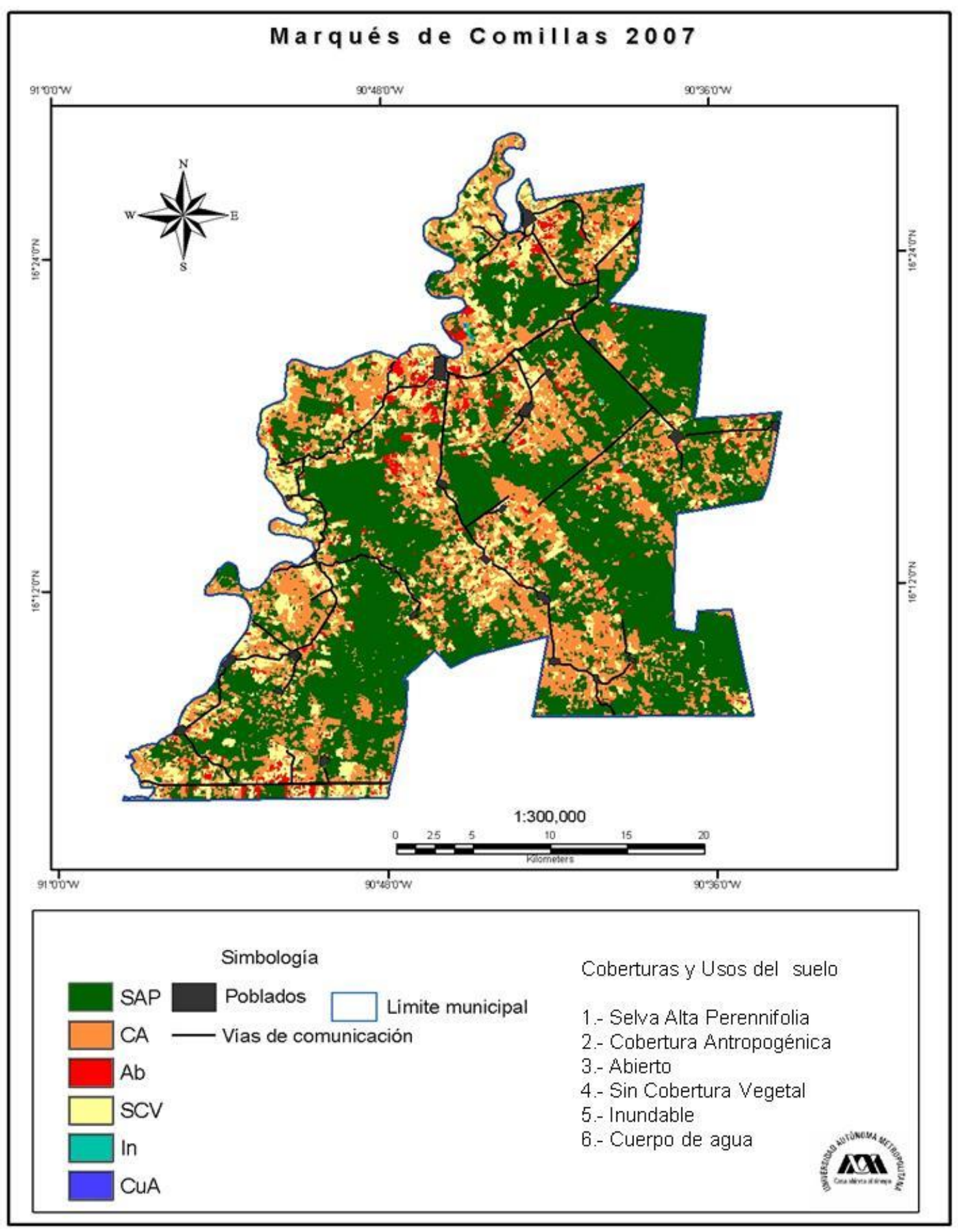

Figura 10. Mapa de Marqués de Comillas de 2007 resultado de la clasificación supervisada 
Lo que se pudo apreciar en los mapas de coberturas y usos del suelo es que las áreas de selva han perdido superficie y continuidad con el paso del tiempo, ya que se encuentran rodeadas por la cobertura antropogénica obstaculizando la continuidad entre ellas y los fragmentos que aparentemente son continuos se encuentran divididos por las vías de comunicación. La mayoría de las áreas de uso antropogénico se presentaron al margen del principal cuerpo de agua (río Lacantún) y siguiendo de manera paralela las vías de comunicación más importantes. También se encontró que la mayoría de las áreas recién abiertas estaban asociadas a la cobertura antropogénica y, de manera esporádica, se encontraron algunas de estas áreas dentro de los parches de la Selva Alta Perennifolia, de lo anterior se podría inferir que la mayoría de las áreas recientemente desprovistas de vegetación están ubicadas en la vegetación que anteriormente sufrió algún tipo de disturbio (vegetación secundaria).

\subsection{Detección de cambios}

Para comprender mejor la dinámica de los cambios ocurridos en el uso del suelo y la vegetación se generó un mapa donde se expresaran los cambios ocurridos en las áreas con SAP de 1986 al 2007 (Figura 11). Los resultados se agruparon en tres tipos para que sea más fácil su comprensión:

1) Permanencia (coberturas sin cambio): se refiere a las coberturas que no han sufrido cambios importantes durante las tres 
fechas del análisis; dentro de este tipo se encuentran las áreas que corresponden a las clases Selva Alta Perennifolia y Sombras.

2) Procesos negativos (Aclareo): son aquellos que propician pérdidas en las áreas de la cubierta SAP y que a su vez indican una ganancia en la superficie de la Categoría Antropogénica; dentro de este tipo se encuentran las áreas pertenecientes a las clases SCV, In y Nub.

3) Procesos positivos (Regeneración): se refieren a los cambios asociados con ganancias en el área de Selva Alta Perennifolia y que a su vez indican una pérdida en el área de Cobertura Antropogénica; dentro de este tipo encontramos las áreas pertenecientes a las clases CA, Ab y CuA (Tabla 6).

Tabla 6. Procesos de cambio de SAP. Colores o números asignados al falso color en RGB (SEMARNAT-INE, 2008).

\begin{tabular}{|c|c|c|c|c|}
\hline Clase & Procesos de Cambio de SAP & $\begin{array}{c}1986-2007 \\
\text { (Ha) }\end{array}$ & $\begin{array}{c}\text { 1986-2007 } \\
(\%)\end{array}$ & Color \\
\hline 1 & Sin cambio, $\mathrm{CA}$ & $9,735.3$ & 10 & \\
\hline 2 & $\begin{array}{l}\text { Aclareo de SAP desde } 86 \text { hasta } 97 \text {, regeneración en } 07 \\
\text { Aclareo de SAP en } 86, \text { en regeneración a partir del } 97\end{array}$ & 543.33 & 1 & \\
\hline 3 & hasta 07 & 756.9 & 1 & \\
\hline 4 & Aclareo de SAP en 86, regeneración en 97, aclareo en 07 & $1,395.09$ & 2 & \\
\hline 5 & Con SAP en 86, aclareo de 97 hasta 07 & $14,464.53$ & 16 & \\
\hline 6 & Con SAP en 86, aclareo 97, regeneración en 07 & $1,985.67$ & 2 & \\
\hline 7 & Con SAP en 86 hasta 97, aclareo en 07 & $18,883.17$ & 20 & \\
\hline 8 & Sin cambio, SAP & $44,961.03$ & 48 & \\
\hline Total & & 92,725 & 100 & \\
\hline
\end{tabular}




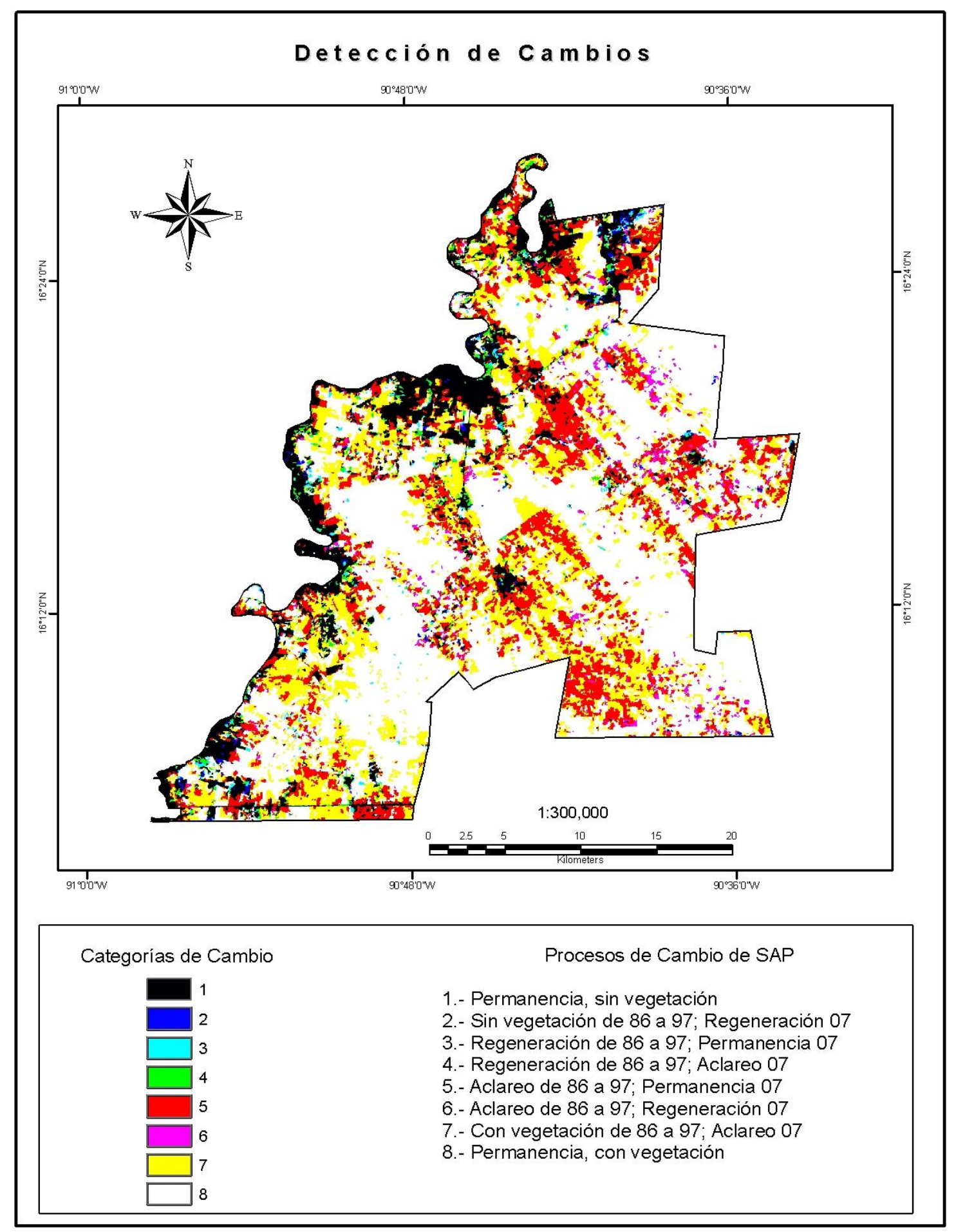

Figura 11. Mapa de detección de cambios de la clase SAP. 
1-Tipo de procesos: Permanencia

De 1986 al 2007, casi la mitad de la superficie del municipio (48\%) permaneció sin cambios aparentes, conservando gran parte de la cobertura SAP (clase 8); el 10\% de la superficie (clase 1) para el mismo periodo de tiempo correspondió a áreas que de igual forma permanecieron sin cambios significativos, pero en este caso se trató de áreas sin cobertura vegetal.

\section{2-Tipo de procesos: Negativos}

La clase 4 ocupó un $2 \%$ de la superficie y se trató de las áreas que en el tiempo uno (1986) no contaban con cobertura vegetal natural (SAP); en el tiempo dos (1997) las áreas se mostraron cubiertas de SAP y para el tiempo tres (2007) esta cobertura se perdió; en la clase In, en 1986, el 16\% de la superficie contaba con cobertura vegetal natural (SAP) y para 1997 esta cobertura desapareció permaneciendo así hasta el 2007; y por último para 1986 y 1997 las áreas pertenecientes a la clase 7 se mostraron bajo la cobertura SAP, pero, para el 2007 la mayoría de estas áreas se encontraban bajo el uso CA. Este cambio podría indicar que en algún momento, entre 1997 y e inicios 2007, un porcentaje significativo (20\%) de la cobertura sufrió un cambio de uso del suelo de SAP a Ab para después formar parte de la categoría CA. 
3-Tipo de procesos: Positivos

La clase 2 en el periodo 86-97 ocupó el 1\% de la superficie y mostró ausencia de la cobertura SAP, posteriormente, esta condición sufrió un cambio positivo de manera que para el 2007 se presentó la cobertura SAP; al igual que la clase anterior, la clase 3 ocupó el 1\% de la superficie pero indicó una probable regeneración de la SAP. Este proceso pudo deberse a que esta área se dejara descansar de las actividades antropogénicas durante 20 años. En 1986 estas áreas no contaban con Selva Alta Perennifolia y para 1997 al 2007, éstas aparecieron con cobertura SAP. Finalmente, la clase 6 inició con la clase SAP, en 1997 sufrió un cambió de uso del suelo donde se perdió esta cobertura y en el 2007 aparece de nuevo esta categoría. Estas dinámicas insinúan que se trata de áreas que todo el tiempo han estado bajo algún tipo de uso tradicional donde se trabaja la tierra y se deja descansar por algún tiempo para ser usada de nuevo.

\subsection{Escenarios prospectivos de cambio}

Se proyectaron tres escenarios con dos variables antropogénicas (vías de comunicación y poblados), a partir de cadenas de Markov, utilizando solamente las clases SAP y CA. Aunque sólo se proyectaron dos clases (SAP y CA), en los escenarios (Figuras 15, 16 y 17) aparecen las clases Abierto (Ab), Sin Cobertura Vegetal (SCV), Inundable (In) y Cuerpo de agua (CuA) con una superficie constante en los tres escenarios que corresponde al 2007 (Tabla 7). Lo anterior se debe a que los cambios históricos que se 
produjeron en la superficie de estas clases fueron pequeños (Henríquez-Dole, 2012), es decir, los cambios ocurridos en estas clases durante el periodo 9707 abarcaron pequeñas superficies (menores o igual al $4 \%$ del territorio) por lo que no fueron significativas, para el programa, al momento de crear los escenarios.

Las probabilidades de cambio mostraron un gran dinamismo ya que para el año 2012 se obtuvo una probabilidad muy alta (0.81) de que SAP permanezca sin cambio alguno, para el 2017 esta probabilidad disminuyó (0.69) y para el 2022 llegó hasta 0.58. En el caso de CA su permanencia en el 2012 mostró una probabilidad de 0.67, en el 2017 la probabilidad detectada fue de 0.58, la cual, en el 2022 se redujo hasta llegar a 0.50 (Tabla 8, Figura 14).

Como en el caso de las clasificaciones, en los modelos se encontró que la superficie de la Selva Alta Perennifolia fue disminuyendo paulatinamente de casi 44 ha en el 2012 hasta un poco más de 39 ha en el 2022. A este comportamiento se suma el aumento progresivo de la Categoría Antropogénica que en 1986 contaba con un área equivalente al 7\% y en el modelo 2012 presentó una superficie de 34\%; finalmente en el modelo 2022 ocuparía un $39 \%$ de la totalidad del municipio.

Estos datos reflejaron una tendencia en el cambio de las superficies, mientras las áreas asignadas a SAP iban en detrimento, la clase CA fue 
abriéndose paso de manera que con el tiempo ganó superficie, en otras palabras se trata de una relación inversa entre estas dos clases (Figura 12).

Por otra parte, los cambios de uso del suelo SAP-CA y CA-SAP mostraron un incremento en las probabilidades de cambio; por ejemplo, la probabilidad de que SAP cambiara a CA inició, en el 2012, con 0.14 y para el escenario 2022 se pronostica que sea de la mitad (0.50). Por otra parte la clase CA obtuvo una probabilidad de cambio hacia SAP muy baja (0.09) en el 2012 y en el escenario 2022 aumentaría a 0.15. Lo anterior prevé que las actividades antropogénicas se incrementarían de tal forma que la clase CA tendrá grandes probabilidades de aumentar su superficie y esto implicaría la pérdida de SAP, pero, existe la probabilidad, aunque relativamente pequeña, de que la Selva Alta Perennifolia recupere superficie durante el periodo 20122022.

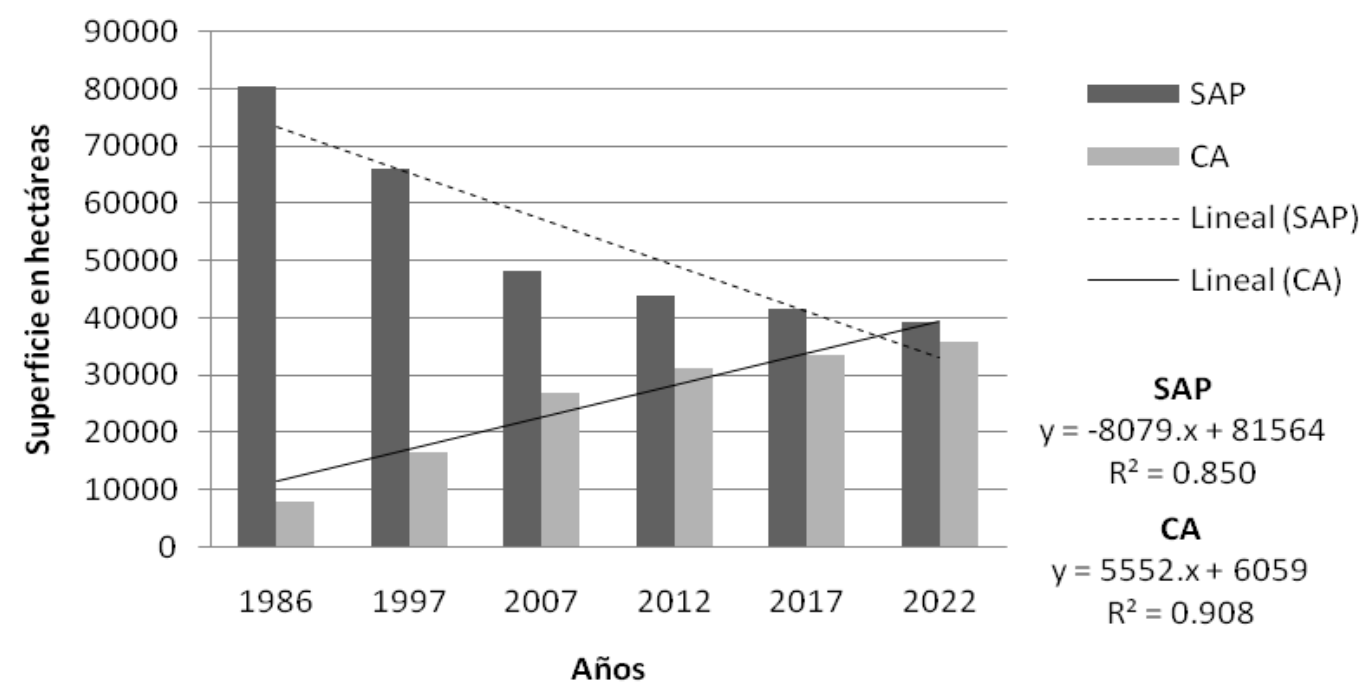

Figura 12. Tendencias de cambio de las superficies de las selvas perennifolias y de la cobertura antrópica. 
Tabla 7. Superficies en hectáreas de los modelos con variables antropogénicas. ${ }^{*}$ Las superficies de estas clases son constantes en los tres escenarios y corresponden al año 2007.

Superficie de los Modelos de Cambio (ha)

\begin{tabular}{|c|c|c|c|c|c|c|}
\hline Clase & 2012 & $\%$ & 2017 & $\%$ & 2022 & $\%$ \\
\hline SAP & $43,865.10$ & 47 & $41,609.34$ & 45 & $39,464.28$ & 43 \\
\hline $\mathrm{CA}$ & $31,465.62$ & 34 & $33,721.38$ & 36 & $35,866.44$ & 39 \\
\hline$A b^{*}$ & $3,295.80$ & 4 & $3,295.80$ & 4 & 3295.8 & 4 \\
\hline $\mathrm{SCV}^{*}$ & $13,750.29$ & 15 & $13,750.29$ & 15 & $13,750.29$ & 15 \\
\hline $\ln ^{*}$ & 96.66 & 0.1 & 96.66 & 0.1 & 96.66 & 0.1 \\
\hline $\mathrm{CuA}^{*}$ & 251.55 & 0.1 & 251.55 & 0.3 & 251.55 & 0.3 \\
\hline Total & $92,725.02$ & 100 & $92,725.02$ & 100 & $92,725.02$ & 100 \\
\hline
\end{tabular}

Tabla 8. Probabilidades de cambio para los modelos con variables antropogénicas.

\begin{tabular}{lcccc}
\hline \multicolumn{5}{c}{ Probabilidades de Cambio } \\
\cline { 2 - 3 } Modelo & SAP-SAP & SAP-CA & CA-SAP & CA-CA \\
\cline { 2 - 2 } & & & & \\
2012 & 0.81 & 0.14 & 0.09 & 0.67 \\
2017 & 0.69 & 0.20 & 0.12 & 0.58 \\
2022 & 0.58 & 0.50 & 0.15 & 0.50 \\
& & & & \\
\hline
\end{tabular}

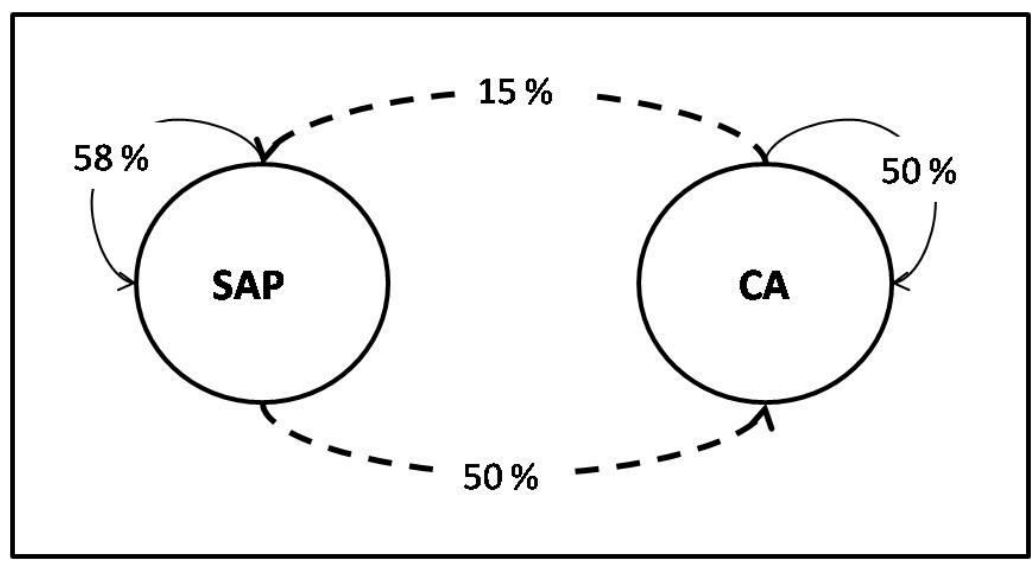

Figura 14. Diagrama de las probabilidades de cambio de la Selva Alta Perennifolia (SAP) y la Cobertura Antropogénica (CA) en el modelo 2022. 


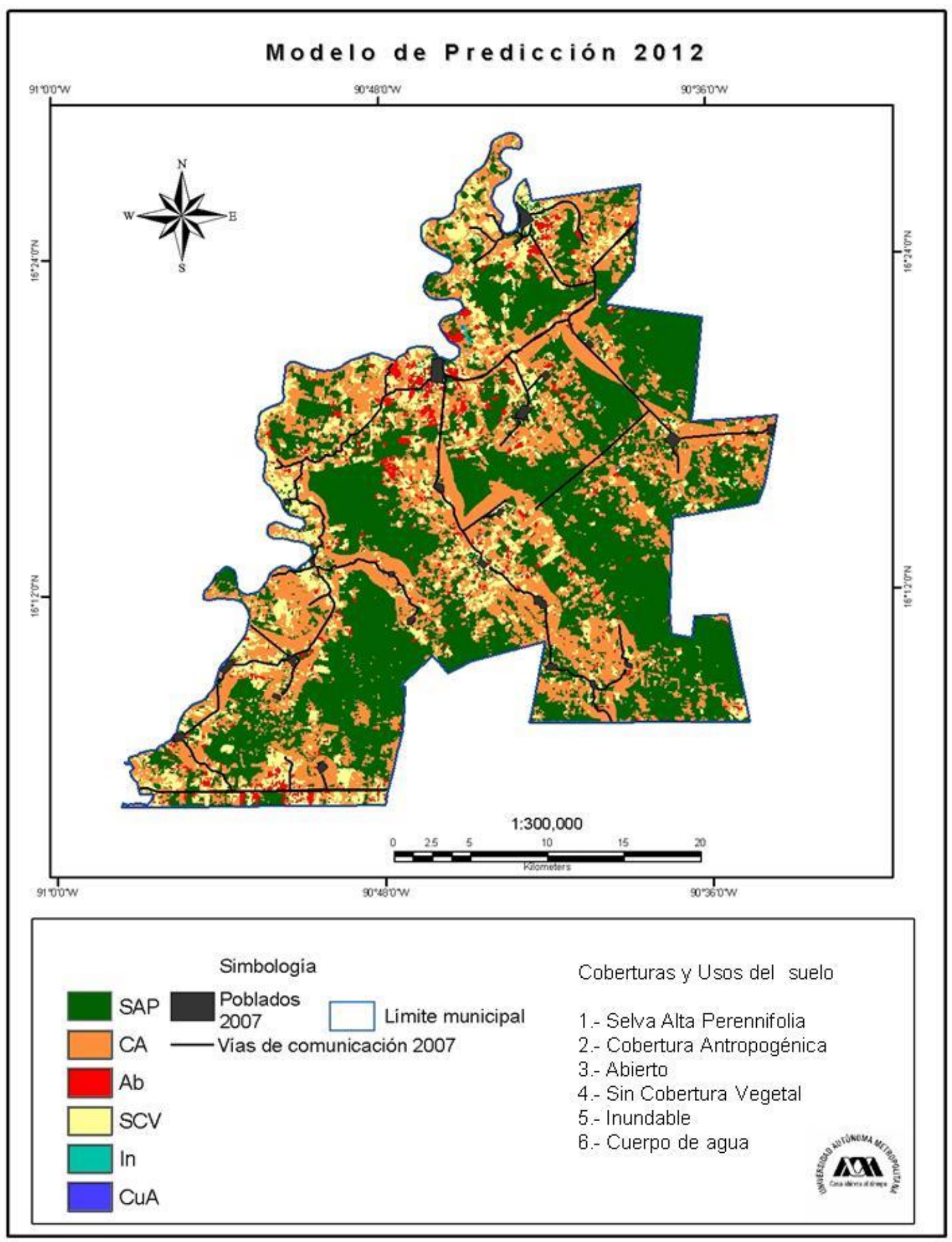

Figura 15. Modelo de cambio de uso del suelo 2012. 


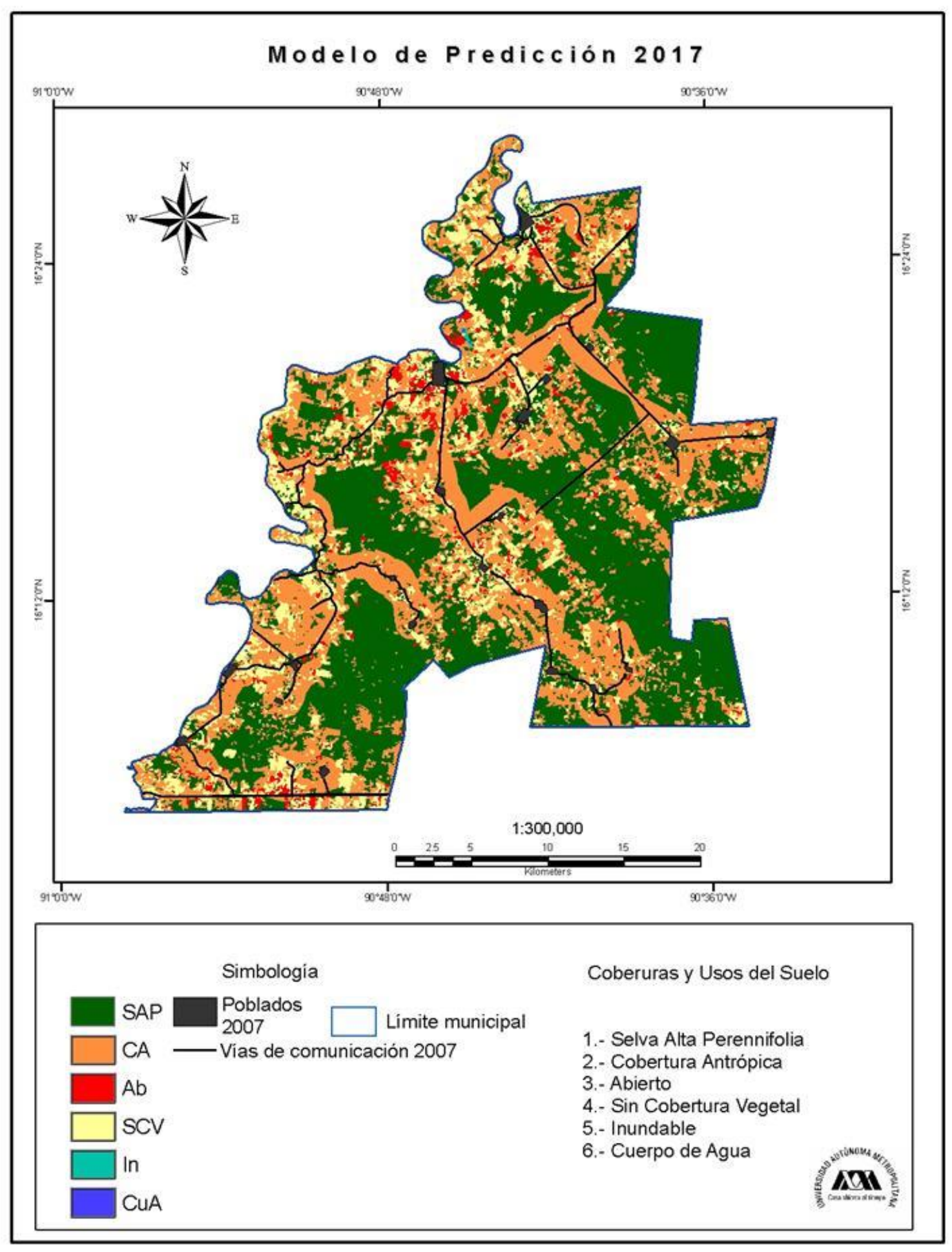

Figura 16. Modelo de cambio de uso del suelo 2017. 


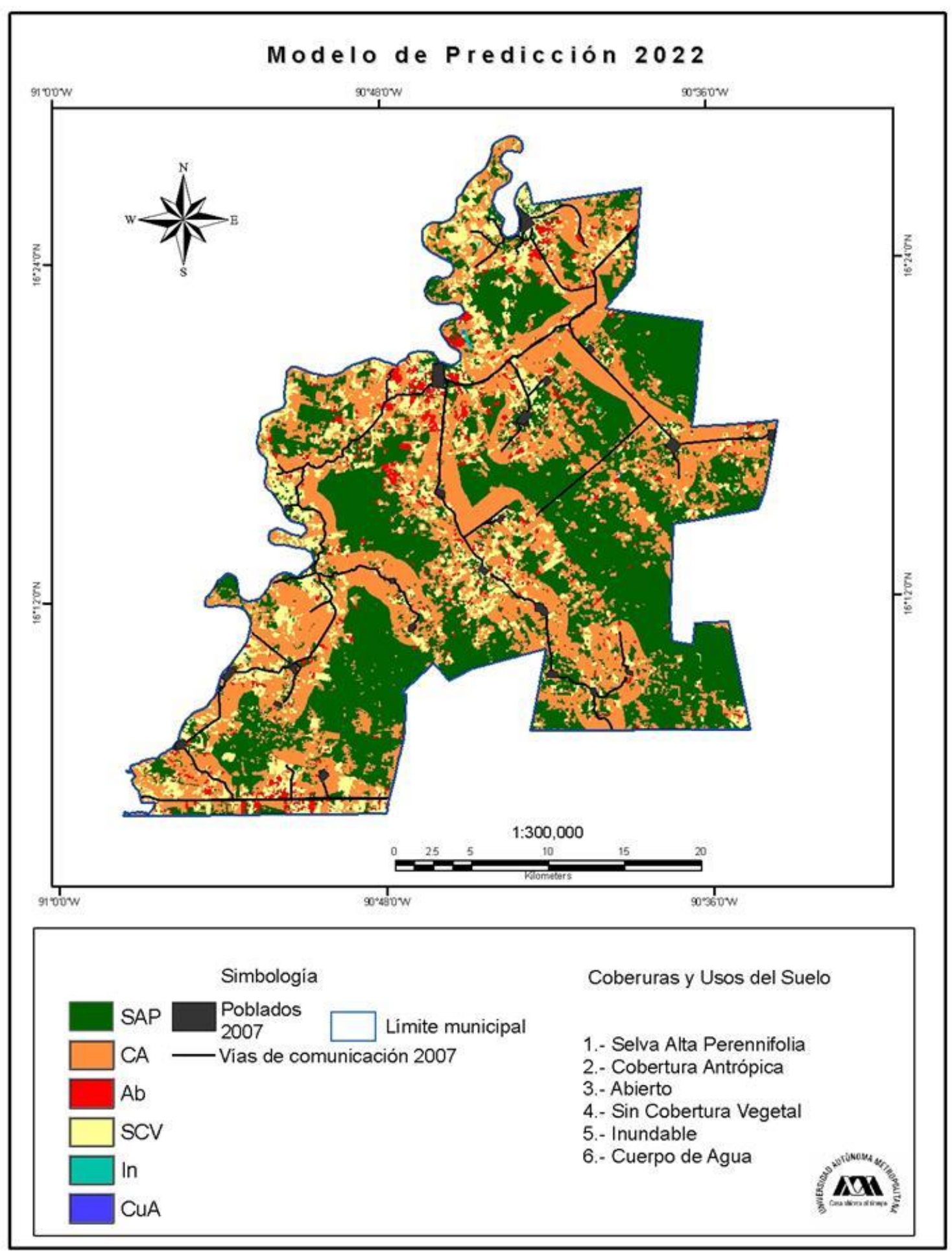

Figura 17. Modelo de cambio de uso del suelo 2022. 
Una vez extraídas las superficies se promediaron las tres fechas de las imágenes clasificadas y aparte se promediaron los escenarios prospectivos. En las imágenes clasificadas la superficie de Selva Alta Perennifolia presentó una influencia positiva ya que aumentó casi el doble de la superficie de la Categoría Antropogénica conforme aumentaba la distancia hacia las vías de comunicación y los poblados (Figura 18 a y b).

En los escenarios prospectivos se observó que la superficie de CA aumentaría casi el doble de la superficie de SAP conforme aumentaba la distancia desde las vías de comunicación y los poblados (Tabla 9 y 10); por ejemplo, en el área de influencia de las vías de comunicación la clase CA en el escenario 2012 presenta a los 500 metros, 9657.3 ha y para el año 2022, a los 2500 metros, la superficie aumentaría hasta 28,709.37 ha. Esto indicaría que para el año 2022 aumentarán los cambios de uso del suelo de la Selva Alta Perennifolia a la Categoría Antropogénica y que estos cambios tendrán lugar no solo en los primeros metros a partir de las vías de comunicación, sino que ocurrirán hasta unos 2500 metros de distancia. De esta forma, las principales vías de comunicación representarían una influencia negativa para los remanentes de selva (Figura $18 \mathrm{c} \mathrm{y} \mathrm{d}$ ). 
Tabla 9. Superficie en promedios de las áreas de influencia de las imágenes clasificadas.

\begin{tabular}{|c|c|c|c|c|c|}
\hline \multicolumn{6}{|c|}{ Vías de Comunicación } \\
\hline & \multicolumn{5}{|c|}{ Promedios por área de influencia en hectáreas (86-07) } \\
\hline & $500 \mathrm{~m}$ & $1000 \mathrm{~m}$ & $1500 \mathrm{~m}$ & $2000 \mathrm{~m}$ & $2500 \mathrm{~m}$ \\
\hline SAP & 5257.11 & $11,442.3$ & $16,960.77$ & $22,421.58$ & $27,362.79$ \\
\hline \multirow[t]{3}{*}{ CA } & 3527.73 & 6491.91 & 8805.63 & $10,582.86$ & $11,954.4$ \\
\hline & \multicolumn{5}{|c|}{ Promedios por área de influencia en hectáreas (12-22) } \\
\hline & $500 \mathrm{~m}$ & $1000 \mathrm{~m}$ & $1500 \mathrm{~m}$ & $2000 \mathrm{~m}$ & $2500 \mathrm{~m}$ \\
\hline SAP & 2649.03 & 6558.18 & $12,139.17$ & $18,457.83$ & $23,969.07$ \\
\hline CA & 9657.3 & $18,260.49$ & $23,379.33$ & $23,483.04$ & $28,709.37$ \\
\hline
\end{tabular}

Tabla 10. Superficie en promedios de las áreas de influencia de acuerdo a las proyecciones de los modelos de Markov.

Poblados

Promedios por área de influencia en hectáreas (86-07)

$\begin{array}{lllll}500 & 1000 & 1500 & 2000 & 2500\end{array}$

$\begin{array}{llllll}\text { SAP } & 1191.96 & 3614.37 & 4655.94 & 12,863.49 & 21,549.9\end{array}$

$\begin{array}{llllll}\text { CA } & 1043.52 & 2560.62 & 3047.31 & 6614.64 & 9230.31\end{array}$

Promedios por área de influencia en hectáreas (12-22)

$\begin{array}{lllll}500 & 1000 & 1500 & 2000 & 2500\end{array}$

$\begin{array}{llllll}\text { SAP } & 1120.92 & 2618.49 & 2398.41 & 8461.08 & 12,906.09\end{array}$

$\begin{array}{llllll}\text { CA } & 1819.35 & 5311.11 & 4326.75 & 15,533.46 & 20,398.32\end{array}$ 


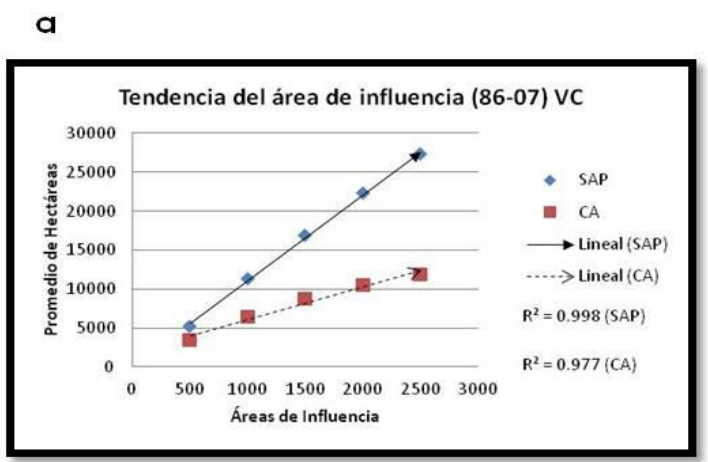

c

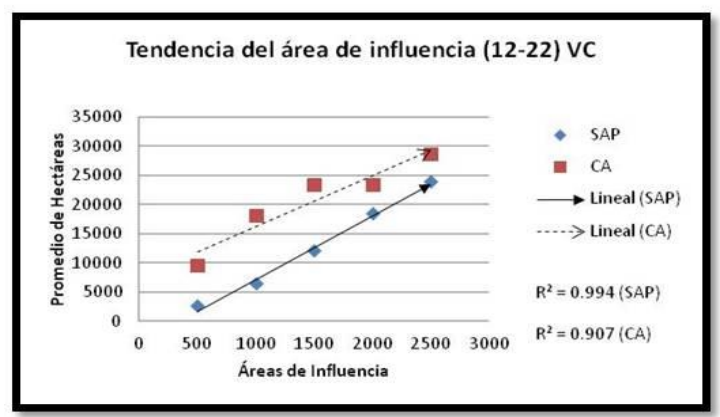

b

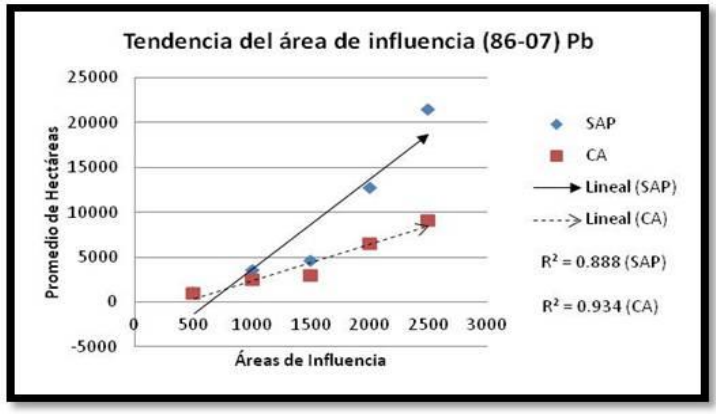

d

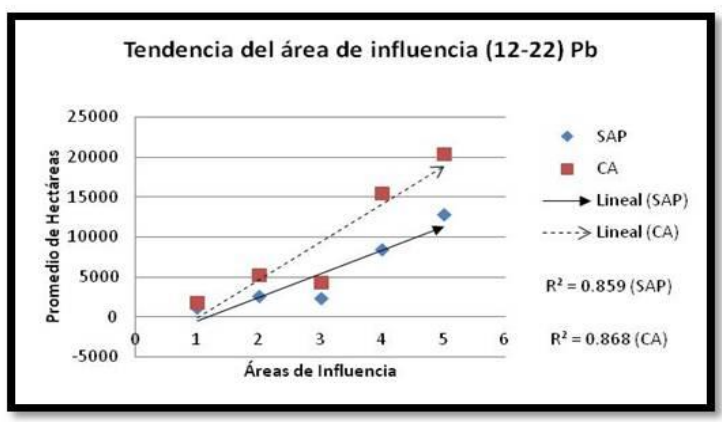

Figura 18. Tendencias de las superficies de las clases SAP Y CA con respecto a las vías de comunicación ( $\mathrm{VC}$ ) y poblados $(\mathrm{Pb})$. A y $\mathrm{B}$ tendencia de las imágenes clasificadas. $\mathrm{C}$ y $\mathrm{D}$ tendencia de los escenarios prospectivos.

\subsection{Validación}

\subsubsection{Verificación de la clasificación con datos de campo}

De la verificación de campo se obtuvieron 94 puntos de control de los cuales un gran porcentaje $(81 \%)$ coincidió con la clasificación más reciente del análisis (año 2007). El mayor número de coincidencias las obtuvo la clase SAP con 36 puntos que equivalen al $84 \%$ de todos los puntos para esta clase, seguida de la clase CA con $33(79 \%)$ y, en la clase SCV coincidieron seis puntos (86\%). La clase CuA logró el $100 \%$ debido a que sólo contaba con un punto de control y la clase In no se incluyó en la prueba, debido a que no se contaba con puntos de control correspondientes a la zona (Tabla 11). 
Por otra parte, el error de omisión se refiere a los puntos correspondientes a una clase en la cubierta real pero que no fueron clasificados de esa manera; para SAP se obtuvo un error de omisión que equivale al 16\%; en CA se tuvo un $21 \%$; en Ab se obtuvo el $100 \%$; la clase SCV presentó un 14\% y la cobertura CuA no mostró ningún error.

El error de comisión indica los puntos clasificados como una clase de cobertura a la que no pertenece por ejemplo para la Selva Alta Perennifolia no se encontró ningún error de comisión, para la Categoría Antropogénica se presentó un 15\% de los puntos; la clase Abierto mostró un 100\%; en el caso de la clase Sin Cobertura Vegetal se obtuvo un 14\% y para Cuerpo de Agua no se registró ningún error de comisión (Tabla 12).

El estadístico Kappa sirve para evaluar la clasificación, si ésta ha discriminado las categorías con exactitud. En este caso, se obtuvo un valor de 0.7. Tomando en cuenta que el valor de $k$ no puede ser menor de cero ni mayor que uno, el resultado obtenido indicó que la clasificación digital es confiable respecto a la realidad registrada en los puntos de control tomados en el campo o que la clasificación resultó ser sustancial de acuerdo con lo propuesto por Landis y Koch (1977). 
Tabla 11. Matriz de confusión de los puntos de referencia con las imágenes clasificadas.

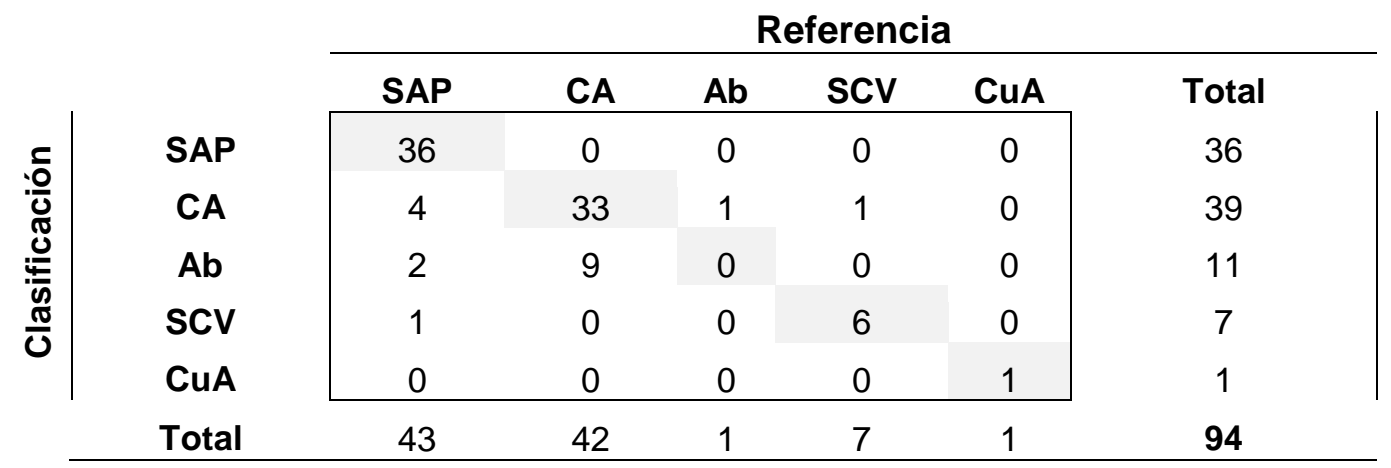

Tabla 12. Errores y exactitud de la clasificación digital.

\begin{tabular}{|c|ccccc|}
\cline { 2 - 6 } \multicolumn{1}{c|}{} & SAP & CA & Ab & SCV & CuA \\
\cline { 2 - 6 } Exac. Producto & 0.837 & 0.786 & 0 & 0.857 & 1 \\
Error Omisión & 0.163 & 0.214 & 1 & 0.143 & 0 \\
\hline Exac. Usuario & 1 & 0.846 & 0 & 0.857 & 1 \\
Error Comisión & 0 & 0.154 & 1 & 0.143 & 0 \\
\cline { 2 - 7 }
\end{tabular}

\subsubsection{Evaluación de la clasificación a partir de una malla}

Se obtuvieron tres matrices de confusión, una para cada imagen clasificada, donde se encontró que la presencia de SAP (1/1) obtuvo el mayor número de coincidencias entre los puntos de referencia y la clasificación; en 1986 las coincidencias alcanzaron un $85 \%$ de los 405 puntos de referencia; en 1997 se obtuvo un $67 \%$ que equivale a 273 puntos y en el 2007 se encontraron casi la mitad (49\%) de puntos. Para la ausencia de SAP (0/0) también se presentaron muchas coincidencias, en el 2007 se encontraron 185 puntos que representan el $46 \%$ del total de los puntos; para 1997 coincidieron 
113 puntos (28\%) y en seguida se encontró que la ausencia de SAP en 1986 coincidió en un 56\% (Tabla 13).

Por otra parte, el estadístico Kappa, para las tres imágenes, resultó ser muy alto (0.9) indicando que la asignación y distribución de la clase SAP se ubica dentro del rango de correspondencia casi perfecta (Landis y Koch, 1977) y que las imágenes clasificadas son altamente confiables respecto a lo observado (Tabla14).

Tabla 13. Resumen de las tres matrices de confusión, donde cero indica ausencia de la clase SAP y uno indica presencia de SAP.

\begin{tabular}{|c|c|c|c|c|c|}
\hline & \multicolumn{4}{|c|}{ Clasificación/Referencia } & \multirow[b]{2}{*}{ Total } \\
\hline & $0 / 0$ & $0 / 1$ & $1 / 0$ & $1 / 1$ & \\
\hline 1986 & 56 & 5 & 1 & 343 & 405 \\
\hline 1997 & 113 & 11 & 8 & 273 & 405 \\
\hline 2007 & 185 & 6 & 17 & 197 & 405 \\
\hline
\end{tabular}

Tabla 14. Valores del estadístico Kappa para las imágenes clasificadas.

\begin{tabular}{|c|c|c|c|}
\hline & 1986 & 1997 & 2007 \\
\hline$K$ & 0.9 & 0.9 & 0.9 \\
\hline$F$ & 98.5 & 95.3 & 94.3 \\
\hline
\end{tabular}

\subsubsection{Validación del modelo de Markov.}

Una manera de validar los modelos de cambio es mediante la comparación de un escenario producto de la clasificación y un escenario 
prospectivo, ambos deben ser de la misma fecha para obtener una tabla donde se muestren las coincidencias entre ambos mapas (Tabla 15); a partir de esta tabla se obtuvo el coeficiente de correlación $V$ de Cramer y el índice estadístico Kappa, los valores de ambos estadísticos (0.54 y 0.72 respectivamente) indicaron que el modelo es adecuado o sustancial, esto significa que los modelos de la Selva Alta Perennifolia formados a partir de las cadenas de Markov pueden ser utilizados como escenarios futuros confiables.

Tabla 15. Tabla de contingencia donde se muestra el número de píxeles del área de estudio que coincidieron entre la clasificación 2007 y el modelo 2007.

Clasificación 2007

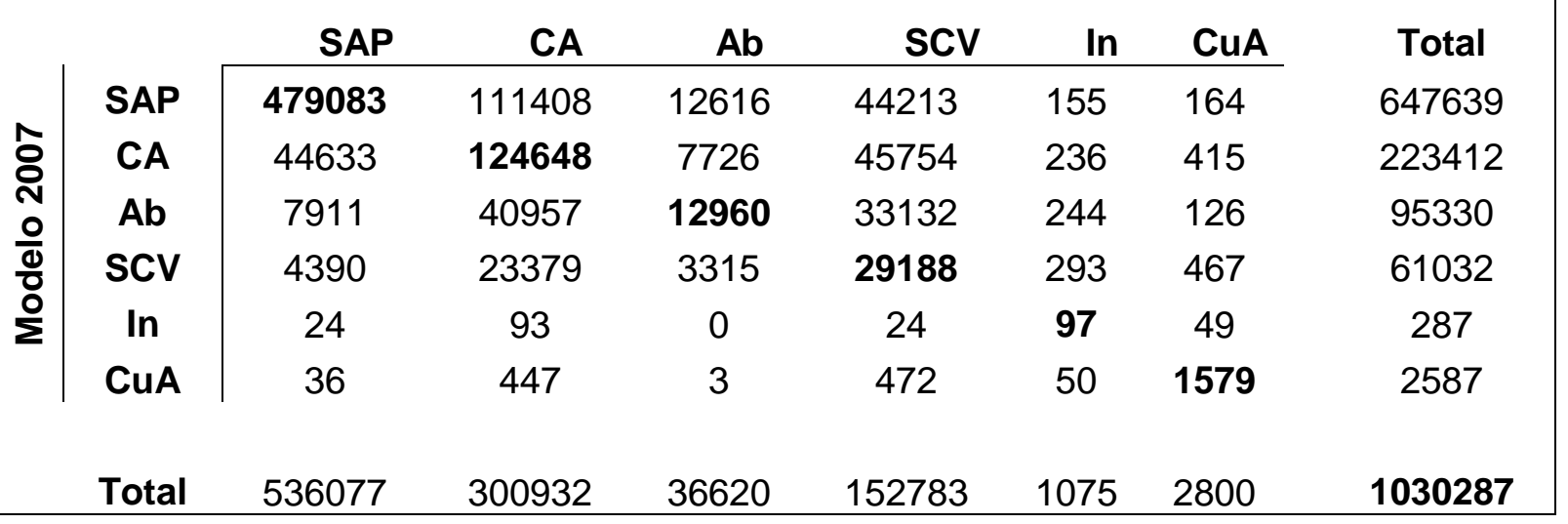

Comparando las áreas ocupadas por las seis categorías en la clasificación y el escenario prospectivo (Tabla 16) se encontraron pocas diferencias; el área abarcada por la Selva Alta Perennifolia en la clasificación del 2007 fue del $52 \%$ del territorio municipal y en el escenario prospectivo esta categoría obtuvo un $63 \%$, esto significa que el $11 \%$ del área abarcada por esta categoría en el modelo de Markov no correspondía a esta (área sobreestimada). El área de la Categoría Antropogénica (CA) en la clasificación 2007 correspondía al 29\% y en el escenario prospectivo abarcó 
un $22 \%$ del territorio municipal, estos porcentajes indican que el $7 \%$ de su área fue asignada a otra categoría (área subestimada).

En la clasificación del 2007 las áreas de la categoría Abierto (Ab) abarcaban un $4 \%$ del municipio Marqués de Comillas y en el escenario producto de las cadenas de Markov abarcaron un $9 \%$, esta diferencia del $6 \%$ indica que en el escenario prospectivo aparecen más áreas desprovistas de vegetación arbórea (área sobrestimada). La siguiente categoría (SCV) ocupó un $15 \%$ del municipio y en el escenario prospectivo su extensión equivale al $6 \%$, dicho de otra forma, esta categoría fue subestimada en el modelo de Markov.

Por último, las áreas de las dos categorías restantes (In y CuA) fueron subestimadas en los escenarios prospectivos con $0.1 \%$ y $0.02 \%$, respectivamente.

Tabla 16. Porcentajes de la superficie abarcada por las categorías en la clasificación 2007 y el modelo de Markov 2007.

\begin{tabular}{|c|c|c|c|c|c|c|}
\hline & \multicolumn{7}{|c|}{ Diferencias de Porcentajes } \\
\hline & SAP & CA & Ab & SCV & In & CuA \\
\hline Clasificación & 52 & 29 & 4 & 15 & 0 & 0 \\
\hline Proyección & 63 & 22 & 9 & 6 & 0 & 0 \\
\hline & & & & & & \\
\hline Diferencia & 11 & -7 & 6 & -9 & -0.1 & -0.02 \\
\hline & Sobrestimado & Subestimado & Sobrestimado & Subestimado & Subestimado & Subestimado \\
\hline
\end{tabular}




\section{DISCUSIÓN}

El propósito de esta tesis fue analizar el cambio de uso del suelo, tomando como estudio de caso el municipio Marqués de Comillas que es un área tropical fuertemente modificada por las actividades humanas. Los resultados obtenidos indicaron que la región que comprende el municipio Marqués de Comillas ha sufrido una serie de procesos de cambio de uso del suelo que han reducido ampliamente la cobertura vegetal natural; como consecuencia de estos procesos, la cobertura Selva Alta Perennifolia (SAP) se ha reducido sensiblemente. Un porcentaje significativo del territorio municipal se encontraba en el 2007 bajo algún tipo de uso agropecuario.

\subsection{Clasificación Digital}

Los resultados de la clasificación digital mostraron una diferencia entre las zonas con Selva Alta Perennifolia (SAP) y las zonas que presentan otro tipo de uso de suelo. De las seis coberturas y usos del suelo definidos solo uno de ellos (SAP) rebasó la mitad de la extensión del territorio municipal en las tres fechas $(1986,1997,2007)$. De acuerdo con el Inventario Forestal del Estado de Chiapas, en 1976 todo el territorio de Marqués de Comillas estaba cubierto por vegetación natural no perturbada (SFF, 1976). Para el año 1986, según lo observado en los resultados, la cobertura SAP contaba con $87 \%$ de la superficie municipal. Para el 2005 el INEGI registró que la superficie cubierta por selva era el $46.6 \%$ del municipio y en el 2007 la Secretaria de Planeación y Desarrollo Sustentable estimó que la superficie de selva 
abarcaba el $44.34 \%$ del municipio; por otra parte, lo observado en la fecha más reciente del análisis (2007), la categoría SAP apenas sobrepasa la mitad del territorio (52\%); con lo que se puede inferir que la selva ha perdido consecutivamente superficie convirtiéndola en la cobertura más susceptible a cambios en el municipio Marqués de Comillas.

Por otra parte, De Jong y colaboradores (2000) estimaron que en la década de los noventas se perdió un porcentaje significativo (31\%) de la cubierta boscosa en la región de La Selva Lacandona. Este dato coincide con el periodo de análisis (97-07) el cual presentó la mayor tasa de cambio (-3\%) de uso del suelo de la cobertura de la Selva Alta Perennifolia (SAP).

De acuerdo con la última fecha de análisis y, tomando en cuenta que Marqués de Comillas es una región donde no existen áreas protegidas ni reservas ecológicas oficiales, el $52 \%$ del territorio conserva aún vegetación natural no perturbada. Esto se podría deber a la voluntad de ciertos pobladores por conservar el ecosistema y que menos del treinta por ciento $(29 \%)$ se encuentra bajo usos agropecuarios. La disminución de la cobertura de la SAP y el incremento de la Cobertura Antropogénica (CA) que se ha observado en las fechas de análisis son un indicador de la importancia que han adquirido las actividades agrícolas y ganaderas en la región; un ejemplo de esto son los programas implementados en el municipio por la Secretaría de Agricultura, Ganadería, Desarrollo Rural, Pesca y Alimentación (SAGARPA); en el 2007 se aplicó el Programa de Apoyos Directos al Campo "PROCAMPO" que incentiva la producción de cultivos, el programa se aplicó 
en dos etapas (otoño-invierno y primavera-verano): en la primera etapa se beneficiaron 52,399 personas con una superficie de 1093.45 ha (representan el $1.2 \%$ del territorio) y para la segunda etapa se beneficiaron 46,743 personas con 2379.22 ha (representan el $2.6 \%$ del territorio) (SAGARPA, 2012). Existen otros tipos de programas que al igual que "Procampo" promueven el cambio de uso del suelo y su uso intensivo, un ejemplo de estos es el Programa de Estímulos a la Actividad Ganadera (PROGAN) el cual fue implementado en el municipio Marqués de Comillas en el 2010 beneficiando a 379 personas y en el 2012 a 366 (SAGARPA (1), 2010). A pesar de que la mayor parte de la superficie de la categoría SAP fue abierta en los años noventa, con los programas gubernamentales que promueven el cambio de uso del suelo, se continúa hasta la fecha con la deforestación de nuevas áreas que se destinan a potreros (pastizales inducidos).

Durante el periodo 2007-2012 entró en vigor el "Plan Nacional de Desarrollo" cuyo objetivo principal era lograr una economía competitiva, generadora de empleos y garantizar la igualdad de oportunidades y la sustentabilidad ambiental (Presidencia de la República, 2007); para lograr dicho objetivo, en este programa se incentivaron varios proyectos entre los cuales estaba el "Proyecto para el Desarrollo Rural Sustentable de la Región Sur-Sureste de México: Trópico Húmedo". Dentro de éste se promovía la formación de plantaciones de palma de aceite (Elaeis guinnensis), originaria de golfo de Guinea en África Occidental. Las plantaciones debían cumplir con ciertas características, por ejemplo, para establecer nuevas plantaciones, el 
terreno deberá estar ubicado en un área con potencial productivo (SAGARPA (2), 2010). Con la promoción de plantaciones de palma podrían presentarse dos escenarios, uno, que las áreas de agricultura y potreros que ya no sean rentables sufran de nuevo un cambio de uso del suelo y, dos, el desmote de selva para establecer nuevas áreas para plantaciones de palma de aceite.

Con la implementación de programas de apoyo como los antes mencionados, se podrían ver amenazados los remanentes de selva, que hasta la última fecha del análisis, representaban un considerable porcentaje del territorio municipal.

Respecto a las zonas de vegetación secundaria no fue posible discriminarlas de otras coberturas debido a una confusión entre las firmas espectrales (ERDAS Imagine, 1999). Esta confusión pudo deberse a las diferentes etapas de la vegetación en recuperación ya que dependiendo de la etapa en la que se encuentre la vegetación esta tendrá una altura y densidad diferente; si la altura y densidad alcanzadas son similares a la selva madura entonces estas se confundirán (Chuvieco, 2002); es probable que estos casos se hayan incluido, de manera automática en la categoría de Selva Alta Perennifolia.

Por el contrario, las zonas donde la vegetación secundaria cuente con poca altura, baja densidad, abarquen pequeñas áreas y se encuentren rodeadas por otros usos del suelo, serán confundidas con otras coberturas. 
En estos casos y a pesar de contar con puntos de control que verificaban la presencia de vegetación secundaría, el programa no logró discriminarlas y las integró a la categoría CA, lo que se podría considerar como una sobrestimación de la Cobertura Antropogénica.

Al analizar los resultados del modelo de detección de cambios se observó que estas zonas sufrieron un algún cambio de uso del suelo durante

el periodo 1986-1997 de manera que para la última fecha del análisis éstas presentaban una cobertura diferente a la original, indicando que estas zonas estuvieron en un momento determinado bajo alguna actividad antropogénica y que son susceptibles a seguir en esta dinámica.

\subsection{Detección de cambios}

Con el modelo de detección de cambios se pudo conocer la dinámica de los cambios de uso del suelo que tuvo la Selva Alta Perennifolia de 1986 al 2007 y gracias a esta dinámica se identificaron las áreas potenciales de vegetación secundaría.

Al hablar de vegetación secundaria se hace referencia a las comunidades naturales de vegetación que se establecen como consecuencia de la destrucción total o parcial de la vegetación primaria o clímax, realizada directamente por el hombre (Rzedowski, 2006) o como consecuencia de las actividades antropogénicas (fuerzas de cambio). 
Dentro de las fuerzas de cambio se pueden encontrar las fuerzas naturales como un huracán o incendio; y las actividades antropogénicas como la ganadería y la agricultura. Aunados a esta fuerzas existen otros factores que pueden ser determinantes para la vegetación secundaría, estos factores son la intensidad y la periodicidad de las fuerzas de cambio; dependiendo de la intensidad de las fuerzas de cambio las perturbaciones serán distintas, por ejemplo, las perturbaciones agudas alteran el medio de manera puntual brindando la oportunidad al sistema de recuperarse y las perturbaciones crónicas al ser constantes, dificultan la recuperación del sistema (Uhl et al., 1990); generalmente las perturbaciones crónicas son dadas por las actividades antropogénicas que causan cambios drásticos en la vegetación y a su vez provocan una serie de consecuencias negativas en las comunidades vegetales.

De acuerdo con Rzedowski (2006) las perturbaciones sobre la Selva Alta Perennifolia causadas por las actividades del hombre han sido constantes desde tiempos prehispánicos en algunas partes del país y se ha ido acentuando, sobre todo en los años recientes, en función de la explosión demográfica, la apertura a eficientes vías de comunicación, saneamiento del ambiente y de otros factores; un ejemplo de esto es la Selva Alta Perennifolia, ubicada en la región que hoy ocupa el municipio Marqués de comillas, que hace cientos de años contaba con pocos habitantes y eran mínimas las perturbaciones ejercidas en la vegetación, a partir de la década de los setentas la selva sufrió cambios significativos (De Vos, 2002) debido a 
políticas de colonización del trópico húmedo y de la frontera sur (GonzálezPonciano, 1996; Tejeda, 2003).

El tamaño de los poblados o el número de pobladores no es necesariamente un factor que determine las perturbaciones, más bien, son las actividades que estos realizan las que van a modificar la cobertura vegetal. Por ejemplo, la agricultura nómada es la más usada en el sur del país, esta agricultura consiste en el proceso de desmonte, incendio y siembra durante una o unas cuantas temporadas sucesivas para después ser abandonadas por varios años (de 4 a 20 años (Sánchez, 1981). Esta práctica realizada por pocos pobladores puede modificar grandes áreas de las cuales desaparece la vegetación original y la zona se convierte en un paisaje heterogéneo formado por una serie de comunidades vegetales secundarias de tipo herbáceo, arbustivo y arbóreo, con frecuencia llamadas "acahuales" (Rzedowski, 2006). De acuerdo con el escenario de 1986 Marqués de Comillas contaba con pocos poblados y casi el $20 \%$ del territorio estaba desprovisto de vegetación original.

La sucesión ecológica se puede considerar como un cambio temporal y direccional en la composición y estructura de una comunidad, es un proceso complejo en el cual los elementos que intervienen pueden determinar la velocidad y la dirección del cambio. Por ejemplo, las zonas de selva que han sido transformadas por la agricultura nómada pueden acelerar el proceso de sucesión debido a que el desmonte no es completo porque al quedar tocones 
vivos la revegetación no parte de cero (Rzedowski, 2006). Ejemplo de esto podrían ser las clases que pertenecen a los cambios de tipo positivo o de regeneración (clases dos, seis y tres).

La clase dos representa las zonas que durante el periodo 86-97 permanecieron sin vegetación y en el 2007 mostraron una cubierta vegetal. Probablemente esta dinámica de cambio se deba a una perturbación crónica o uso constante el cual puede disminuir de forma significativa la capacidad de recuperación y es probable que la comunidad vegetal presente en el 2007 esté en una etapa temprana de sucesión; por otra parte, las zonas que pertenecen a la clase seis podrían haber sufrido una perturbación aguda o un cambio puntual porque fue poco el tiempo que permanecieron sin vegetación, de forma que las comunidades vegetales tuvieron mayor posibilidad de recuperarse a pesar de tener el mismo tiempo de abandono que la clase dos (diez años).

La última clase con procesos positivos o de regeneración es la número tres. Esta clase representa aquellas zonas que al inicio del análisis (1986) no contaban con vegetación natural y para 1997 hasta el 2007 aparecen con una cobertura vegetal. El origen de esto pudo ser una alteración puntual la cual brinda más oportunidades a las comunidades vegetales para recuperarse. A diferencia de las clases anteriores, la vegetación representada en la clase tres se podría encontrar en una etapa de sucesión menos joven debido a que tuvo 
más tiempo para recuperarse, dicho en otras palabras, la vegetación secundaria de estas zonas podrían ser la de más edad (Figura 19).

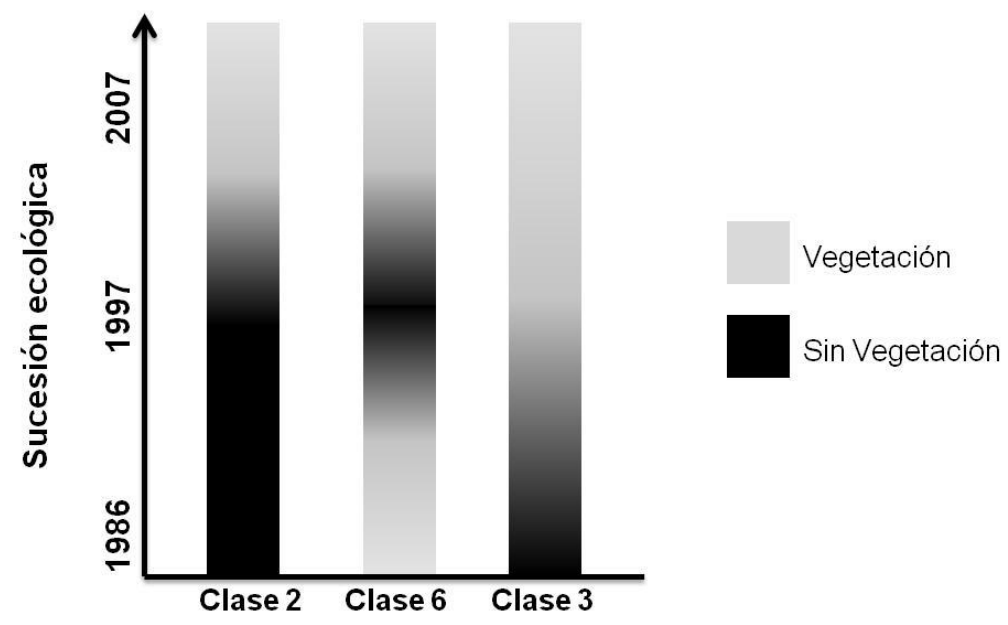

Figura 19. Sucesión vegetal detectada en el modelo de detección de cambios.

Dentro de la dinámica de cambios también se encontraron áreas que permanecieron sin cambio durante las tres fechas de análisis, en este grupo se encuentran las áreas de Selva Alta Perennifolia (SAP) que han permanecido con un nivel muy bajo o nulo de actividades antropogénicas y que no se encuentran asociadas a vegetación secundaria en los veintiún años que abarca el análisis; también, en esta categoría se encuentran las áreas que no mostraron algún tipo de cubierta vegetal, como los poblados o construcciones urbanas, las carreteras y los bancos de arena o de material para construcción, estos tipos de cobertura y uso del suelo, al igual que la vegetación natural, no presentaron un incremento o decremento durante el periodo de tiempo que abarcó el análisis; por el contrario, se observó cierto 
aumento en el número de poblados y aunque éste no fue significativo, promovió de forma simultanea el crecimiento de las vías de comunicación.

A través del color blanco (clase 8) se destacan las áreas que permanecieron con vegetación natural (44,961,03 ha). Esta clase comprende los remanentes de selva que probablemente estén situados en terrenos con cierta pendiente o con suelos poco profundos convirtiéndolos en terrenos no aptos para la agricultura. En la actualidad, muchos paisajes en regiones tropicales cálido-húmedas se caracterizan por presentar fragmentos de selvas esparcidos en una matriz de pastizales ganaderos, tierras agrícolas, plantaciones forestales, huertos frutícolas y bosques secundarios (Martínez y García, 2007). Algunos investigadores han observado que el tamaño de los fragmentos es, con frecuencia, menor que 100 ha y es común que el grado de alteración del ecosistema en su entorno sea severo (Turner y Corlett, 1996; Guevara et al., 2004; Laurance, 2004), ya que el aumento de la presión demográfica promueve la ocupación de terrenos con condiciones poco favorables para usos agrícolas y con ello, puede presentarse alguna fuerza de cambio de uso del suelo, como la tala y el fuego para preparar el terreno que será utilizado para la agricultura.

En color negro indica las zonas que permanecieron sin cobertura vegetal en las tres fechas del análisis, cabe destacar que la mayoría de estas áreas se localizan a orillas del río Lacantún y aparecieron desde la primer fecha de análisis, probablemente este cambio de uso del suelo obedezca a la 
cercanía con la principal fuente de agua y a las condiciones del suelo ya que la agricultura intensiva en la Selva Alta Perennifolia se concentra principalmente en suelos profundos de las vegas de los ríos y de otros terrenos aluviales (Rzedowski, 2006) porque presentan un alto potencial productivo (Orozco y Vázquez, 2013).

En cuanto a los procesos de cambio negativos, estos se refieren a la pérdida de cobertura vegetal natural (SAP) y a su vez indican una ganancia en la Cobertura Antropogénica (clases 4, 5 y 7). Estos cambios pudieron deberse a varias causas, entre las cuales se encuentra la deforestación provocada por el cambio de uso del suelo de SAP a usos agropecuarios y la expansión de los asentamientos humanos, así como alteraciones asociadas a la vegetación secundaria. En términos generales, las perturbaciones antropogénicas provocan cambios dramáticos tanto en la vegetación como en el suelo de un determinado ecosistema (Ceccon, 2013), como es el caso de La Selva Lacandona en Chiapas. De Jong y colaboradores (2000) estimaron que el $31 \%$ de la vegetación natural se perdió durante la década de los noventas y esta pérdida se debió principalmente al avance de las actividades agropecuarias, y en la actualidad la ganadería se está popularizando por ser más rentable que la agricultura.

La clase 4 (en color verde) representa áreas que probablemente se encuentran bajo uso agrícola, ya que en el primer año del análisis no presentan cobertura vegetal, para la segunda fecha muestran algún tipo de 
cobertura vegetal y en la última fecha esta cobertura desaparece de nuevo. Este comportamiento indica una dinámica de uso del suelo constante; quizás se trate de zonas de agricultura tradicional donde se dejan descansar los terrenos por largos periodo para retomarlos más tarde.

A continuación se encuentra la clase 5 (en color rojo) que muestra áreas que sufrieron una deforestación total. Esto se pudo observar porque al inicio del análisis estas áreas estaban cubiertas de vegetación natural (SAP) y en las dos siguientes fechas permanecieron sin ningún tipo de cobertura vegetal, no es de extrañar que se desmonte cierta cantidad de selva ya que en la zona actúan varios programas gubernamentales en los que predomina una visión industrial y que requieren ciertas condiciones de la tierra para poder actuar. Esta situación también se pudo observar en la clase 7 (en color amarillo) que representa áreas recientemente abiertas y que en el año 2007 coincidieron con las áreas que se encuentran bajo algún uso agropecuario (clase CA en la clasificación digital).

Una vez identificadas las áreas potenciales de vegetación secundaria resulta importante conocer la dinámica de cambio que las llevo de selva a las diferentes etapas de sucesión, porque al distinguir las posibles rutas de cambio de la Selva Alta Perennifolia se reconocerá a la vegetación secundaria como un cambio de uso de suelo (Figura 20). 
Las posibles rutas sucesionales de la Selva Alta Perennifolia pueden comenzar a partir de dos tipos de perturbación o cambio, el agudo y el crónico. Dentro de los cambios agudos se localiza la agricultura y en los crónicos se encuentra la ganadería. La sucesión y la composición de especies dependerán de la actividad realizada.

El tiempo que dure la agricultura tradicional o nómada puede determinar la composición de las especies vegetales y su dinámica, en el caso de la vegetación secundaria que se desarrolla después de cultivos cortos en La Selva Lacandona se tienen como especies sucesoras a Mutingia calabora "capulín", Trema micrantha "capulín cimarrón", Cecropia peltata "guarumbo", Belotia mexicana, Spondias mombin "jobo", Tabebuia rosea "maculis", Ceiba pentandra "ceiba", Ochroma lagopus "pomoy", Zuelania guidonia "trementino", entre otras (Granados et al., 2000) y de acuerdo con lo observado en el área de estudio, las formas de vida características de una etapa temprana de sucesión son las hierbas, plantas trepadoras, palmas y plántulas.

La otra ruta, hacia la ganadería, es un cambio crónico debido a que esta actividad es constante, tiende a durar más tiempo que la agricultura y sus efectos dependen de varios factores como el tipo de ganado, densidad, características del suelo y de la comunidad vegetal. 
La ganadería no solo afecta a la vegetación por su remoción (parcial o total) sino porque el ganado disminuye la regeneración de los árboles al eliminar las plántulas y yemas; también el peso y el constante apisonamiento compactan el suelo evitando el crecimiento de las raíces y el establecimiento de nuevas plántulas; por otra parte, la densidad del ganado afecta directamente la capacidad de regeneración de los pastos que les sirven de alimento provocando, con el tiempo, que los pastizales inducidos sean menos rentables provocando que dicha actividad se transforme en extensiva sustituyendo a la vegetación natural por pastos (Vázquez y Orozco, 2013). Cuando los pastizales dejan de ser rentables suelen ser abandonados y esto puede dar paso a que se perpetué un estadio de pastizal secundario o que se establezca otro tipo de vegetación secundaria.

Por otra parte, cuando la agricultura tradicional deja de ser una actividad rentable pueden presentarse dos rutas de cambio, la primera es la vegetación secundaría producto del abandono de la parcela y la segunda son los monocultivos, este tipo de cultivo se caracteriza por la presencia y aprovechamiento de un solo cultivo. Al respecto, se observó en un municipio vecino al área de estudio un invernadero de palma de aceite (Elaeis guineensis) de grandes dimensiones, el cual funcionaba como punto de distribución; de acuerdo con lo mencionado por los trabajadores del invernadero originalmente solo se utilizarían las parcelas abandonadas o con poco rendimiento para plantar la palma, pero, debido a la novedad y "rentabilidad" de este cultivo algunos pobladores estaban desmontando 
nuevas zonas de selva o de vegetación secundaría. La introducción de especies exóticas causa la pérdida de biodiversidad porque, entre otras causas, modifican los hábitats, compiten con las especies nativas, transmiten enfermedades o plagas, y en este caso también por el uso de agroquímicos que contaminan el suelo y el agua.

Una comunidad secundaria, sin embargo, puede también mantenerse indefinidamente como tal si persiste el disturbio que la ocasionó, o bien si el hombre impide su posterior transformación. Tal efecto se logra frecuentemente con el pastoreo, con el fuego o ambos factores combinados, prácticas bastante comunes en México (Rzedowski, 2006) . 


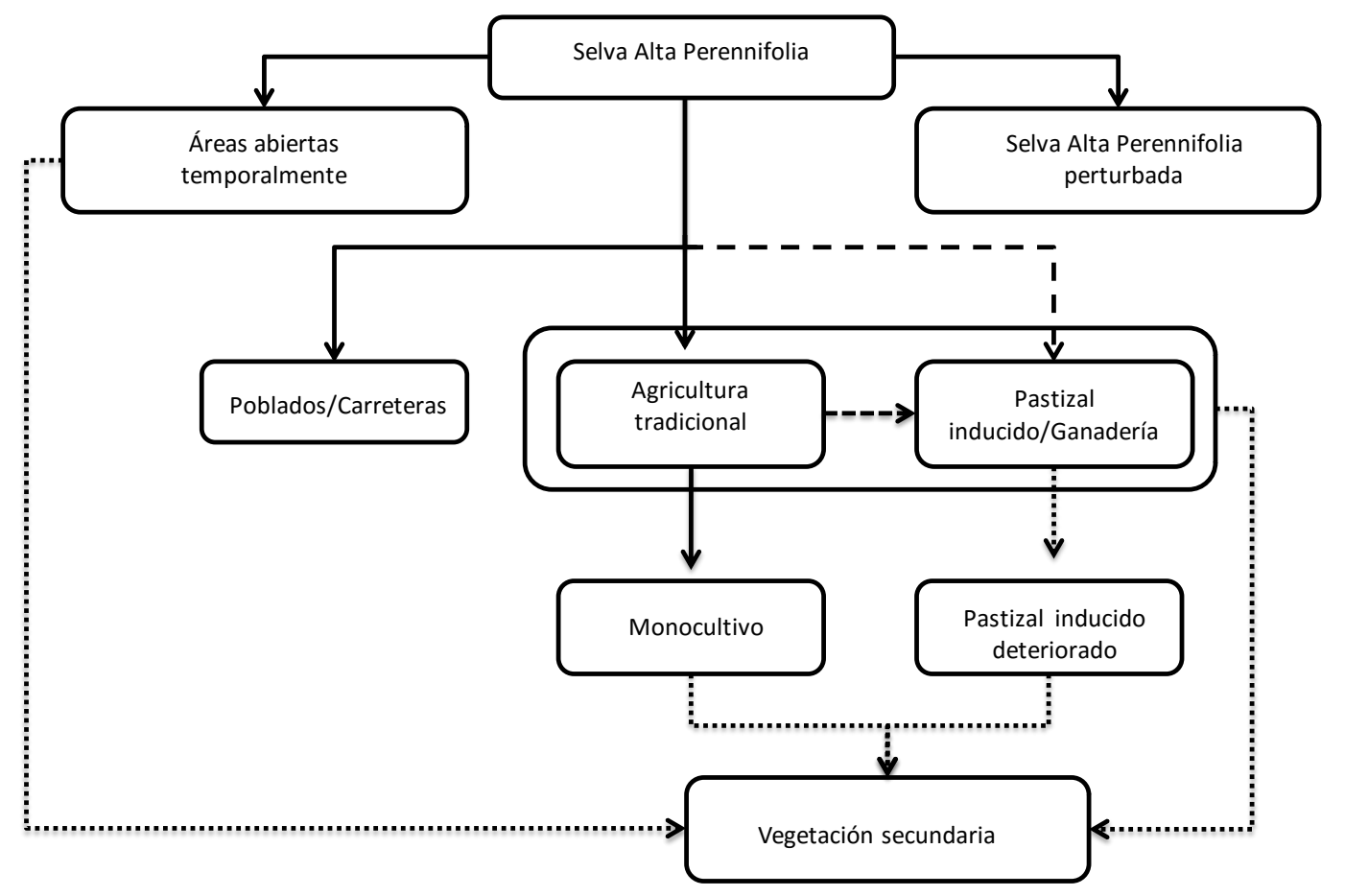

SAP $\rightarrow$ Selva Alta Perennifolia: Vegetación natural

CA $\rightarrow$ Cobertura antropogénica: Agricultura, ganadería, vegetación secundaria

Ab $\rightarrow$ Abierto: Áreas abiertas temporalmente

$\mathrm{SCV} \rightarrow$ Sin Cobertura Vegetal: Poblados y carreteras

Cambios agudos

Cambios crónicos

Abandono

Figura 20. Posibles rutas susecionales de la Selva Alta Perennifolia en el municipio Marqués de Comillas después de distintos cambios de uso del suelo producto de actividades antropogénicas.

\subsection{Escenarios prospectivos}

Con respecto a los escenarios prospectivos de cambio basados en Cadenas de Markov, éstos representan una alternativa muy sencilla y rápida para el establecimiento de escenarios, ya que se basan únicamente en el comportamiento histórico del cambio de uso del suelo, y no se requiere contar con información socioeconómica para estimar la magnitud de los cambios. Sin embargo en esa misma medida, se encuentra limitado, ya que es difícil bajo ese enfoque simular el efecto de variables de manera independiente, como en 
el caso del crecimiento de las vías de comunicación que se observó en el último periodo.

Con la intención de generar un modelo robusto y confiable que permitiera predecir el cambio de uso del suelo a través del tiempo se utilizó la extensión Land Change Modeler (LCM) para la sostenibilidad ecológica del programa IDRISI, ya que este es capaz de generar escenarios de cambio del uso del suelo integrando variables explicativas y descriptivas como algunos factores socioeconómicos (carreteras y los poblados) que influyen en el cambio de uso de la tierra (OñateValdivieso y Bosque Sendra, 2010). Este tipo de escenarios también pueden usarse para valorar el impacto de las carreteras (Oñate-Valdivieso y Bosque Sendra, 2010), para identificar las fuerzas que pueden influir en los patrones espaciales de conversión agrícola (Jiang, 2007) o para entender las ganancias y pérdidas del de uso del suelo en los bosques (Jaimes 2008).

Los escenarios prospectivos resultaron ser adecuados para conocer la tendencia del CUS y mostraron las áreas con mayor probabilidad de cambio. Éstas áreas resultaron ser aledañas a las carreteras, esta distribución fue establecida por la propiedad de contigüidad espacial y por el conocimiento de la probable distribución espacial de la transición. Los componentes celularesautómata son los que establecen las probabilidades de transición de un pixel función de los píxeles vecinos (Eastman, 2009), esta condición se cumplió porque desde la primer fecha de análisis se observó que la mayoría de las 
áreas transformadas a CA se presentaron a orillas del río Lacantún y de la principal carretera pavimentada; ambos elementos (río y carretera) son las principales vías de comunicación del municipio y representan la accesibilidad a ciertas áreas y la posibilidad de transportar cantidades significativas de insumos o materiales; de igual manera los poblados presentaron también cierta tendencia al cambio (de SAP a CA) pero en menor proporción dado que las condiciones para establecer un poblado no necesariamente son las mismas que se requieren para realizar una actividad agrícola o ganadera, por lo que resulta congruente que el cambio de uso de suelo sea constante en áreas cercanas a las vías de comunicación y poblados.

Por otra parte, es importante retomar que al generar escenarios prospectivos el modelo de Cadenas de Markov presenta cierta limitantes como es el hecho no se consideran áreas que cuenten con poca superficie, probablemente porque presenten una baja probabilidad de cambio, es decir, los escenarios prospectivos producto de las cadenas de Markov presentan una restricción en cuanto a superficies de cambio; esta condición se podría superar si se trabaja a una escala más pequeña de manera que las clases o categorías no presenten mucha diferencia en cuanto a superficies.

A pesar de la limitante antes mencionada el modelo cuenta con ciertas bondades como la posibilidad de incorporar variables explicativas y la capacidad de trabajar a diferentes escalas. En el caso de este análisis se aplicó a una escala de paisaje, el cual se ha definido como un nivel de 
organización de los sistemas ecológicos superior al ecosistema, que se caracteriza esencialmente por su heterogeneidad y por su dinámica, controlada en gran parte por las actividades humanas (Burel y Baudry, 2002). También se puede aplicar para comprender la dinámica que tiene lugar en las tierras de labor abandonadas porque el modelo de Cadenas de Markov puede analizar el proceso de sucesión ecológica, es decir, puede describir las formas en que las comunidades cambian de un estado a otro a través del tiempo (Gotelli, 2008 ).

Un ejemplo de la dinámica que puede ocurrir en las comunidades como consecuencia del cambio de uso del suelo es la introducción o establecimiento de especies exóticas que ponen en peligro la biodiversidad y los servicios que los ecosistemas proporcionan al romper el equilibrio natural que existe en ellos; la invasión biológica más evidente es a través de las alteraciones humanas causadas por las múltiples actividades de uso de suelo (agricultura, horticultura, silvicultura, construcciones y desarrollo de infraestructura). La transformación de los paisajes puede otorgar nuevas oportunidades para invasiones biológicas (Vitousek et al. 1997). 


\section{CONCLUSIONES}

De acuerdo con los resultados de la clasificación digital y de los escenarios prospectivos, la deforestación de la Selva Alta Perennifolia presente en el municipio Marqués de Comillas continuará hasta el año 2022 de manera que la selva abarcará un $43 \%$ de la superficie del municipio; la velocidad del cambio de la Selva Alta Perennifolia se verá disminuida en el periodo 12-22, en comparación con las tasas de cambio calculadas en el periodo anterior ya que en el periodo 97-07 la selva disminuyó un 19\% del territorio municipal y para el periodo $12-22$ se estima una pérdida constante del $2 \%$.

También se observó que es posible que se lleven a cabo procesos de recuperación de la vegetación aunque en este sentido sería conveniente realizar estudios de monitoreo a mediano y largo plazo en estas zonas para conocer qué dirección toman y qué características van adquiriendo con el tiempo.

El municipio Marqués de Comillas está sometido a una dinámica de cambios de uso del suelo que, básicamente, están relacionados con la expansión de las actividades agrícolas promovidas por financiamientos (e. g. PROCAMPO, PROGAN, "el trópico húmedo") que no toman en cuenta los procesos de dinámica de poblaciones y comunidades naturales y los servicios ambientales que presenta este territorio. 
La Selva Alta Perennifolia mostró una gran dinámica de cambio como consecuencia de la presión social y económica que demanda más áreas para el desarrollo de actividades relacionadas con la apertura de cultivos, pastizales, poblados, etc. Un aspecto que merece la pena mencionar es la importancia que tiene la ubicación de las áreas que sufren algún cambio de uso del suelo ya que el daño podría ser más severo en áreas que pueden ser más vulnerables, por ejemplo las orillas de los cuerpos de agua o a orillas de las carreteras y en fragmentos aislados cuando se pierde la conectividad de los parches de vegetación.

Con este estudio se muestra la utilidad de la información proveniente de los sensores remotos y el uso de metodologías de análisis con procesos estocásticos, dado que permiten detectar problemas asociados al impacto que tienen los cambios de uso del suelo y, al mismo tiempo, permiten identificar las tendencias de los mismos, siendo de utilidad en la elaboración de diagnósticos para el desarrollo de programas eficientes y, con esto se puede conducir al mejor uso del territorio y de igual manera colaborar en la creación de políticas, programas y proyectos de desarrollo social para que respondan eficientemente a las necesidades de la sociedad tratando de minimizar la afectación a los ecosistemas.

Como se observó, el modelo de Cadenas de Markov presenta ciertas limitantes al generar escenarios prospectivos, sin embargo cuenta con ciertas 
bondades como la posibilidad de incorporar variables explicativas y trabajar a diferentes escalas.

En el caso de este análisis, se aplicó a una escala de paisaje, el cual se ha definido como un nivel de organización de los sistemas ecológicos superior al ecosistema, que se caracteriza esencialmente por su heterogeneidad y por su dinámica, controlada en gran parte por las actividades humanas (Burel y Baudry, 2002).

Por las características que presenta la zona de estudio, aunado a los resultados obtenidos del análisis del cambio de uso del suelo, no sería aventurado decir que el municipio Marqués de Comillas es el escenario ideal para implementar una estructura de organización en cuanto al uso del suelo que establezca las posibles actividades antropogénicas que se adapten mejor a las necesidades de los pobladores y que cubran los requerimientos de una zona de amortiguamiento. 


\section{LITERATURA CITADA}

Anderson, J. R., E. E. Hardy, J. T. Roach y R. E. Witmer. 1976. A land use and land cover classification system for use with remote sensor data. Geological Survey Professional Paper, 964:1-28.

Berry, M. W., R. O. Flamm, B. C. Hazen y R. L. Maclntyre. 1996. The LandUse Change and Analysis System (LUCAS) for evaluating landscape management decisions. IEEE computational science and engineering, 3: 24-35.

Burel, F. y Baudry, J. 2002. Ecología del paisaje: conceptos, métodos y aplicaciones. Mundi-Prensa Ediciones, Madrid, España.

Bocco, G., M. Mendoza y O. Masera. 2001. La dinámica del cambio de uso de suelo en Michoacán. Una propuesta metodológica para el estudio de los procesos de deforestación. Boletín del instituto de Geografía, UNAM, 44:18-38.

Carabias, J., P. Meli, G. Hernández y G. Almeida. 2006. Estrategia de restauración ambiental y prevención de incendios en ejidos ribereños del río Lacantún, colindantes a la Reserva de la Biósfera Montes Azules. Reporte final. Instituto Nacional de Ecología y Facultad de Ciencias, Universidad Nacional Autónoma de México.

Castillo-Campos, G. y H. Narave. 1992. Contribución al conocimiento de la vegetación de la Reserva de Montes Azules, Selva Lacandona, Chiapas, México en Reserva de la Biosfera Montes Azules, Selva Lacandona: investigación para su conservación. Publicaciones especiales ecosfera, 1: 51-85.

Ceccon, E. 2013. Restauración en bosques tropicales: fundamentos ecológicos, prácticos y sociales. Universidad Nacional Autónoma de México, México, 288 pp.

Challenger, A. R. y R. Dirzo. 2009. Factores de cambio y estado de la biodiversidad. Pp. 37-73, en: Capital natural de México, volumen II: Estado de conservación y tendencias de cambio. Comisión Nacional para el Conocimiento y Uso de Biodiversidad, México.

Chen L. Y. y H. C. H. Yang. 2008. Scenario simulation and forecast of land use/cover in northern China. Chines Science Bulletin, 53: 1401-1412.

Castillo-Santiago, M.A., G. Helier, R. Tipper y B. H. J. de Jong. 2007 Carbon emissions from land-use change: an analysis of causal factors in Chiapas, Mexico. Mitigation and Adaptation Strategies for Global Change, 12:1213-1235. 
Chuvieco, S. E. 2002. Teledetección Ambiental. Ariel Ciencia. España. 584 pp.

Cincotta, R. P., J. Winsnewski, y R. Engelman. 2000. Human population in the biodiversity hotspots. Nature, 404: 990-991.

Cortez, R. 1998. ¿Hay futuro para la población de la selva lacandona? (colonización y desarrollo sustentable en Marques de Comillas) ponencia presentada en el congreso de la Latin America Studies Association. EUA. Pp. 14.

de Jong, B. H. J., S. Ochoa-Gaona, M. A. Castilo-Santiago, N. RamírezMarcial y M. A. Cairns. 2000. Carbon flux and patterns of land-use/landcover change in the Selva Lacandona, Mexico. AMBIO, 29: 504-511.

de la Maza R. 1997. El paisaje. La visión primigenia. Pp. 29-47, en: Selva Lacandona: Un paraíso en extinción (Hernández Obregón V. H. y E. A. Blanchard, coords.). Pulsar, México, 157 pp.

de la Maza J. 2010. Reserva de la Biosfera Montes Azules. Pp. 30-31, en Patrimonio Natural de México: cien casos de éxito. (Carabias, J., J. Sarukhán, J. de la Maza, C. Galindo, coords.). Comisión Nacional para el Conocimiento y Uso de la Biodiversidad, 240 pp.

De Vos J. 2002. Una tierra para sembrar sueños. Historia reciente de la Selva Lacandona 1950 - 2000, Fondo de Cultura Económica, México.

Díaz, G. J., J. Mas y A. Velázquez. 2008. Monitoreo de los patrones de deforestación en el corredor biológico mesoamericano, México. Interciencia, 33:882-890.

DGEIA (Dirección General de Estadística e Información Ambiental). Secretaria de Medio Ambiente y Recursos Naturales (SEMARNAT). 2005. Informe de la Situación del Medio Ambiente en México: Compendio de estadísticas ambientales.

DOF (Diario Oficial de la Federación). 2000. Reglamento de la Ley General del Equilibrio Ecológico y Protección Ambiental en Materia de Evaluaciones de Impacto Ambiental, México D.F., 30 Mayo.

Eastman, J. R. y M. Fulk. 1993. Long sequence time series evaluation using standardized principle components. Photogrammetric Engineering and Remote Sensing, 59:991-996.

Eastman, J. 2004. IDRISI Kilimanjaro, Guía para SIG y procesamiento de imágenes. Clark Labs. U. S. A. pp. 291. 
Eastman, J. 2009. IDRISI Taiga Tutorial. Clark Labs. U. S. A. pp. 298.

Entrevistas Semi estructuradas con actores locales del municipio. Diseño del Diagnóstico Municipal. 2002. Marqués de Comillas, Chiapas.

Ehlers, M., M. A. Jadkowski, R. R. Howard, D. E. Brostuen. 1990. Application of SPOT data for regional growth analysis and local planning. Photogrammetric Engineering and Remote Sensing, 56: 175-180.

ERDAS Inc. y Universidad Distrital de Bogotá, 1999. Manual de Erdas Imagine. Versión en español.

Espinoza, J. 2007. Matrices de transición y cadenas de Markov. Ciencia Ahora, 20: 119-125.

Fahrig L. 2003. Effects of habitat fragmentation on biodiversity. Annual Review of Ecology, Evolution and Systematics, 34:487-515.

FAO (Food and Agricultural Organization of the United Nations). 1995. Evaluación de los Recursos Forestales 1990, países tropicales. Estudios Forestales de FAO, 112:1-41.

FAO (Food and Agricultural Organization of the United Nations). 1996. Survey of tropical forest cover and study of change processes. FAO Forestry Paper 130:1-152.

FAO (Food and Agricultural Organization of the United Nations). 2006. Global Forest Resource Assessment, 2005. Progress towards sustainable forest management, $320 \mathrm{pp}$.

FMCN (Fondo Mexicano para la Conservación de la Naturaleza). 2009. Critical Ecosistema Partnership Found. Protocolo de comunicación y coordinación de emergencias por incendios forestales para el municipio Marqués de Comillas.

Ferguson, B. G., J. Vandermeer, H. Morales y D. M. Griffith. 2003. Postagricultural succession in El Petén, Guatemala. Conservation Biology, 17: 818-828.

García-Amaro, E. 2004. Modificaciones al sistema de clasificación climática de Köppen. Instituto de Geografía, Universidad Nacional Autónoma de México, México, 90 pp.

Geist, H. J. y E. F. Lambin. 2001. ¿What drives tropical deforestation? A meta-analysis of proximate and underlying causes of deforestation based on subnational case study evidence. LUCC Report Series 4, 116 pp. 
Giardina, C. P., R. L. Sanford, I. C. Dockersmith y V. J. Jaramillo. 2000. The effects of slash burning on ecosystem nutrients during the land preparation phase of shifthing cultivation. Plant Soil, 220: 247-260.

Gotelli, J. N. 2008. A primer of ecology. Sinauer Associates, Inc. U.S.A. 291 pp.

Granados-Sánchez, G.F. López-Ríos y J. Hernández-Solano. 2000. Estudio integral de la selva lacandona, Chiapas. Revista Chapingo Serie Ciencias F ores tales y del Ambiente 5(2): 97-106. 1999.

Grubb P.J. 1985. Plant population and vegetation in relation to habitat, disturbance and competition: problems of generalization. Pp. 595-621, en: The Population Structure of Vegetation (White J. ed.). Handbook of Vegetation Science.

Guariguata, M. R. y R. Ostertag. 2001. Neotropical secondary forest succession: changes in structural and functional charasteristics. Forest Ecology and Management, 148: 185-206.

González-Ponciano J. 1996. Marqués de Comillas: cultura y sociedad en la selva fronteriza México-Guatemala. En: J.P. Viqueira y M.H. Ruz (coord.), Chiapas los rumbos de otra historia, UNAM-CIESAS, México, pp. 425-444.

Guevara, S., J. Laborde y G. Sánchez-Ríos. 2004. La fragmentación. Pp. 111-134, en: Los Tuxtlas: el Paisaje de la Sierra (Guevara S., J. Laborde y G. Sánchez-Ríos, eds. Instituto de Ecología, A. C. y Unión Europea, Xalapa, Veracruz.

Harris, P. M. y S. J. Ventura. 1995. The integration of geographic data with remotely sensed imagery to improve classification in an urban area. Photogrammetric Engineering and Remote Sensing, 56:175-180.

Hathout, S. 2002. The use of GIS for monitoring and predicting urban growth in East and West St. Paul, Winnipeg, Manitoba, Canada. Journal Environmental Management, 66:229-238.

Hayes, J. D. y Sader, A. S. 2001. Comparison of change detection techniques for monitoring tropical forest clearing and vegetation regrowth in a time series. Photogrammetric Engineering and Remote Sensing, 9:10671075.

Henríquez, C., G. Azocar y M. Aguayo. 2006. Cambio de uso del suelo y escorrentía superficial: aplicación de un modelo de simulación espacial en los Ángeles, VIII región del Biobío, Chile. Revista de Geografía Norte Grande, 36:61-74. 
Henríquez-Dole, L. 2012. Escenarios Futuros de Uso de Suelo para el Análisis del Efecto del Cambio Global en los Recursos Hídricos aplicado al Acuífero de la Mancha Oriental. Tesis de Maestría. Universidad Politécnica de Valencia, 190 pp.

Hernández, P.G. 2011. Plan de Desarrollo Municipal. 2011-2012. Municipio Marqués de Comillas, Chiapas, 290 pp.

INEGI, 2004. Instituto Nacional de Estadística Geografía e Informática. Guía para la interpretación de cartografía: Edafología. INEGI. México, 27 pp.

INEGI, 2005. Instituto Nacional de Estadística y Geografía. Carta de uso actual del suelo y vegetación Serie III.

INEGI, 2005. Instituto Nacional de Estadística y Geografía. Prontuario de información geográfica municipal de los Estados Unidos Mexicanos: Marqués de Comillas, Chiapas.

INEGI, 2009. Instituto Nacional de Estadística y Geografía. (www.semarnat.gob.mx). Fecha de consulta: 19 de Noviembre de 2009.

INEGI, 2009. Instituto Nacional de Estadística y Geografía Anuario Estadístico de Chiapas.

Jaimes, N., Sendra, J., Delgado, M. y Rocha, W. 2008. Analysis of landuse changes in the State of Mexico using regression analysis and GIS: an approach to the deforestation processes Investigaciones Geográficas, Boletín del Instituto de Geografía, UNAM, 69:33-52.

Jensen, J.R. y D.C. Cowen. 1999. Remote sensing of urban suburban infrastructure and socio-economic attributes. Photogrammetric Engineering and Remote Sensing, 65:611-622.

Jiang, Z. 2007. The Road Extension Model in the Land Change Modeler for Ecological Sustainability of IDRISI. International Symposium on Advances in Geographic Information Systems, November 7- 9, 2007, Seattle, WA.

Lal, R. 1998. Soil erosion impact on agronomic productivity and environment quality. Critical Reviews in Plant Sciences, 17: 319-464.

Lambin, E. F. 1997. Modelling and monitoring land-cover change processes in tropical regions. Progress in Phisycal Geography, 21: 375-393.

Lambin, F. Eric, B. L. Turner, H. J. Geist, S. B. Agbola, A. Angelsen, J. W. Bruce, O. T. Coomes, R. Dirzo, G. Fischer, C. Folke, P. S. George, K. Homewood, J. Imbernon, R. Leemans, X. Li, E. F. Moran, M. 
Mortimore, P. S. Ramakrishnan, J. F. Richards, H. Skanes, W. Steffen, G. D. Stone, U. Svedin, T. A. Veldkamp, C. Vogel y J. Xu. 2001. The causes of land-use and land-cover change: moving beyond the myths. Global Environmental Change, 11: 261-269.

Lambin, E. F., H. J. Geist y E. Lepers. 2003. Dymanics of land-use and landcover change in tropical regions. Annual Review of Environment and Resources, 28: 205-241.

Laurance, W. F. 2004. Forest-climate interactions in fragmented tropical landscapes. Philosophical Transactions of the Royal Society of London 359: 345-352.

Maass, J. M. 1995. Conversion of tropical dry forest to pasture and agriculture. Pp. 399-422, en: Seasonally dry tropical forest (Bullock, S. H., H. A. Mooney y E. Medina, eds.). Cambridge University Press.

Martínez, R. y X. García. 2007. Sucesión ecológica y restauración de las selvas húmedas. Boletín de las Sociedad Botánica de México, 80: 6984.

Masera, O. R. 1996. Deforestación y degradación forestal en México. Documentos de trabajo. Núm. 19. GIRA A. C., Pátzcuaro, México.

Meyer, W. B. y B. L. Turner II. 1991. Changes in land use and land cover: a global perspective. Cambridge University Press.

Monserud, R. A. y R. Leamans. 1992. Comparing global vegetation maps with the kappa statistic. Ecological Modelling, 62: 275-293.

Morón, M. 1992. Estado actual del conocimiento sobre los insectos de la Selva Lacandona. Pp. 119-134, en: Reserva de la Biosfera Montes Azules, Selva Lacandona: investigación para su conservación (Vázquez-Sánchez, M. y M. Ramos, eds.). Publicaciones Especiales Ecósfera 1. Ecósfera, México.

Mooney, H.A. \& R.J. Hobbs. 2000. Invasive species in a changing world. Island Press, Washington, D.C.

Noble, I. R. y R. Dirzo. 1997. Forest as human dominated ecosistem. Science, 277: 522-525.

Olson, J. S., J. A. Watts, L. J. Allison. 1983. Carbon in live vegetation of major world ecosystems. Office of Energy Research, U.S. Department of Energy, Washington, D. C. 
Oñate-Valdivieso, F., Bosque Sendra, J. 2010. Application of GIS and remote sensing techniques in generation of land use scenarios of hydrological modeling. Journal of Hydrology Vol. 395, p. 256-263.

Orozco, H. E., V. Peña, R. Franco y N. Pineda. 2004. Atlas Agrario Ejidal del Estado de México. Cuadernos de Investigación, No. 34, Universidad Autónoma del Estado de México, México.

Orozco, S. A. y C. Y. Vázquez. 2013. La destrucción de la naturaleza. La ciencia para todos. Num. 83. Fondo de Cultura Económica.

Perfiles Municipales. 2013. Municipio Marqués de Comillas. Secretaria de Planeación, Gestión Pública y Programa de Gobierno. Gobierno del Estado de Chiapas. (http://www.ceieg.chiapas.gob.mx/perfiles/). Fecha de Consulta 12 julio del 2013.

Pickett, S. T. A., S. L. Collins y J. J. Armesto. 1987. A hierarchical consideration of causes and mechanisms of succession. Vegetatio, 69: 109-114.

Pickett S. T. A. y P. S. White. 1985. Patch dynamics: a synthesis. Pp. 371383, en: The ecology of natural disturbance and patch dynamics (Pickett S. T. A. y P.S. White, eds.). Academic Press, New York.

Pinilla, C. 1995. Elementos de Teledetección. Ed. Rama, Madrid, 313 pp.

Presidencia de la República, Poder Ejecutivo Federal. 2007. Plan Nacional de Desarrollo 2007-2012. Gobierno de los Estados Unidos Mexicanos, Presidencia de la República, 324 pp.

Quesada, J. E. 2006. El cambio de uso de suelo y sus repercusiones en la atmósfera. Pp. 191-193, en: Más allá del cambio climático: las dimensiones psicosociales del cambio ambiental global (Quesada, J. E., editor). Instituto Nacional de Ecología, 287 pp.

Rzedowski, J. 2006. 1ra. Edición digital, Comisión Nacional para el Conocimiento y Uso de la Biodiversidad. México.

Rubio, T. C. 2000. Introducción a la utilización de los modelos de Markov en el análisis farmaeconómico. Farmacia Hospitalaria, 24: 241-247.

SAGARPA (1) (Secretarias de agricultura, ganadería, desarrollo rural, pesca y alimentación). 2010. Padrón de beneficiarios PROGAN 2010 (http://www.sagarpa.gob.mx/ganaderia/Programas/Paginas/PROGRAM aspx). Fecha de consulta el 2012. 
SAGARPA (2) (Secretaria de Agricultura, Ganadería, Desarrollo rural, Pesca y Alimentación). 2010. Proyecto para el Desarrollo Rural Sustentable de la Región Sur-Sureste de México: Trópico Húmedo, 32 pp.

SAGARPA (Secretaria de Agricultura, Ganadería, Desarrollo rural, Pesca y Alimentación). 2012. Listado de beneficiarios PROCAMPO 2007 (http://www.sagarpa.gob.mx/agricultura/Programas/proagro/procampo/ Beneficiarios/Paginas/2007.aspx). Fecha de consulta el 2012.

Sánchez, P. 1981.Suelos del trópico, características y manejo. Instituto Interamericano de Cooperación para la Agricultura, Costa Rica. 634 pp.

SEMARNAT (Secretaría del Medio Ambiente y Recursos Naturales) e INE (Instituto Nacional de Ecología). 2008. Análisis comparativo de la deforestación de los ejidos de Marqués de Comillas y determinación de corredores biológicos que conecten los fragmentos de selva de los ejidos con la Reserva de la Biosfera. Segundo Informe. Avances. Coordinación del Programa de Cambio Climático, 17 pp.

SEPLADE (Secretaría de Planeación y Desarrollo Sustentable). 2007. Perfiles Municipales. Dirección de Geografía, Estadística e Información, Gobierno del Estado de Chiapas (http://www.ceieg.chiapas.gob.mx). Fecha de consulta el 2013.

SFF (Subsecretaría Forestal y de la Fauna). 1976. Inventario Forestal del Estado de Chiapas. Dirección General de Inventario Nacional ForestalSubsecretaria Forestal y de la Fauna. México.

Sousa, W. P. 1984. The role of natural disturbance in natural communities. Annual Review of Ecology and Systematics, 15: 353-391.

Tejeda, C. C. 2003. Apropiación territorial y aprovechamiento de recursos forestales en la comunidad Frontera Corozal, Selva Lacandona, Chiapas, México. Universidad Autónoma de Chiapas, México, 29 pp.

Turner I. M. 1996. Species loss in fragments of tropical rain forest: a review of the evidence. Journal of Applied Ecology, 33: 200-205.

Turner I. M. y R. T. Corlett. 1996. The conservation value of small, isolated fragments of lowland tropical rain forest. Trends in Ecology and Evolution 11: 330-333.

Uhl, C., D. Nepstad, R. Buschbacher, K. Clark, B. Kauffman y S. Subler. 1990. Studies of ecosystem response to natural and anthropogenic disturbances provide guidelines for designing sustainable land-use system in Amazonia. Pp. 24-42, en: Alternatives to deforestation, steps 
toward sustainable use of the Amazon Rain Forest (Anderson, A. B. ed.). Columbia University Press.

Uhl, C. 1987. Factors controlling succession following slash and burn agriculture in Amazonia. Journal of Ecology 75:377-407.

Valderrama, B. M. 2009. Modelos estocásticos dinámicos. Academia de Ciencias Matemáticas, Fisico-Químicas y Naturales de Granada. España, 27 pp.

Velázquez, A., J. F. Mas, R. Mayorga-Saucedo, J. L. Palacio, G. Bocco, G. Gómez-Rodriguez, L. Luna-Gonzáles, I. Trejo, J. López-García, M. Palma, A. Peralta y J. Prado-Molina. 2001. El Inventario Forestal Nacional 2000: Potencial de Uso y Alcances. Ciencias, 64: 13-19.

Velázquez, A., J. F. Mas, J. L. Palacio, J. R. Díaz, R. Mayorga, C. Alcántara, R. Castro y T. Fernández. 2002. Análisis de cambio de uso del suelo. Informe técnico. Convenio INE-Instituto de Geografía, UNAM.

Vitousek, P.M., P. R. Ehrlich, A. H. Ehrlich, P. A. Matson. 1986. Human appropriation of the products of photosynthesis. Bioscience, 36:368373.

Vitousek, P. M., H. A. Mooney, J. Lubchenco y J. M. Melillo. 1997. Human domination of Earth's ecosystems. Science, 277: 494-499.

Wijdeven, M. J. y Kuzee, M. E. 2000. Seed availability as a limiting factor in forest recovery processes in Costa Rica. Restoration Ecology, 8: 414424.

Wu, Q, L. Hong-Qing, W. Ru-song, J. P., Y. Hec, M. Wang, W. Bi-hui, Z. Wang. 2006. Monitoring and predicting land use change in Beijing using remote sensing and GIS. Landscape and Urban Planning, 78: 322-333.

Vázquez, C. y Orozco, A. 2013. La destrucción de la naturaleza. Fondo de cultura económica. México. Pp 102

Zavaleta, H. S. 2012. ¿Qué es el coeficiente V de Cramer?. Revista Emprende. Universidad Autónoma Benito Juárez de Oaxaca. Num. 3. 